INSTITUTO DE PESQUISAS ENERGÉTICAS E NUCLEARES

AUTARQUIA ASSOCIADA À UNIVERSIDADE DE SÃO PAULO

\title{
ESTUDO DE MÉTODOS DE INVERSÃO EM SENSORIAMENTO REMOTO COM LASERS
}

WELLINGTON CARLOS DE JESUS

DISSERTAÇÃO APRESENTADA COMO PARTE DOS REQUISITOS PARA OBTENÇÃO DO GRAU DE MESTRE EM CIÊNCIAS NA ÁREA DE TECNOLOGIA NUCLEAR - MATERIAIS

Orientador: Eduardo Landulfo

UNIVERSIDADE DE SÃO PAULO

Instituto de Pesquisas Energéticas e Nucleares

São Paulo, SP

2009 


\section{UNIVERSIDADE DE SÃO PAULO}

Data: abril de 2009.

Autarquia Associada: Instituto de Pesquisas Energéticas e Nucleares

Autor: Wellington Carlos de Jesus

Título: $\quad$ ESTUdO DE MÉTODOS DE INVERSÃO EM SENSORIAMENTO REMOTO COM LASERS

Titulação: Mestre

Ano: 2009

Autorizo a reprodução e divulgação total ou parcial deste trabalho, por qualquer meio convencional ou eletrônico, para estudo e pesquisa, desde que citada a fonte. 
Dedico este trabalho à maravilhosa família que tenho - meu pai Augusto, minha mãe Lucia, meus irmãos: Wilson, Claudete, Caroline, meu sobrinho Bruno, minha amada Jéssica e meu quase irmão Ricardo. 


\section{Sumário}

Lista de Tabelas vii

Lista de Figuras $\quad$ viii

$\begin{array}{ll}\text { Agradecimentos } & \text { i }\end{array}$

Resumo $\quad$ v

Abstract vi vi vi vis

1 Introdução 1

1.1 Sensoriamento Remoto da Atmosfera - Aspectos Gerais . . . . . . . 1

1.2 Problemas inversos no sensoriamento remoto . . . . . . . . . . . . . . 2

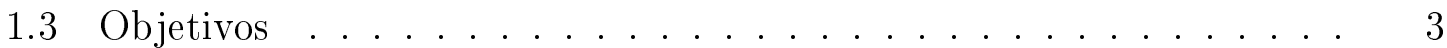

2 Técnica LIDAR 5

2.1 Sistema Lidar - IPEN . . . . . . . . . . . . . . . . . . . . 6

2.1.1 Fonte Luminosa - Laser . . . . . . . . . . . . . . . . 6

2.1 .2 Telescópio MSP-LIDAR $1 \ldots \ldots \ldots 7 \ldots$

2.1.3 Sistema de Detecção . . . . . . . . . . . . . . . . . . . 9

2.2 Modelo Matemático . . . . . . . . . . . . . . . . . . . . . 9

2.2.1 Interações da radiação eletromagnética com a atmosfera . . . 9

2.2.2 Equação de LIDAR . . . . . . . . . . . . . . . . . . . . . . . . 11

2.2.3 Modelo Discretizado . . . . . . . . . . . . . . . . . 15 
3 Métodos de Inversão 18

3.1 O Problema Inverso . . . . . . . . . . . . . . . . . . . . . . . . . 18

3.2 O método de inversão do declive . . . . . . . . . . . . . . . . . . . . . 19

3.3 Método de inversão de Klett . . . . . . . . . . . . . . . . . . 20

3.4 Método de Inversão Ótima . . . . . . . . . . . . . . . . . . . . 27

3.4.1 Estimativa do Coeficiente de absorção . . . . . . . . . . 30

3.4.2 Estimativa com restrição da espessura ótica . . . . . . . . . . 32

3.4.3 Diagnóstico das estimativas . . . . . . . . . . . . 34

4 Resultados $\quad 40$

4.1 Cálculo do Espalhamento Rayleigh . . . . . . . . . . . . . . . 40

4.2 Aplicando o algoritmo de recuperação para o sinal Lidar . . . . . . . 43

5 Conclusões $\quad 66$

$\begin{array}{ll}\text { A Número de condicionamento de uma matriz } & 70\end{array}$

B Decomposição de Valores Singulares (SVD) 75

$\begin{array}{ll}\text { Referências Bibliográficas } & 79\end{array}$ 


\section{Lista de Tabelas}

4.1 Informações referentes ao dado medido 19/05/2006 de $10 \mathrm{~h} 51 \mathrm{~min} 37 \mathrm{~s}$ a $10 \mathrm{~h} 53 \mathrm{~min} 18 \mathrm{~s} . \ldots \ldots \ldots \ldots$

4.2 Informações referentes ao dado simulado com "ruído" gaussiano de média zero e desvio padrão igual a $10 \%$ da mediana do perfil de dado simulado. . . . . . . . . . . . . . . . . . . 55

4.3 Informações referentes ao dado simulado com "ruído" gaussiano de média zero e desvio padrão definido localmente como $9 \%$ da potência retornada $($ simulada) . . . . . . . . . . . . . . . . 56

4.4 Informações do dado simulado "alisado" com "ruído" gaussiano de média zero e desvio padrão definido localmente como $9 \%$ da potência retornada (simulada) . . . . . . . . . . . . . . . . 58

4.5 Informações referentes ao dado medido no dia 19/05/2006 no intervalo de 11 h 35 min 15 s a 11 h 36 min 0 s. . . . . . . . . . . . . . . 58

4.6 Informações referentes ao dado medido no dia 19/05/2006 no intervalo de $13 \mathrm{~h} 17 \mathrm{~min} 37 \mathrm{~s}$ a $13 \mathrm{~h} 19 \min 18 \mathrm{~s} . \ldots \ldots . \ldots 59$ 


\section{Lista de Figuras}

1.1 (a) Problema direto; (b) Problema inverso [22] . . . . . . . . . . . 3

2.1 Sistema Lidar de retroespalhamento genérico . . . . . . . . . . . 5

2.2 Foto do equipamento LIDAR do Laboratório de Aplicações Ambientais a Laser. . . . . . . . . . . . . . . . . . . . . . 7

2.3 Foto do Laser utilizado pelo Lidar do IPEN. . . . . . . . . . . . . . 8

2.4 Abertura no teto com clarabóia . . . . . . . . . . . . . . . . 9

2.5 Vista do interior durante operação do laser. . . . . . . . . . . . . . . 9

3.1 M e D são respectivamente os espaços dos Modelos e dos Dados, extraída de [13]. . . . . . . . . . . . . . . . . . . . . . . . . . . 18

4.1 Perfil de temperatura. . . . . . . . . . . . . . . . . . 42

4.2 Perfil de pressão atmosférica . . . . . . . . . . . . . . . . . . . 42

4.3 Densidade do ar calculado com dados de sondagem para o cálculo do espalhamento Rayleigh. . . . . . . . . . . . . . . . . . . . . . 42

4.4 Espalhamento Rayleigh calculado com dados de sondagem e para uma atmosfera padrão . . . . . . . . . . . . . . . . . . . . . 42

4.5 Evolução temporal da atmosfera detectada pelo sistema lidar no dia $19 / 05 / 2006 \ldots \ldots \ldots \ldots \ldots 4 \ldots \ldots \ldots \ldots$

4.6 Sinal Bruto de lidar . . . . . . . . . . . . . . . . . . . . . . 45

4.7 Sinal corrigido pela distância . . . . . . . . . . . . . . . . 45

4.8 Exemplo de calibração do sinal lidar . . . . . . . . . . . . . . . . 47 
4.9 Sinal identificado como o vetor de medidas y no algoritmo . . . . . .

4.10 Estimativa pelo método de Klett para uma altitude de referência de $1,5 \mathrm{~km} \ldots \ldots \ldots \ldots \ldots \ldots$

4.11 Estimativa pelo método de Klett para uma altitude de referência de $1,6 \mathrm{~km} \ldots \ldots \ldots \ldots \ldots$

4.12 Estimativa pelo método de Klett para uma altitude de referência de $1,7 \mathrm{~km} \ldots \ldots \ldots \ldots \ldots$

4.13 Estimativa pelo método de Klett para uma altitude de referência de $1,8 \mathrm{~km} \ldots \ldots \ldots \ldots \ldots \ldots$

4.14 Estimativa pelo método de Klett para uma altitude de referência de $2,5 \mathrm{~km} \ldots \ldots \ldots \ldots \ldots \ldots \ldots$

4.15 Estimativa pelo método de Klett para uma altitude de referência de 7 $\mathrm{km} \ldots \ldots \ldots \ldots \ldots \ldots \ldots$

4.16 Estimativa do coeficiente de extinção (a estimativa por Klett apresentada dependeu de informações recuperadas pela Inversão ótima). . . 49

4.17 Algumas linhas da matriz de sensibilidade A. . . . . . . . . . . . . 50

4.18 Desvio padrão da estimativa e seus componentes. . . . . . . . . . . . 50

4.19 Erro aleatório Gaussiano de média zero e desvio padrão 10\% da mediana das potências retornadas . . . . . . . . . . . . . . 52

4.20 Dado bruto de lidar simulado no módulo analógico, acrescido de um erro gaussiano . . . . . . . . . . . . . . . . . . . 52

4.21 Sinal corrigido pela distância ao quadrado. . . . . . . . . . . . 52

4.22 Sinal normalizado pela contribuição Rayleigh. . . . . . . . . . . . . 52

4.23 ln do sinal normalizado, considerado como o vetor y do algoritmo. . . 53

4.24 Estimativa obtida pelo algoritmo com 05 iterações. . . . . . . . . . 53

4.25 Duas estimativas (a estimativa por Klett apresentada dependeu de informações recuperadas pela Inversão ótima) para os mesmos parâmetros. 53

4.26 Desvio padrão da estimativa e seus componentes, obtido pela Inversão ótima aplicado para um sinal simulado de Lidar. . . . . . . . . . . . . 53 
4.27 Estimativa pelo método de Klett para uma altitude de referência de $2,5 \mathrm{~km} \ldots \ldots \ldots \ldots \ldots \ldots \ldots$

4.28 Estimativa pelo método de Klett para uma altitude de referência de 3 km. . . . . . . . . . . . . . . . . . . . 54

4.29 Estimativa pelo método de Klett para uma altitude de referência de $4,5 \mathrm{~km} \ldots \ldots \ldots \ldots \ldots \ldots \ldots$

4.30 Estimativa pelo método de Klett para uma altitude de referência de 5

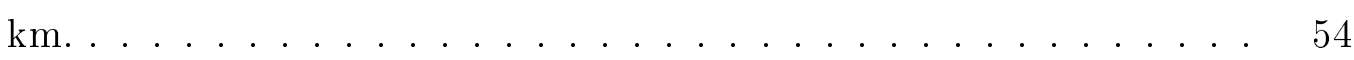

4.31 Iteração 01 e $\chi^{2}=1380,28 \ldots \ldots \ldots$. . . . . . . . . . . 60

4.32 Linhas da matriz A na iteração 01. . . . . . . . . . . . . . . . 60

4.33 Iteração 05 apresentando $\chi^{2}=726,387 \ldots \ldots$. . . . . . . . 60

4.34 Linhas da matriz A na iteração 05. . . . . . . . . . . . . . . . 60

4.35 Iteração 12 apresentando $\chi^{2}=614252 \ldots \ldots$. . . . . . . . . . . 60

4.36 Linhas da matriz A na iteração 12. . . . . . . . . . . . . . . . 60

4.37 Desvio padrão da estimativa na iteração 01. . . . . . . . . . . . . . 61

4.38 Desvio padrão da estimativa na iteração 12 . . . . . . . . . . . . 61

4.39 Erro percentual na medida devido a adição de "ruído". . . . . . . . . 61

4.40 Erro gaussiano de média zero e desvio padrão de $9 \%$ de $P\left(r_{i}\right)$. . . . . 61

4.41 Dado bruto de lidar simulado, acrescido de um erro gaussiano . . . . 61

4.42 Sinal corrigido pela distância ao quadrado. . . . . . . . . . . . . . 61

4.43 Sinal normalizado pela contribuição Rayleigh. . . . . . . . . . . . . 62

4.44 ln do sinal normalizado, considerado como o vetor y do algoritmo. . . 62

4.45 Duas estimativas (a estimativa por Klett dependeu de informações recuperadas pela Inversão ótima) . . . . . . . . . . . . . . . . . . . . . 62

4.46 Algumas linhas da matriz de sensibilidade A, obtida durante o processo de inversão pela Inversão ótima. . . . . . . . . . . . . . . . . . . . . 62

4.47 Desvio padrão da estimativa e seus componentes. . . . . . . . . . . . 62

4.48 Dado bruto de lidar simulado, acrescido de um erro gaussiano . . . . 63

4.49 Sinal corrigido pela distância ao quadrado. . . . . . . . . . . . . 63 
4.50 Sinal normalizado pela contribuição Rayleigh. . . . . . . . . . . . 63

4.51 ln do sinal normalizado, considerado como o vetor y do algoritmo. . . 63

4.52 Duas estimativas (a estimativa por Klett dependeu de informações recuperadas pela Inversão ótima $)$. . . . . . . . . . . . . . . . . . 63

4.53 Algumas linhas da matriz de sensibilidade $\mathbf{A}$, obtida durante o processo de inversão pela Inversão ótima. . . . . . . . . . . . . . . . . . . . . 63

4.54 Desvio padrão da estimativa e seus componentes. . . . . . . . . . . 63

4.55 Dado bruto de lidar. . . . . . . . . . . . . . . . . . . . . . . 64

4.56 Sinal corrigido pela distância. . . . . . . . . . . . . . . . 64

4.57 Sinal normalizado pela contribuição Rayleigh. . . . . . . . . . . . 64

4.58 ln do sinal normalizado, considerado como o vetor y do algoritmo. . . 64

4.59 Duas estimativas (a estimativa por Klett dependeu de informações recuperadas pela Inversão ótima). . . . . . . . . . . . . . . . . . . . . . 64

4.60 Algumas linhas da matriz de sensibilidade A, obtida durante o processo de inversão pela Inversão ótima. . . . . . . . . . . . . . . . . . . . . . 64

4.61 Desvio padrão da estimativa e seus componentes. . . . . . . . . . . . 64

4.62 Dado Bruto de lidar. . . . . . . . . . . . . . . . . . . . . 65

4.63 Sinal corrigido pela distância. . . . . . . . . . . . . . . 65

4.64 Sinal normalizado pela contribuição Rayleigh. . . . . . . . . . . . 65

4.65 ln do sinal normalizado, considerado como o vetor y do algoritmo. . . 65

4.66 Duas estimativas (a estimativa por Klett dependeu de informações recuperadas pela Inversão ótima). . . . . . . . . . . . . . . . . . 65

4.67 Algumas linhas da matriz de sensibilidade A, obtida durante o processo de inversão pela Inversão ótima. . . . . . . . . . . . . . . . . . . 65

4.68 Desvio padrão da estimativa e seus componentes. . . . . . . . . . . 65 


\section{ESTUDO DE MÉTODOS DE INVERSÃO EM SENSORIAMENTO REMOTO COM LASERS}

Wellington Carlos de Jesus

20 de maio de 2009 


\section{Agradecimentos}

Quero agradecer àquelas pessoas que, de alguma forma, contribuíram para a realização deste trabalho e me incentivaram de inúmeras formas. A todos vocês quero expressar minha sincera gratidão. Em especial ao Dr. Eduardo Landulfo pela orientação, apoio e discussões que possibilitaram a realização desse trabalho e o Dr. Haroldo Fraga de Campos Velho por sua ajuda incondicional, desde minha iniciação científica, me indicando livros, cursos, apoio em revisão de projetos e até mesmo suporte financeiro para um seminário internacional de problemas inversos.

Aos colegas e amigos do grupo LAAL, do CLA e da Divisão de Ensino do IPEN, pessoas que tiveram grande importância para minha vida pessoal e acadêmica. À minha família pelo suporte nas horas difíceis, especialmente minha mãe Lucia, minha fortaleza nas tribulações. À Deus por permitir que eu trilhasse este caminho com sucesso. Por fim agradeço a FAPESP, ao CNPq, a CAPES e a Coordenadoria de Assistência Social - COSEAS pelo apoio financeiro, além do IPEN e seus dirigentes, pelo uso das dependências e recursos que possibilitaram este trabalho. 


\section{Lista de símbolos}

- $P_{0}:$ sinal (potência) emitido;

- $P(r)$ : sinal (potência) retornado da distância r;

- $r$ : distância do volume investigado na atmosfera;

- $c$ : velocidade da luz;

- $\tau$ : duração do pulso do laser;

- $\beta$ : coeficiente de retroespalhamento total (moléculas e partículas), $\beta=\beta_{m}+\beta_{p}$;

- $\beta_{m}$ : coeficiente de retroespalhamento devido ao espalhamento por moléculas;

- $\beta_{p}$ : coeficiente de retroespalhamento devido ao espalhamento por partículas;

- $\beta_{\text {ray }}$ : coeficiente de espalhamento devido a iteração Rayleigh;

- $\beta_{s}$ : coeficiente de espalhamento para uma atmosfera de referência devido a iteração Rayleigh;

- $\beta_{\pi}$ : coeficiente de retroespalhamento devido a iteração Rayleigh (espalhado sob o ângulo de $\pi$ );

- $\sigma$ : coeficiente de extinção total (moléculas e partículas), $\sigma=\sigma_{m}+\sigma_{p}$;

- $\sigma_{m}$ : coeficiente de extinção por molécula (absorção e espalhamento), $\sigma_{m}=$ $\sigma_{m}^{a b s}+\sigma_{m}^{e s p}$

- $\sigma_{m}^{a b s}$ : coeficiente de extinção devido à absorção por moléculas;

- $\sigma_{m}^{e s p}$ : coeficiente de extinção devido ao espalhamento por moléculas;

- $\sigma_{p}$ : coeficiente de extinção por partículas (absorção e espalhamento), $\sigma_{p}=$ $\sigma_{p}^{a b s}+\sigma_{p}^{e s p}$ 
- $\sigma_{p}^{a b s}$ : coeficiente de extinção devido à absorção por partículas;

- $\sigma_{p}^{e s p}$ : coeficiente de extinção devido ao espalhamento por partículas;

- $\omega$ : razão de retroespalhamento e extinção;

- $\varphi$ : seção de choque de espalhamento Rayleigh total;

- $\lambda$ : comprimento de onda;

- $m_{r}$ : índice de refração do ar;

- $N$ : densidade molecular;

- $N_{s}$ : densidade molecular de referência;

- $P_{s}$ : pressão de referência;

- $T_{s}$ : temperatura de referência;

- $z_{s}$ : altitude de referência;

- $\mathbf{x}$ : representa a informação que deve ser recuperada;

- $\hat{\mathbf{x}}$ : estimativa da informação que deve ser recuperada;

- $\mathbf{x}_{\mathbf{a}}$ : indica valores a priori;

- y : é o vetor das informações medidas;

- $\mathbf{S}_{\mathbf{a}}$ : matriz de covariância dos dados a priori;

- $\mathbf{S}_{\mathbf{y}}$ : matriz de covariância dos valores medidos;

- $\hat{\mathrm{S}}_{\mathbf{x}}$ : matriz covariância dos erros da solução estimada, a matriz dos dados a priori e matriz dos valores medidos.

- b : representa o verdadeiro estado da atmosfera; 
- $u$ : representa os parâmetros do modelo inverso que nos dados a priori não são usados no modelo direto;

- $\sigma_{\tau}$ : desvio padrão da espessura ótica; 


\title{
Resumo
}

\section{ESTUDO DE MÉTODOS DE INVERSÃO EM SENSORIAMENTO REMOTO COM LASERS}

\author{
Wellington Carlos de Jesus
}

O Laboratório de Aplicações Ambientais a Laser do Centro de Lasers e Aplicações do IPEN realiza o estudo de propriedades atmosféricas, tais como os coeficientes de extinção e retroespalhamento. Esses coeficientes são estimados por meio de um método inverso, cuja qualidade não é facilmente certificada, ou seja não existe um diagnóstico sistemático da qualidade das estimativas. Neste trabalho um método inverso com sólidas bases estatísticas é proposto, para recuperar os mesmos coeficientes. O algoritmo proposto oferece vantagens comparada com o método atual em uso pelo grupo, pois: (1) possibilita a incorporação de diferentes tipos de informações de fontes heterogêneas durante a inversão. E (2) o método permite diversos tipos de diagnósticos quanto a qualidade do processo de inversão e do parâmetro recuperado. Fatores que potencializam as chances de estimativas com maior acurácia. 


\title{
Abstract
}

\section{STUDY OF INVERSE METHODS IN REMOTE SENSING WITH LASER}

\author{
Wellington Carlos de Jesus
}

The Laboratory of Environmental Applications of Lasers at Ipen realizes a study about atmospherics properties, such as extinction and backscattering coefficient. These coefficients are estimated by an inverse method, whose estimate quality is difficult to measure. This work presents a method with good statistic approach to retrieval the same coefficients. The new method, however, offers a number of advantages compared to the first method in use, including (1) the ability to incorporate different kinds of information under a common retrieval philosophy and (2) the method provides number of ways for evaluating the quality of the retrieval. Thus we hope improve the accuracy of estimates. 


\section{Capítulo 1}

\section{Introdução}

\subsection{Sensoriamento Remoto da Atmosfera - Aspectos Gerais}

O sensoriamento remoto da atmosfera pode ser considerado como uma ciência multidisciplinar e, portanto, a tarefa de reduzir a sua essência a uns poucos parágrafos é extremamente difícil. Assim, a forma mais adequada de abordar os temas relacionados seria a de os confinar a um caso mais particular, diminuindo assim a quantidade de informação a ser fornecida. Nosso tema, portanto, se concentrará na inspeção da baixa atmosfera, ou troposfera, por meio de medidas de radiação eletromagnética enviada de uma base terrestre e que interaja com os componentes atmosféricos, em outras palavras, serão discutidos aqui tópicos de sensoriamento remoto ativo, em detrimento dos meios passivos que observam os níveis de radiação natural na atmosfera, emitidos na superfície da Terra ou através da luz solar refletida pela atmosfera. Uma classificação interessante para se entender as interações entre a radiação eletromagnética e a atmosfera é mostrada por [22], onde as categorias dos tópicos são discutidas em termos de:

a ) métodos de extinção; 
b ) métodos de emissão;

c ) métodos de espalhamento;

No caso a) faz-se a observação da radiação de uma dada fonte conhecida, e a quantidade de radiação atenuada ou perdida no feixe é transmitida para um sensor (detector). Determina-se, pelas diferentes características de absorção dos átomos e moléculas, os constituintes atmosféricos presentes no caminho entre a fonte e o sensor. No método de emissão, item b), o objeto atmosférico é a fonte que emite radiação na região do infravermelho e microondas que é medida para se obter informação da estrutura atmosférica e outras propriedades correlatas [22]. A terceira categoria de sensoriamento remoto, item c), explora as propriedades de espalhamento da radiação eletromagnética, havendo a possibilidade desse espalhamento ser elástico, sem alteração entre as freqüências incidente e espalhada, ou ser inelástico, ocorrendo então um desvio na freqüência após o espalhamento. No espalhamento envia-se uma radiação coerente ou não-coerente, por meio de um transmissor que pode ser a luz solar (incoerente), um radar ou um laser (coerentes) e posiciona-se um receptor otimizado para detetectar radiações no comprimento de onda enviado, e mede-se o quanto da radiação foi espalhada e/ou absorvida. No caso da utilização de um laser, a luz é coerente e há flexibilidade para selecionar a frequência de emissão. Os sistemas que trabalham dessa maneira são denominados LIDAR (Light Detection And Ranging).

\subsection{Problemas inversos no sensoriamento remoto}


Problemas de sensoriamento remoto, em geral, caem em uma categoria conhecida como problemas inversos ou problemas de inversão. A natureza destes problemas é, às vezes, semelhante pictoricamente à procura de um dragão a partir das suas pegadas [22]. Com a devida precaução vemos que sem conhecer a natureza do que (dragão) estamos estudando, a priori, tornase infrutífera a pesquisa dos elementos e parâmetros (pegadas) relacionadas ao objeto de estudo. A Figura 1.1 ilustra a situação do problema direto e do problema inverso. A atmosfera comporta-se de maneira muito semelhante e as aplicações em sensoriamento remoto se encaixam nesse contexto.

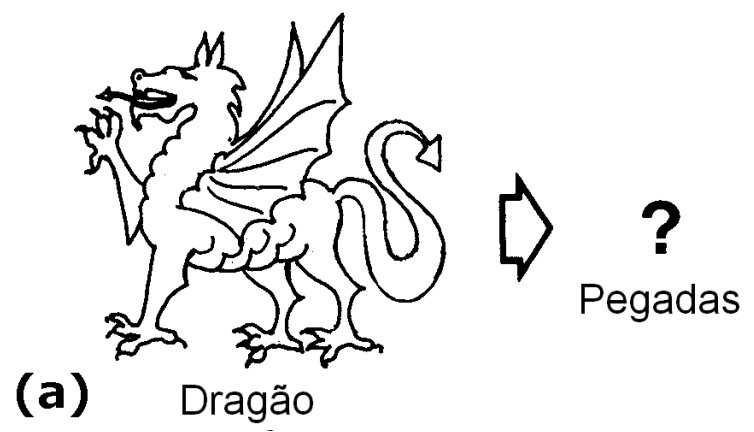

\section{$1.3 \quad$ Objetivos}

O algoritmo proposto neste trabalho oferece inúmeras vantagens comparada com o método atual em uso pelo grupo, pois diferente do mesmo:

a ) na possibilidade de incorporação de diferentes tipos de informações de fontes heterogêneas durante a inversão. Permitindo por exemplo limitar parâmetros como a espessura ótica no modelo, ou ainda a razão $\omega$, que reconhecidamente possui intervalo de variabilidade grande, validar erros no processo de medição, entre outras associações fisícas pertinentes ao problema;

b ) o método fornece diversas maneiras para avaliar a qualidade do processo de inversão e do parâmetro recuperado (no método em uso tal avaliação é praticamente inexistente). 
Portanto este trabalho tem por objetivos desenvolver uma metodologia que permita:

a ) Estimar com acurácia medidas de coeficiente de extinção atmosférico por aerossóis;

b ) Relacionar informações de diferentes fontes, buscando otimizar a solução;

c ) Avaliar os erros contidos na medida, permitindo o reconhecimento dos mesmos. 


\section{Capítulo 2}

\section{Técnica LIDAR}

Como citado na seção 1.1, a técnica LIDAR é o sensoriamento remoto da atmosfera utilizando uma fonte de radiação laser. Possui o acrônimo de Light Detection And Ranging (LIDAR). São utilizados princípios físicos semelhantes à técnica de radar.

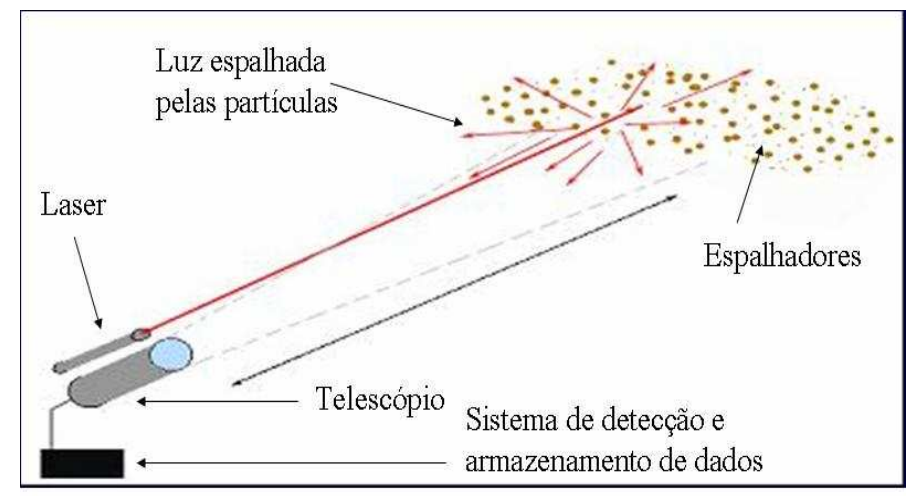

Figura 2.1: Sistema Lidar de retroespalhamento genérico

Um pequeno pulso de laser é usado para emitir um feixe através da atmosfera (Figura 2.1). Esse pulso emitido com intensidade de propagação $F$ através da atmosfera interage com os constituintes atmosféricos em seu percurso. Uma fração da luz laser emitida é espalhada por partículas e moléculas na atmosfera, em menor 
proporção pode ser absorvida. O espalhamento do laser é emitido em todas as direções de incidência do laser. Somente uma pequena parte desse espalhamento do laser retorna para o sistema de recepção e coleta ótico do Lidar, fenômeno esse chamado de retroespalhamento. O telescópio coleta o laser retroespalhado e direciona para o photoreceptor, onde é convertido de luz para sinal elétrico. Já o fenômeno que a luz laser é espalhada em outras direções e absorvida pelos constituintes atmosféricos, chamamos de atenuação ou extinção atmosférica. A atmosfera determina o sinal Lidar através de dois fatores:

- coeficiente de retroespalhamento $(\beta)$

- coeficiente de atenuação ou extinção $(\sigma)$

\subsection{Sistema Lidar - IPEN}

Um sistema LIDAR é composto por 3 módulos principais (veja Figura 2.2):

- a Fonte Luminosa (LASER)(a);

- o Sistema de Coleta e Envio de Feixe (Telescópio)(b);

- e o Sistema de Detecção (Detectores + Módulos de Aquisição)(c e d).

Iremos a seguir abordar as principais características desses módulos.

\subsubsection{Fonte Luminosa - Laser}

A fonte luminosa em nosso sistema consiste num laser de estado sólido de Nd:YAG refrigerado a ar. As principais características desse laser são: 


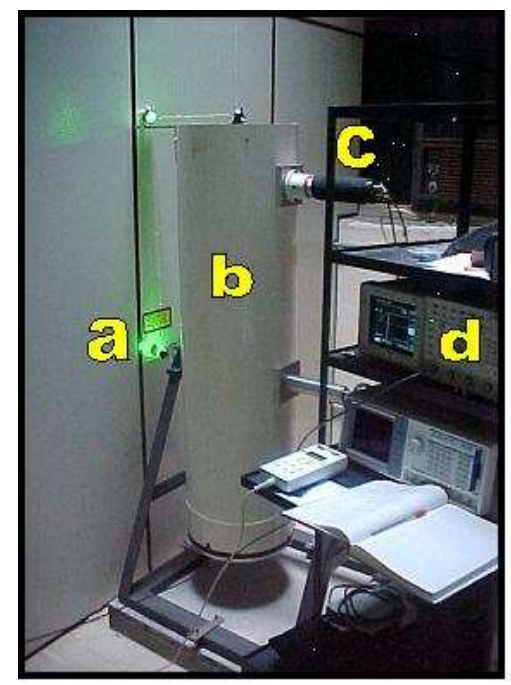

Figura 2.2: Foto do equipamento LIDAR do Laboratório de Aplicações Ambientais a Laser.

- Taxa de Repetição: $20 \mathrm{~Hz}$

- Energia por pulso: 160 mJ @532 nm (máxima)

- Duração temporal do pulso: 4 ns @532 nm

- Divergência: $0,5 \mathrm{mrad}$

- Diâmetro do Feixe de Saída: $6 \mathrm{~mm}$

\subsubsection{Telescópio MSP-LIDAR 1}

Na concepção de um telescópio há um compromisso forte entre a distância mínima a ser detectada, o diâmetro do espelho e sua distância focal, optou-se por um Telescópio Newtoniano com emissão coaxial, intitulado MSP -LIDAR 1. Nesse foram concebidas as seguintes características: 


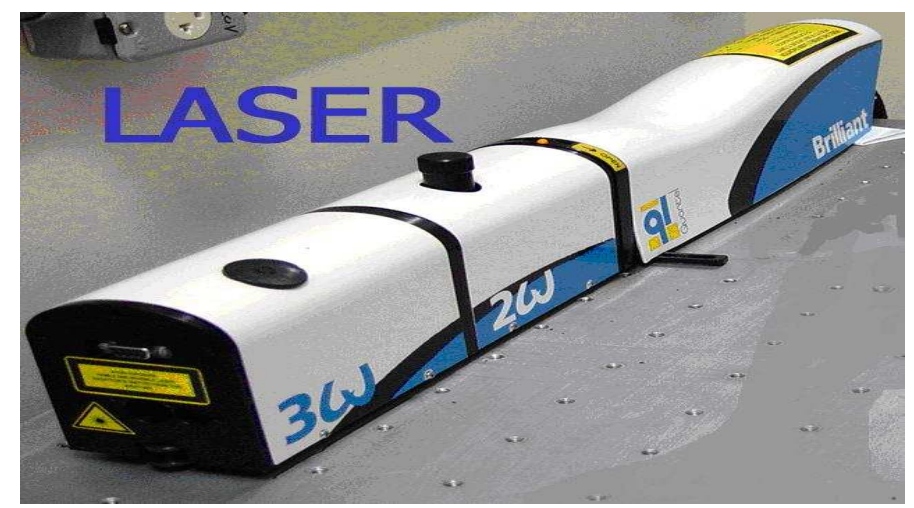

Figura 2.3: Foto do Laser utilizado pelo Lidar do IPEN.

- Distância mínima detectável: $300 \mathrm{~m}$

- Diâmetro do Espelho Primário: $30 \mathrm{~cm}$

- Material do Espelho Primário: Duran 50 (Baixo coeficiente de dilatação térmica)

- Distância Focal do Espelho: $130 \mathrm{~cm}$

- Deposição de Filme de SiO e Alumínio para otimizar a recepção na luz visível e absorver no Infravermelho

Em função destes valores uma estrutura mecânica do telescópio foi construída com possibilidade de executar uma varredura azimutal, de $0^{\circ}$ a $90^{\circ}$. No presente a operação do sistema é feita a $90^{\circ}$, onde o laser passa por uma abertura no teto, onde se encontra uma clarabóia retrátil (Figura: 2.4 e Figura: 2.5 ). 

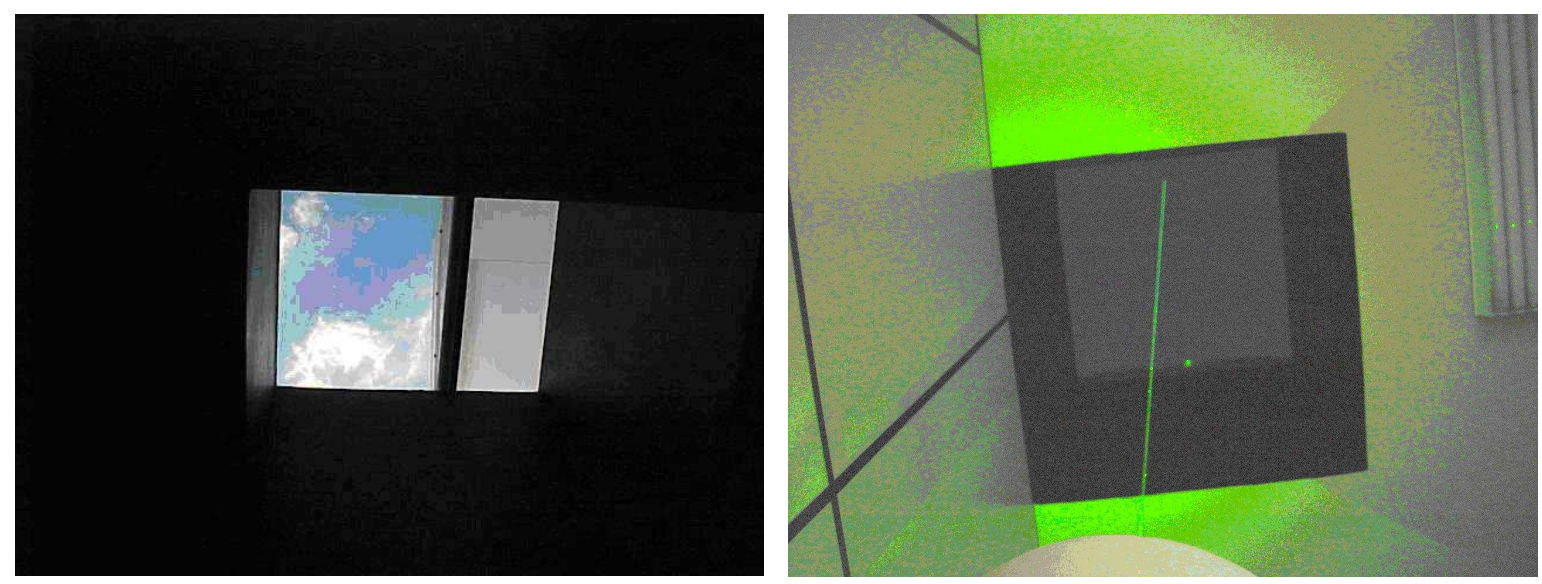

Figura 2.4: Abertura no teto com clara- Figura 2.5: Vista do interior durante opebóia ração do laser.

\subsubsection{Sistema de Deteç̧ão}

O nosso sistema consiste de uma fotomultiplicadora Hamamatsu, possui resposta espectral no intervalo de 185 a $900 \mathrm{~nm}$ e eficiência quântica de $25 \%$. A sua operação é com uma tensão negativa de $-900 \mathrm{~V}$. Existem duas técnicas distintas de detecção do sinal: Analógica e de Contagem de Fótons.

\subsection{Modelo Matemático}

\subsubsection{Interações da radiação eletromagnética com a atmosfera}

As fontes de radiação eletromagnética podem ser divididas em naturais (Sol, Terra, etc) e artificiais (Radar, Laser, etc) [28]. Toda substância com temperatura superior a de zero absoluto (0 Kelvin ou $\left.-273^{\circ} \mathrm{C}\right)$ emite radiação eletromagnética, como resultado de suas oscilações atômicas e moleculares. Essa radiação emitida pode incidir sobre a superfície de outra substância podendo ser refletida, absorvida ou transmitida. No caso da absorção, a energia é geralmente reemitida, normalmente com diferentes comprimentos de onda. Na prática, os quatro processos: emissão, 
absorção, reflexão e transmissão ocorrem simultaneamente e suas intensidades relativas caracterizam a substância em investigação. Dependendo das características físicas e químicas da mesma, aqueles quatro processos ocorrem com intensidades diferentes em diferentes regiões do espectro. Esse comportamento espectral das diversas substâncias é denominado assinatura espectral e é utilizado em sensoriamento remoto para distinguir diversos materiais entre si. Existem regiões de espectro eletromagnético para as quais a atmosfera é opaca, ou seja, não permite a passagem da radiação eletromagnética. Estas regiões definem as "bandas de absorção da atmosfera". As regiões do espectro eletromagnético em que a atmosfera é transparente à radiação eletromagnética proveniente do Sol são conhecidas como "janelas atmosféricas". No caso de um laser, que produz um feixe de radiação eletromagnética colimada, a radiação incide em linha reta, mas os gases e aerossóis presentes na atmosfera podem causar seu espalhamento, dispersando-a em todas as direções. As características do espalhamento dependem, em grande parte, do tamanho das moléculas de gás ou aerossóis. O espalhamento por partículas cujo raio é bem menor que o comprimento da onda da radiação espalhada, como o caso de espalhamento da luz visível por moléculas de gás da atmosfera, é dependente do comprimento de onda (espalhamento Rayleigh), de forma que a irradiância monocromática espalhada é inversamente proporcional a quarta potência do comprimento de onda. Quando a radiação é espalhada por partículas cujos raios se aproximam ou excedem em aproximadamente oito vezes o comprimento da onda da radiação, o espalhamento não depende do comprimento de onda (espalhamento Mie). A radiação é espalhada igualmente em todos os comprimentos de onda. Partículas que compõem as nuvens (pequenos cristais de gelo ou gotículas de água) e a maior parte dos aerossóis atmosféricos espalham a luz do 
Sol desta maneira. Por isso as nuvens parecem brancas e quando a atmosfera contém grande concentração de aerossóis o céu inteiro aparece esbranquiçado. Quando o raio das partículas é maior que aproximadamente 8 vezes o comprimento de onda da radiação, a distribuição angular da radiação espalhada pode ser descrita pelos princípios da óptica geométrica. O espalhamento de luz visível por gotas de nuvens, gotas de chuva e partículas de gelo pertence a este regime e produz uma variedade de fenômenos ópticos como arco-íris, auréolas, entre outros. O espalhamento e a reflexão simplesmente mudam a direção da radiação. Contudo, através da absorção, a radiação é convertida em calor. Quando uma molécula de gás absorve radiação, esta energia é transformada em movimento molecular interno, detectável como aumento de temperatura. Os espalhamentos Rayleigh e Mie serão os fenômenos considerados para a análise do sinal de Lidar nesse trabalho.

\subsubsection{Equação de LIDAR}

A Equação de Lidar é um importante instrumento para investigação dos aerossóis atmosféricos [12]. A equação relaciona a potência retornada, com os parâmetros ópticos atmosféricos $(\sigma$ e $\beta)$, além de fatores da geometria do sistema. Segue abaixo a equação lidar de espalhamento único:

$$
P(r)=P_{0} \frac{c \tau}{2} A \frac{\beta(r)}{r^{2}} \exp \left[-2 \int_{r_{0}}^{r} \sigma\left(r^{\prime} d r^{\prime}\right)\right]
$$

Onde:

- $P(r)$ é o sinal (potência) retornado da distância r no tempo t, $(\mathrm{W})$

- $r$ é distância do volume investigado na atmosfera, (m)

- $P_{0}$ é o sinal recebido no tempo $t_{0},(\mathrm{~W})$ 
- $c$ é a velocidade da luz $\left(m . s^{-1}\right)$,

- $\tau$ duração do pulso da laser (ns),

- $A$ é a area da seção transversal do telescópio $\left(m^{2}\right)$,

- $\beta(r)$ é o coeficiente de retroespalhamento na distância $r,\left(k m^{-1} . s r^{-1}\right)$

- $\sigma(r)$ é o coeficiente de extinção na distância $r,\left(\mathrm{~km}^{-1}\right)$

Como $c$ é conhecida, a distância dos espalhadores que produzem o sinal Lidar pode ser determinada através do intervalo de tempo da transmissão do feixe e sua detecção.

Método analítico para extrair o coeficiente de extinção e retroespalhamento

O mais apropriado sinal para análise segundo Klett [5] é o logaritmo do sinal recebido corrigido pela distância ao quadrado. Esse sinal é definido como:

$$
S(r) \equiv \ln \left[r^{2} P(r)\right]
$$

Tomando $S=S(r)$ e $S_{0}=S\left(r_{0}\right)$, onde $r_{0}$ é uma constante de referência,

$$
\begin{aligned}
S(r) \equiv \ln \left[r^{2} P(r)\right] \Longrightarrow & \\
S-S_{0} & =\ln \left[r^{2} P(r)\right]-\ln \left[r_{0}^{2} P\left(r_{0}\right)\right] \\
& =\ln \left[\frac{r^{2} P(r)}{r_{0}^{2} P\left(r_{0}\right)}\right] \\
S-S_{0}=\ln \left[\frac{r^{2} P(r)}{r_{0}^{2} P\left(r_{0}\right)}\right] &
\end{aligned}
$$

Substituindo a equação (2.2.1) em (2.2.3), 


$$
\begin{aligned}
& S-S_{0}=\ln \left\{\frac{\frac{r^{2} P_{0} c \tau A \beta(r) \exp \left[-2 \int_{0}^{r} \sigma\left(r^{\prime}\right) d r^{\prime}\right]}{2 r^{2}}}{\frac{r_{0}^{2} P_{0} c \tau A \beta\left(r_{0}\right) \exp \left[-2 \int_{0}^{r_{0}} \sigma\left(r^{\prime}\right) d r^{\prime}\right]}{2 r_{0}^{2}}}\right\} \\
& =\ln \left\{\frac{\beta(r) \exp \left[-2 \int_{0}^{r} \sigma\left(r^{\prime}\right) d r^{\prime}\right]}{\beta\left(r_{0}\right) \exp \left[-2 \int_{0}^{r_{0}} \sigma\left(r^{\prime}\right) d r^{\prime}\right]}\right\} \\
& =\ln \left[\frac{\beta(r)}{\beta\left(r_{0}\right)}\right]+\ln \left\{\exp \left[-2 \int_{0}^{r} \sigma\left(r^{\prime}\right) d r^{\prime}+2 \int_{0}^{r_{0}} \sigma\left(r^{\prime}\right) d r^{\prime}\right]\right\} \\
& =\ln \left[\frac{\beta(r)}{\beta\left(r_{0}\right)}\right]-2\left[\int_{0}^{r} \sigma\left(r^{\prime}\right) d r^{\prime}-\int_{0}^{r_{0}} \sigma\left(r^{\prime}\right) d r^{\prime}\right] \\
& =\ln \left[\frac{\beta(r)}{\beta\left(r_{0}\right)}\right]-2 \int_{r_{0}}^{r} \sigma\left(r^{\prime}\right) d r^{\prime} \\
& S-S_{0}=\ln \left[\frac{\beta(r)}{\beta\left(r_{0}\right)}\right]-2 \int_{r_{0}}^{r} \sigma\left(r^{\prime}\right) d r^{\prime}
\end{aligned}
$$

Derivando (2.2.4) em $\mathrm{r}$ temos:

$$
\begin{aligned}
\frac{d}{d r}\left(S-S_{0}\right) & =\frac{d}{d r}\left(\ln \left[\frac{\beta(r)}{\beta\left(r_{0}\right)}\right]-2 \int_{r_{0}}^{r} \sigma\left(r^{\prime}\right) d r^{\prime}\right) \\
& =\frac{d}{d r}\left(\ln \left[\frac{\beta(r)}{\beta\left(r_{0}\right)}\right]\right)+\frac{d}{d r}\left(-2 \int_{r_{0}}^{r} \sigma\left(r^{\prime}\right) d r^{\prime}\right) \\
& =\frac{1}{\beta} \cdot \frac{d \beta}{d r}-2 \sigma \\
& \frac{d S}{d r}=\frac{1}{\beta} \cdot \frac{d \beta}{d r}-2 \sigma(2.2 .5)
\end{aligned}
$$




\section{Coeficiente de extinção}

É a soma da contribuição de moléculas e partículas por absorção e por espalhamento.

$$
\sigma=\sigma_{m}^{a b s}+\sigma_{m}^{e s p}+\sigma_{p}^{a b s}+\sigma_{p}^{e s p}
$$

ou ainda

$$
\sigma=\sigma_{m}+\sigma_{p}
$$

na qual

$$
\begin{gathered}
\sigma_{m}=\sigma_{m}^{a b s}+\sigma_{m}^{e s p} \\
\sigma_{p}=\sigma_{p}^{a b s}+\sigma_{p}^{e s p}
\end{gathered}
$$

- $\sigma$ é o coeficiente de extinção,

- $\sigma_{m}^{a b s}$ coeficiente de extinção devido à absorção por moléculas,

- $\sigma_{p}^{a b s}$ coeficiente de extinção devido à absorção por partículas,

- $\sigma_{m}^{e s p}$ coeficiente de extinção devido ao espalhamento por moléculas,

- $\sigma_{p}^{e s p}$ coeficiente de extinção devido ao espalhamento por partículas, 


\section{Coeficiente de retroespalhamento}

É a soma da contribuição de moléculas e partículas:

$$
\beta=\beta_{m}+\beta_{p}
$$

- $\beta$ coeficiente de retroespalhamento,

- $\beta_{m}$ coeficiente de retroespalhamento devido ao espalhamento por moléculas,

- $\beta_{p}$ coeficiente de retroespalhamento devido ao espalhamento por partículas,

\subsubsection{Modelo Discretizado}

Tratando o problema na notação abordada na seção 3.4.1 a seguir, temos $\mathbf{y}$, o vetor contendo o valor do logaritmo do sinal recebido corrigido pela distância ao quadrado, a matriz $\mathbf{K}$ que descreve o modelo de transmissão. Queremos estimar a condição inicial, o vetor $\mathbf{x}$, dos parâmetros atmosféricos que originou tais dados.

Generalizando podemos considerar o modelo linear discreto expresso por $\mathbf{y}=\mathbf{K} \mathbf{x}$ , onde

$$
\mathbf{y}=\left[\ln \left[\mathbf{C r}_{1}^{2} \mathbf{P}\left(\mathbf{r}_{1}\right)\right], \ln \left[\mathbf{C r}_{2}^{2} \mathbf{P}\left(\mathbf{r}_{2}\right)\right], \ldots, \ln \left[\mathbf{C r}_{\mathbf{N}}^{2} \mathbf{P}\left(\mathbf{r}_{\mathbf{N}-1}\right)\right], \tau\right]^{\mathbf{T}}
$$

é o vetor de dados ou observações, na qual $\tau$ é a espessura ótica descrita na seção 3.4.2, a seguir

$$
\mathbf{x}=\left[\sigma\left(\mathbf{r}_{1}\right), \sigma\left(\mathbf{r}_{\mathbf{2}}\right), \ldots, \sigma\left(\mathbf{r}_{\mathbf{N}-\mathbf{1}}\right), \omega\right]^{\mathbf{T}}
$$

é o vetor de parâmetros a ser determinado e 


$$
\begin{array}{r}
f\left(\hat{\mathbf{x}}_{\mathbf{j}}, \hat{\mathbf{b}}_{\mathbf{j}}\right)=\ln \left[\beta_{\pi}\left(r_{j}\right)+\omega\left(r_{j}\right) \hat{x}\left(r_{j}\right)\right]-2 \sum_{l=1}^{j}\left[u \bar{\beta}_{m, l}+\bar{x}_{l}\right] \Delta r ; j=1, \ldots, N-1 \\
f\left(\hat{\mathbf{x}}_{\mathbf{j}}, \hat{\mathbf{b}}_{\mathbf{j}}\right)=\sum_{l=2}^{N} \bar{x}_{l} \Delta r ; \text { para } j=N
\end{array}
$$

definido para cada $r_{j}, j=2, \ldots, N$ contados a partir da base da atmosfera, no qual $\Delta r$ é a resolução do sistema lidar, a "barra" faz referência a valores médios da camada $\left(\bar{x}_{l}\right.$ é a média da camada $\left.\left(0.5\left(x_{j}+x_{j+1}\right)\right)\right)$, foi usado a discretização pela regra do trapézio. O termo $u \bar{\beta}_{m, l}$ faz referência a valores médios de espalhamento rayleigh em ângulos diferentes de $\pi$ (veja mais detalhes na seção 4.1). Além do vetor b, citado anteriormente, que denota quantidades que afetam as medidas mas não são recuperadas com o algoritmo.

$$
\hat{\mathbf{b}}=b_{1}
$$

no qual

$$
b_{1}=\beta_{m, j}, j=1, \ldots, N \text {. }
$$

assumiremos aqui que $\omega$ é constante [22].

Os elementos da Matriz $\mathbf{K}, K_{i j}$, calculados pela derivada de (2.2.12) com relação a x são dados por: 


$$
\begin{aligned}
K_{i j} & =0 \text { se } i<j, \\
K_{i j} & =2 \Delta r \text { se } i>j, \\
K_{i j} & =\frac{\omega}{\beta_{\pi}+\omega x_{i}}+2 \Delta r \text { se } i=j, \\
K_{i j} & =\frac{x i}{\beta_{\pi}+x_{N} x_{i}} \text { se } j=N, \\
& K_{i j}=\Delta r \text { se } i=N . \\
\mathbf{K}=\left(\begin{array}{ccc}
K_{11} & \ldots & K_{1 N} \\
\vdots & & \vdots \\
K_{D 1} & \ldots & K_{D N}
\end{array}\right) &
\end{aligned}
$$

é a matriz $D \times N$.

Se $D=N$ (como é o nosso caso) a solução formal é dada pela inversão direta: $\mathbf{x}=\mathbf{K}^{-\mathbf{1}} \mathbf{y}$. Na prática porém a matriz $\mathbf{K}$ é freqüentemente quase-singular, ou mesmo singular e o procedimento é inaplicável. Uma das formas de avaliar como uma matriz é mal condicionada (Apêndice A) e o quanto pode degenerar a solução do problema inverso, é usar a decomposição de $\mathbf{K}$ em valores singulares (singular value decomposition - SVD, descrita no Apêndice B ). Buscando contornar o mal-condicionamento de uma matriz, são usadas técnicas de regularização, utilização da pseudo-inversa, ou ainda por estimação ótima descrita em 3.4 ). 


\section{Capítulo 3}

\section{Métodos de Inversão}

\subsection{O Problema Inverso}

Um problema inverso pode ser caracterizado pela determinação de causas desconhecidas a partir de efeitos desejados ou observados [13]. Neste trabalho os coeficientes $\beta$ e $\sigma$ da equação (2.2.1) são as causas para o efeito $P(r)$, potência retornada, da equação (2.2.1).

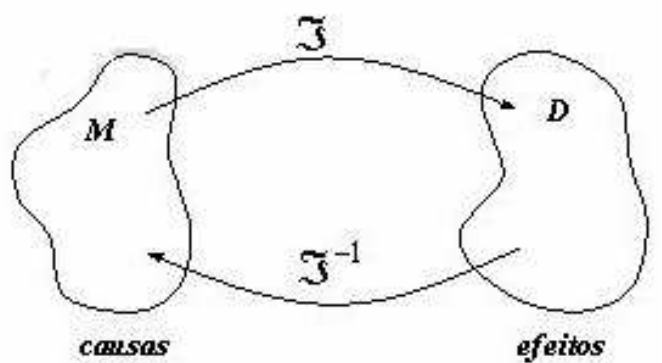

Figura 3.1: M e D são respectivamente os espaços dos Modelos e dos Dados, extraída de [13].

Matematicamente alguns problemas inversos podem ser classificados como um problema mal-posto (segundo o matemático francês Jacques Hadamard) [13]. Ou 
seja aquele que não cumpre uma dessas condições:

a ) Existe solução;

b ) A solução é única;

c ) A solução tem uma dependência contínua (suave) com os dados de entrada.

\subsection{O método de inversão do declive}

O método de inversão do declive (em inglês "slope method") foi primeiramente proposto por Collis [15] e tem sido usado por mais de 30 anos como método de inversão para os parâmetros óticos da atmosfera, extinção, e retroespalhamento em atmosferas homogêneas quanto ao sinal de retorno.

O método do declive é útil para atmosferas homogêneas. Em muitos casos é razoável assumir na atmosfera a homogeneidade em perfis horizontais. E essa conjectura pode ser checada facilmente pela análise da curva do sinal lidar. Com o método do declive um valor médio do coeficiente de extinção do intervalo medido numa atmosfera homogênea é obtido.

O método possui as seguintes características [2]:

- vantagens: ser simples e não necessitar de quantidades precedentes.

- desvantagens: ser aplicável somente para atmosferas homogêneas.

- variáveis determinadas: coeficiente de extinção.

- variáveis assumidas ou requeridas: coeficiente de retroespalhamento constante. 
Assume-se que os espalhadores possuem uma distribuição homogênea no trajeto percorrido pelo laser na atmosfera. Essa é a base do "slop method" [10].

$$
\frac{d \beta}{d r} \approx 0
$$

Considerando (3.2.1) em (2.2.5) temos que:

$$
\frac{d S}{d r}=-2 \sigma \Longrightarrow \sigma_{h o m}=\frac{-1}{2} \frac{d S}{d r}
$$

Onde $\sigma_{\text {hom }}$ é o coeficiente de atenuação para uma atmosfera homogênea.

\subsection{Método de inversão de Klett}

A técnica da solução geral foi primeiramente desenvolvida por Barrett e Ben-Dov em 1967, [29]. Já o primeiro estudo de estabilidade da solução e uso da integração do retorno para melhorar a estabilidade ocorreu na União Soviética por Kaul em 1997 e Zuev em 1978. Esse empenho por parte deles não é conhecido no ocidente, a fonte mais conhecida dessa técnica é um artigo de Klett lançado em 1981 [2, 26]. Um método analítico com potencial para tratar o problema de extrair o coeficiente de retroespalhamento e atenuação, em uma atmosfera não homogênea a partir de um sinal retornado que é monostático e de comprimento de onda único de um sistema lidar (que são as características de nosso sinal). O método assume a validade do espalhamento único da equação lidar, além da lei da energia da relação entre retroespalhamento e extinção.

A técnica de solução para a equação de lidar segundo o método de Klett usa a transformação da equação (2.2.5) em uma equação diferencial de Bernoulli e conseqüentemente sua resolução. 
Várias observações e estudos teóricos demonstram que os coeficientes, $\beta$ e $\sigma$, podem ser relacionados em uma grande variedade de casos, como para uma atmosfera encoberta, neblina, ou condições de nevoeiro [5, 6], da seguinte forma:

$$
\beta=\omega \sigma^{k}
$$

onde $\omega$ e $k$, tomados como constantes, dependem do comprimento de onda e de várias propriedades do aerosol. Os valores assumidos para o expoente geralmente estão no intervalo $0,67 \leq k \leq 1,0$ de acordo com [5].

Tomando a relação dada por (3.3.1) na equação (2.2.5) temos que:

$$
S-S_{0}=\ln \left[\frac{\omega \sigma^{k}(r)}{\omega \sigma^{k}\left(r_{0}\right)}\right]-2 \int_{r_{0}}^{r} \sigma\left(r^{\prime}\right) d r^{\prime}
$$

Derivando (3.3.2) em $r$ temos:

$$
\begin{aligned}
\frac{d}{d r}\left(S-S_{0}\right) & =\frac{d}{d r}\left(\ln \left[\frac{\omega \sigma^{k}(r)}{\omega \sigma^{k}\left(r_{0}\right)}\right]-2 \int_{r_{0}}^{r} \sigma\left(r^{\prime}\right) d r^{\prime}\right) \\
& =\frac{d}{d r}\left(\ln [\omega]+k \ln [\sigma(r)]-\ln \left[\omega \sigma^{k}\left(r_{0}\right)\right]\right)+\frac{d}{d r}\left(-2 \int_{r_{0}}^{r} \sigma\left(r^{\prime}\right) d r^{\prime}\right) \\
& =\frac{k}{\sigma} \frac{d \sigma}{d r}-2 \sigma
\end{aligned}
$$

$$
\frac{d S}{d r}=\frac{k}{\sigma} \frac{d \sigma}{d r}-2 \sigma(3.3 .3)
$$

Multiplicando os termos por $\sigma$ e organizando na forma diferencial de bernoulli: 


$$
\begin{gathered}
\frac{\sigma d S}{d r}=k \frac{d \sigma}{d r}-2 \sigma^{2} \\
k \frac{d \sigma}{d r}-\sigma \frac{d S}{d r}=2 \sigma^{2} \\
k \frac{d \sigma}{d r}-\sigma \frac{d S}{d r}=2 \sigma^{2}
\end{gathered}
$$

Onde $\sigma$ é uma função de $r$. O processo geral de resolução é utilizar algumas substituições para transformar a equação diferencial de Bernoulli (não linear) em uma equação diferencial linear:

$$
v(r)=\sigma^{-1}
$$

Derivando (3.3.5) em $\mathrm{r}$ temos:

$$
\frac{d v}{d r}=-\sigma^{-2} \frac{d \sigma}{d r}
$$

Dividindo (3.3.4) por $\sigma^{2}$ e reorganizando os termos:

$$
\begin{array}{r}
\frac{k}{\sigma^{2}} \frac{d \sigma}{d r}-\frac{1}{\sigma} \frac{d S}{d r}=2 \\
\frac{k}{\sigma^{2}} \frac{d \sigma}{d r}=2+\frac{1}{\sigma} \frac{d S}{d r} \\
\sigma^{-2} \frac{d \sigma}{d r}=\frac{1}{k}\left[2+\frac{1}{\sigma} \frac{d S}{d r}\right] \\
\sigma^{-2} \frac{d \sigma}{d r}=\frac{2}{k}+\frac{1}{k \sigma} \frac{d S}{d r}
\end{array}
$$


Substituindo (3.3.29) em (3.3.6) temos:

$$
\frac{d v}{d r}=-\left[\frac{2}{k}+\frac{1}{k \sigma} \frac{d S}{d r}\right]
$$

A equação (3.3.8) pode ser identificada como uma equação linear de primeira ordem da forma:

$$
\frac{d v}{d r}+v(r) H(r)=Q(r)
$$

Onde:

$$
\begin{aligned}
& H(r)=\frac{1}{k} \frac{d S}{d r} \\
& Q(r)=-\frac{2}{k}
\end{aligned}
$$

Seja $H(r)$ a equação (3.3.10) uma função contínua e a função definida por:

$$
I(r)=e^{\left[\int_{0}^{r} H(t) d t\right]}
$$

Tome $I=e^{g(x)}$, tal que

$$
g(r)=\int_{0}^{r} H(t) d t
$$

$g(r)=\int_{0}^{r} H(t) d t ;$ se $F^{\prime}(r)=H(t)$ teremos $g(r)=F(r)-F(0)$

$$
g^{\prime}(r)=P(r)
$$

voltando a função (3.3.12); substituindo (3.3.13) em (3.3.12) 


$$
I(r)=e^{g(r)}
$$

$$
\begin{aligned}
& I^{\prime}(r)=e^{g(r)} g^{\prime}(r) \\
& I^{\prime}(r)=I(r) H(r)
\end{aligned}
$$

ou ainda expressa como

$$
\frac{d I}{d r}=I(r) H(r)
$$

Multiplicando (3.3.9) pelo fator integrante expresso pela função (3.3.12)

$$
I(r) \frac{d v}{d r}+I(r) H(r) v(r)=I(r) Q(r)
$$

Substituindo (3.3.18) em (3.3.19)

$$
I(r) \frac{d v}{d r}+\frac{d I}{d r} v(r)=I(r) Q(r)
$$

Sabemos que:

$$
\frac{d}{d r}[I(r) v(r)]=I(r) \frac{d v}{d r}+\frac{d I}{d r} v(r)
$$

Substituindo (3.3.23) em (3.3.20) temos:

$$
\frac{d}{d r}[I(r) v(r)]=I(r) Q(r)
$$

E realizando a integral indefinida em ambos os lados da igualdade, obteremos: 


$$
I(r) v(r)=\int I(r) Q(r)+C
$$

Isolando $v(r)$,

$$
v(r)=\frac{\int I(r) Q(r) d r+C}{I(r)}
$$

Substituindo (3.3.12) em (3.3.24),

$$
v(r)=\frac{\int\left[e_{0}^{\int_{0}^{r} H(t) d t} Q(r)\right] d r+C}{e^{\int_{0}^{r} H(t) d t}}
$$

Substituindo (3.3.25) em (3.3.5),

$$
\sigma^{-1}=\frac{\int\left[e_{0}^{\int_{0}^{r} H(t) d t} Q(r)\right] d r+C}{e^{\int_{0}^{r} H(t) d t}}
$$

Substituindo (3.3.10) e (3.3.11) em (3.3.27) 


$$
\sigma=\frac{e^{\left[\int_{0}^{r}\left(\frac{1}{k} \frac{d S}{d t}\right) d t\right]}}{\int\left[e^{\left(\int_{0}^{r} \frac{1}{k} \frac{d S}{d t} d t\right)}\left(\frac{-2}{k}\right)\right] d r+C}
$$

Realizando algumas integrações e considerando $C=\sigma_{0}^{-1}$,

$$
\begin{gathered}
\sigma=\frac{e^{\left[\frac{(S(r)-S(0))}{k}\right]}}{-\frac{2}{k} \int e^{[S(r)-S(0)] d r}+\sigma_{0}^{-1}} \\
\sigma=\frac{e^{\left[\frac{\left(S-S_{0}\right)}{k}\right]}}{\sigma_{0}^{-1}-\frac{2}{k} \int_{r_{0}}^{r} e^{\left[S-S_{0}\right] d r^{\prime}}}
\end{gathered}
$$

O grupo lidar-ipen tem utilizado o método de Klett, como condições de contorno são utilizados: (1) uma atmosfera de referência, um limite superior, uma região livre de aerossóis na qual temos apenas contribuição molecular, [5, 6], e (2) uma estimativa do fator $\omega$, presente na equação (3.3.1), se utilizando de dados da rede de fotômetros solares AERONET (AErosol RObotic NETwork), responsável por medidas de propriedades atmosféricas de aerossóis. Segue a estimativa pela equação (3.3.31), tais condições de contorno são melhor detalhadas em [17, 4]:

$$
\omega=\frac{4 \pi}{\varrho_{0} F F_{i}\left(180^{0}\right)}
$$

Na qual $\varrho_{0}$ é o albedo de espalhamento único e $F F_{i}\left(180^{\circ}\right)$ é a função de fase para o ângulo de retroespalhamento. 


\subsection{Método de Inversão Ótima}

O método foi primeiramente proposto por Rodgers [7] entre outros, foi aplicado por Stephens e Engelen [24] para recuperar informações da atmosfera usando um lidar a bordo de um satélite. Um resumo das etapas do método são:

- Teorema de Bayes;

- estatística Gaussiana;

- linearização (descrito em na seção 2.2.3);

- procura iterativa pela solução;

- diagnóstico da estimativa.

A notação usada aqui representará vetores com letras minúsculas em negrito, e matrizes com letras maiúsculas também em negrito. Um vetor com um acento circunflexo $\hat{\mathbf{v}}$ denota uma quantidade estimada. A letra "T" sobrescrita em um vetor ou em uma matriz denota o operador de transposição do vetor ou da matriz, enquanto $\mathrm{i}, \mathrm{i}+1$, sobrescritas indicam quantidades interativas. $\mathrm{O}$ vetor declarado como $\mathbf{x}$, representa a informação que deve ser recuperada, enquanto o vetor declarado por $\mathbf{x}_{\mathbf{a}}$ indica valores a priori, e $\mathbf{y}$ é o vetor das informações medidas. $\hat{\mathbf{S}}_{\mathbf{x}}, \mathbf{S}_{\mathbf{a}}$, e $\mathbf{S}_{\mathbf{y}}$, são respectivamente a matriz covariância dos erros da solução estimada, a matriz dos dados a priori e matriz dos valores medidos.

O vetor dos valores medidos pode ser escrito como

$$
\mathbf{y}=f(\mathbf{x}, \mathbf{b})+\epsilon_{\mathbf{y}}
$$


na qual $f$ é a "função direta" da atmosfera, representando os detalhes físicos da medida (mas conhecidos de forma imperfeita). O verdadeiro estado da atmosfera representado por $\mathbf{x}$ e $\mathbf{b}$, os quais denotam quantidades que afetam as medidas mas que não são recuperadas com o algoritmo. Como elemento de ruído temos o $\epsilon_{\mathbf{y}}$, assumido para ter média zero e covariância $\mathbf{S}_{\mathbf{y}}$. Usando estimativas $\hat{\mathbf{x}}$ e $\hat{\mathbf{b}}$, um "modelo direto" f, representando nosso melhor esforço para descrever fisicamente, fornece nos os dados sintetizados por $\hat{\mathbf{y}}=\mathbf{f}(\hat{\mathbf{x}}, \hat{\mathbf{b}})$. O algoritmo de estimação óptima usado por Rodgers [7] entre outros, produziu um meio de usar o modelo direto pra construir a solução mais provável consistente com as medidas e as informações a priori. O uso de dados a priori melhora as características do ruído e a estabilidade da solução, relativa a uma recuperação "exata" da informação $\left(\hat{\mathbf{x}}=\mathbf{f}^{-\mathbf{1}}(\mathbf{y})\right)$, para o caso da razão sinal ruído ser pequena [7]. Usando a notação de Rodgers [8], uma representação formal do esquema de recuperação é:

$$
\hat{\mathbf{x}}=I\left(\mathbf{y}, \hat{\mathbf{b}}, \mathbf{x}_{\mathbf{a}}, \mathbf{u}\right)
$$

Esse é o "modelo inverso" com o qual nossa solução é construída. Aqui u representa os parâmetros do modelo inverso que nos dados a priori não são usados no modelo direto, por exemplo um primeiro palpite inicial $\hat{\mathbf{x}}$.

Deduzindo o algoritmo pelo Teorema de Bayes:

O Teorema de Bayes [11]:

$$
P(\mathbf{x} \mid \mathbf{y})=\frac{P(\mathbf{y} \mid \mathbf{x}) P(\mathbf{x})}{P(\mathbf{y})}
$$

fdp: função densidade de probabilidade.

$P(\mathbf{x})$ : fdp a priori do estado $\mathbf{x}$, (expressa quantitativamente nosso conhecimento de 
$\mathbf{x}$ antes da realização da medida;

$P(\mathbf{y} \mid \mathbf{x})$ : fdp condicional $\mathbf{y}$ dado $\mathbf{x}$, (problema direto e erro associado);

$P(\mathbf{x} \mid \mathbf{y})$ : fdp condicional de $\mathbf{x}$ dado $\mathbf{y}$ (informação inversa desejada, a máxima $P(\mathbf{x} \mid$

y) equivale a solução mais provável).

Considere a fdp de vetor Gaussiano, [27].

Dado y um vetor Gaussiano, temos que sua fdp é dada por:

$$
f_{y}=\frac{1}{(2 \Pi)^{n / 2}\left|\mathbf{S}_{\mathbf{y}}\right|^{1 / 2}} \exp \left[\frac{-1}{2}(\mathbf{y}-<\mathbf{y}>)^{T} \mathbf{S}_{\mathbf{y}}^{-\mathbf{1}}(\mathbf{y}-<\mathbf{y}>)\right]
$$

Na qual

$\left|\mathbf{S}_{\mathbf{y}}\right|$ é o determinante da matriz de covariância.

\section{Teorema de Bayes com estatística Gaussiana}

Pela equação (3.4.4) temos que a fdp $P(\mathbf{y})$ é dada por:

$$
P(\mathbf{y})=\frac{1}{(2 \Pi)^{n / 2}\left|\mathbf{S}_{\mathbf{y}}\right|^{1 / 2}} \exp \left[\frac{-1}{2}(\mathbf{y}-<\mathbf{y}>)^{T} \mathbf{S}_{\mathbf{y}}^{-\mathbf{1}}(\mathbf{y}-<\mathbf{y}>)\right]
$$

ou ainda

$$
-2 \ln [P(\mathbf{y})]=(\mathbf{y}-<\mathbf{y}>)^{T} \mathbf{S}_{\mathbf{y}}^{-\mathbf{1}}(\mathbf{y}-<\mathbf{y}>)+c 1
$$

Na qual $c 1$ é constante.

Analogamente obtemos para $P(\mathbf{y} \mid \mathbf{x})$ :

$$
-2 \ln [P(\mathbf{y} \mid \mathbf{x})]=\left[(\mathbf{y}-f(\mathbf{x}))^{T} \mathbf{S}_{\mathbf{y}}^{-\mathbf{1}}(\mathbf{y}-f(\mathbf{x}))+c 2\right.
$$

Com $c 2$ constante.

E representando nosso conhecimento a priori: 


$$
-2 \ln [P(\mathbf{x})]=\left[\left(\mathbf{x}-\mathbf{x}_{\mathbf{a}}\right)^{T} \mathbf{S}_{\mathbf{a}}^{-\mathbf{1}}\left(\mathbf{x}-\mathbf{x}_{\mathbf{a}}\right)\right]+c 3
$$

Dado que $c 3$ é constante.

Para se obter a solução mais provável devemos maximizar $P(\mathbf{x} \mid \mathbf{y})$.

$-2 \ln [P(\mathbf{x} \mid \mathbf{y})]=\left[(\mathbf{y}-f(\mathbf{x}))^{T} \mathbf{S}_{\mathbf{y}}^{-\mathbf{1}}(\mathbf{y}-f(\mathbf{x}))+\left[\left(\mathbf{x}-\mathbf{x}_{\mathbf{a}}\right)^{T} \mathbf{S}_{\mathbf{a}}^{-\mathbf{1}}\left(\mathbf{x}-\mathbf{x}_{\mathbf{a}}\right)\right] c 4\right.$

Na qual $c 4$ é constante.

\subsubsection{Estimativa do Coeficiente de absorção}

Considerando especificamente um vetor de medidas $\mathbf{y}$ com matriz de covariância $\mathbf{S}_{\mathbf{y}} \mathrm{e}$ uma informação a priori $\mathbf{x}_{\mathbf{a}}$ e desejamos estimar um vetor de parâmetros atmosféricos $\mathbf{x}$.

Linearizando a função $f(\mathbf{x})$ (mais detalhes podem ser apreciados na seção 2.2.3).

$\mathbf{K} \mathbf{x}=f(\mathbf{x})$

Tomemos as seguintes relações:

$$
\begin{gathered}
P(\mathbf{y} \mid \mathbf{x}) \propto \exp \left[-(\mathbf{K} \mathbf{x}-\mathbf{y})^{T} \mathbf{S}_{\mathbf{y}}^{-\mathbf{1}}(\mathbf{K} \mathbf{x}-\mathbf{y})\right] \\
P(\mathbf{x}) \propto \exp \left[-\left(\mathbf{x}-\mathbf{x}_{\mathbf{a}}\right)^{T} \mathbf{S}_{\mathbf{a}}^{-\mathbf{1}}\left(\mathbf{x}-\mathbf{x}_{\mathbf{a}}\right)\right]
\end{gathered}
$$

Queremos maximizar (3.4.12), portanto devemos minimizar (3.4.13).

$$
P(\mathbf{x} \mid \mathbf{y}) \propto \exp [-\Phi(\mathbf{x})]
$$

na qual 


$$
\Phi(\mathbf{x})=(\mathbf{K} \mathbf{x}-\mathbf{y})^{T} \mathbf{S}_{\mathbf{y}}^{-\mathbf{1}}(\mathbf{K} \mathbf{x}-\mathbf{y})+\left(\mathbf{x}-\mathbf{x}_{\mathbf{a}}\right)^{T} \mathbf{S}_{\mathbf{a}}^{-\mathbf{1}}\left(\mathbf{x}-\mathbf{x}_{\mathbf{a}}\right)
$$

$\max \exp [-\Phi(\mathbf{x})] \Longrightarrow \min \Phi(\mathbf{x})$

Usando máxima verossimilhança.

$$
\begin{gathered}
\frac{\partial}{\partial x}\left[(\mathbf{K} \mathbf{x}-\mathbf{y})^{T} \mathbf{S}_{\mathbf{y}}^{-\mathbf{1}}(\mathbf{K} \mathbf{x}-\mathbf{y})+\left(\mathbf{x}-\mathbf{x}_{\mathbf{a}}\right)^{T} \mathbf{S}_{\mathbf{a}}^{-\mathbf{1}}\left(\mathbf{x}-\mathbf{x}_{\mathbf{a}}\right)\right]=0 \\
\mathbf{K}^{\mathbf{T}} \mathbf{S}_{\mathbf{y}}^{-\mathbf{1}}(\mathbf{K} \hat{\mathbf{x}}-\mathbf{y})+\mathbf{S}_{\mathbf{a}}^{-\mathbf{1}}\left(\hat{\mathbf{x}}-\mathbf{x}_{\mathbf{a}}\right) \\
\left(\mathbf{K}^{\mathbf{T}} \mathbf{S}_{\mathbf{y}}^{-\mathbf{1}} \mathbf{K}+\mathbf{S}_{\mathbf{a}}^{-\mathbf{1}}\right) \hat{\mathbf{x}}-\left(\mathbf{K}^{\mathbf{T}} \mathbf{S}_{\mathbf{y}}^{-\mathbf{1}} \mathbf{y}+\mathbf{S}_{\mathbf{a}}^{-\mathbf{1}} \mathbf{x}_{\mathbf{a}}\right)=0
\end{gathered}
$$

Rearranjando a solução ótima temos:

$$
\hat{\mathbf{x}}=\left(\mathbf{K}^{\mathbf{T}} \mathbf{S}_{\mathbf{y}}^{-1} \mathbf{K}+\mathbf{S}_{\mathbf{a}}^{-1}\right)^{-1}\left[\mathbf{K}^{\mathbf{T}} \mathbf{S}_{\mathbf{y}}^{-1} \mathbf{y}+\mathbf{S}_{\mathbf{a}}^{-1} \mathbf{x}_{\mathbf{a}}\right]
$$

Note que (3.4.17) é muito parecida com a aproximação por mínimos quadrados, se diferenciando apenas pelos termos que indicam a informação a priori, $\left(\mathbf{x}_{\mathbf{a}}\right.$ e $\left.\mathbf{S}_{\mathbf{a}}\right)$.

A equação (3.4.18) representa a matriz de covariância da estimativa $\hat{\mathbf{x}}$.

$$
\hat{\mathbf{S}}_{\mathbf{x}}=\left(\mathbf{K}^{\mathbf{T}} \mathbf{S}_{\mathbf{y}}^{-1} \mathbf{K}+\mathbf{S}_{\mathbf{a}}^{-\mathbf{1}}\right)^{-\mathbf{1}}
$$

\section{$\mathrm{O}$ algoritmo na forma iterativa}

A estimativa $\hat{\mathbf{x}}$ descrita acima pela equação 3.4 .17 pode ser apresentada segundo Marks e Rodgers [18] pela equação abaixo:

$$
\hat{\mathbf{x}}=\mathbf{x}_{\mathbf{a}}+\mathbf{S}_{\mathbf{a}} \mathbf{K}^{\mathbf{T}} \mathbf{S}_{\mathbf{y}}^{-\mathbf{1}}(\mathbf{y}-\mathbf{f}(\hat{\mathbf{x}}))
$$


Aqui $\mathbf{K}=\partial \mathbf{f} / \partial \mathbf{x}$ avaliado pelo $\hat{\mathbf{x}}$. Para obter $\hat{\mathbf{x}}$, nós iteramos em direção a solução, linearizando sobre a estimação corrente, $\hat{\mathbf{x}}$, cada tempo:

$$
\mathbf{f}(\hat{\mathbf{x}})=\mathbf{f}^{\mathbf{i}}+\mathbf{K}^{\mathbf{i}}\left(\hat{\mathbf{x}}-\mathbf{x}^{\mathbf{i}}\right)+O\left(\hat{\mathbf{x}}-\mathbf{x}^{\mathbf{i}}\right)^{2}
$$

Aqui $\mathbf{f}^{\mathbf{i}}=\mathbf{f}\left(\mathbf{x}^{\mathbf{i}}\right)$ etc. Usando (3.4.20) em (3.4.19), substituindo $\hat{\mathbf{x}}$ com $\mathbf{x}^{\mathbf{i}+\mathbf{1}}$, ignorando $\partial \mathbf{K} / \partial \mathbf{x}$, e rearanjando, temos:

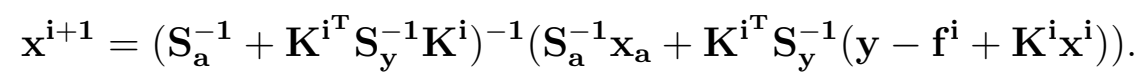

a equação (3.4.21) pode ser rearranjada em

$$
\mathbf{x}^{\mathrm{i}+\mathbf{1}}=\mathrm{x}^{\mathrm{i}}+\left(\mathrm{S}_{\mathrm{a}}^{-1}+\mathbf{K}^{\mathrm{i}^{\mathrm{T}}} \mathbf{S}_{\mathbf{y}}^{-1} \mathbf{K}^{\mathrm{i}}\right)^{-1}\left(\mathbf{K}^{\mathrm{i}^{\mathrm{T}}} \mathbf{S}_{\mathbf{y}}^{-1}\left(\mathbf{y}-\mathbf{f}^{\mathrm{i}}\right)+\mathrm{S}_{\mathrm{a}}^{-1}\left(\mathrm{x}_{\mathrm{a}}-\mathbf{x}^{\mathrm{i}}\right)\right) .
$$

ou ainda apresentada como segue abaixo

$$
\left.\mathbf{x}^{\mathbf{i}+\mathbf{1}}=\mathbf{x}_{\mathbf{a}}+\mathbf{S}_{\mathbf{a}} \mathbf{K}^{\mathbf{i}^{\mathrm{T}}}\left(\mathbf{K}^{\mathbf{i}} \mathbf{S}_{\mathbf{a}} \mathbf{K}^{\mathbf{i}^{\mathrm{T}}}\right)+\mathbf{S}_{\mathbf{y}}\right)^{-\mathbf{1}}\left(\mathbf{y}-\mathbf{f}^{\mathbf{i}}-\mathbf{K}^{\mathbf{i}}\left(\mathbf{x}_{\mathbf{a}}-\mathbf{x}^{\mathbf{i}}\right)\right)
$$

A estimativa inicial $x^{0}$ pode ser convenientemente tomado como $x_{a}$ (citado como a escolha mais sensível quanto a análise do erro [8]).

\subsubsection{Estimativa com restrição da espessura ótica}

\section{Descrição do cálculo da espessura ótica para o comprimento de $532 \mathrm{~nm}$}

A espessura ótica por aerossóis para o comprimento de onda de $532 \mathrm{~nm}, \tau_{532}$ denotado por (3.4.24) [9]: 


$$
\tau_{532}=\tau_{500}\left(\frac{532}{500}\right)^{-\alpha}
$$

$\mathrm{Na}$ qual $\tau_{500}$ é a espessura ótica por aerossóis para $500 \mathrm{~nm}$ e $\alpha$ é o expoente de Ångström dado por

$$
\alpha=\frac{\log \left[\frac{\tau_{440}}{\tau_{670}}\right]}{\log \left[\frac{\tau_{670}}{\tau_{440}}\right]}
$$

Tal que $\tau_{440}$ e $\tau_{670}$ são as espessuras ótica por aerossóis para $440 \mathrm{~nm}$ e $670 \mathrm{~nm}$ respectivamente, disponibilizados pela AEROSOL ROBOTIC NETWORK - NASA (AERONET), medidos por um fotômetro solar localizado no Instituto de Física da Universidade de São Paulo.

\section{Utilizando um vínculo no Algoritmo de recuperação}

Temos que a espessura ótica por aerossóis é dada por $\tau_{\lambda}=\int_{r_{1}}^{r^{2}} \mathbf{x} d r$, na qual $\mathbf{x}$ representa o coeficiente de extinção por partículas (aerossóis), $\sigma_{p}, r_{1}$ e $r_{2}$ são as altitudes que limitam a faixa da atmosfera estudada [16].

O vínculo aplicado aqui relaciona a espessura ótica por aerossóis, $\tau_{532}$, calculada com dados da AERONET e a espessura ótica por aerossóis calculada pelo lidar, por meio da estimativa do coeficiente de extinção por aerossóis.

Tal informação adicional é usada para complementar a equação (3.4.13) que agora está em função da estimativa $\hat{\mathbf{x}}$ e $\mathbf{f}(\hat{\mathbf{x}})$. Descrita na seção 3.4.1, como segue abaixo.

$$
\left(\hat{\mathbf{x}}-\mathbf{x}_{\mathbf{a}}\right)^{T} \mathbf{S}_{\mathbf{a}}^{-\mathbf{1}}\left(\hat{\mathbf{x}}-\mathbf{x}_{\mathbf{a}}\right)+[\mathbf{y}-\mathbf{f}(\hat{\mathbf{x}})]^{T} \mathbf{S}_{\mathbf{y}}^{-\mathbf{1}}[\mathbf{y}-\mathbf{f}(\hat{\mathbf{x}})]+\frac{\left[\tau_{532}-G(\hat{\mathbf{x}})\right]^{2}}{\sigma_{\tau}^{2}}
$$


Com $G(\hat{\mathbf{x}})=\sum_{i} 0.5\left(x_{i}+x_{i+1}\right) \Delta r \approx \tau_{532}, \sigma_{\tau}$ é o desvio padrão da tal espessura ótica.

Minimizando (3.4.26) analogamente como se operou com a equação (3.4.13) na seção 3.4.1 chegamos na expressão (3.4.27).

$$
\hat{\mathbf{x}}=\mathbf{x}_{\mathbf{a}}+\mathbf{S}_{\mathbf{a}} \mathbf{K}^{\mathbf{T}} \mathbf{S}_{\mathbf{y}}^{-\mathbf{1}}[\mathbf{y}-\mathbf{f}(\hat{\mathbf{x}})]+\mathbf{S}_{\mathbf{a}} \mathbf{L}^{\mathbf{T}} \frac{\left[\tau_{532}-G(\hat{\mathbf{x}})\right]}{\sigma_{\tau}^{2}} .
$$

Na qual L é o vetor contendo o gradiente de $G(\hat{\mathbf{x}})$ com relação a $\hat{\mathbf{x}}$.

A equação (3.4.27) então é resolvida de forma iterativa por (3.4.28) [21].

$$
\begin{array}{r}
\mathbf{x}^{\mathbf{i}+1}=\left(\mathbf{S}_{\mathbf{a}}^{-1}+\mathbf{K}^{\mathrm{i}^{\mathrm{T}}} \mathbf{S}_{\mathbf{y}}^{-1} \mathbf{K}^{\mathrm{i}}+\mathbf{L}^{\mathrm{i}} \mathbf{L}^{\mathrm{i}^{\mathrm{T}}} \sigma_{\tau}^{-\mathbf{2}}\right)^{-1}\left(\mathbf{S}_{\mathbf{a}}^{-1} \mathbf{X}_{\mathbf{a}}+\mathbf{K}^{\mathbf{i}^{\mathrm{T}}} \mathbf{S}_{\mathbf{y}}^{-1}\left[\mathbf{y}-\mathbf{f}^{\mathbf{i}}+\mathbf{K}^{\mathrm{i}} \mathbf{x}^{\mathbf{i}}\right)\right]+ \\
+\mathbf{L}^{\mathrm{i}} \sigma_{\tau}^{-2}\left[\tau_{\mathbf{5 3 2}}-\mathbf{G}\left(\mathbf{x}^{\mathrm{i}}\right)\right]+\mathbf{L}^{\mathbf{i}^{\mathrm{T}}} \mathbf{x}^{\mathbf{i}}
\end{array}
$$

Com matriz de covariância, $\mathbf{S}_{\mathbf{x}}$, calculada por (3.4.29).

\subsubsection{Diagnóstico das estimativas}

O diagnóstico das estimativas descrito por Rodgers [8] é realizado por meio da matriz de sensibilidade A obtida pela equação (3.4.33), que avalia o processo de inversão a cada iteração, também é possível reconhecer as parcelas de contribuição:

- das medidas;

- do a priori;

- do vínculo. 
para as incertezas da estimativa. A recuperação da informação, sob a ótica de um ajuste, pode permitir ainda o cálculo de $\chi^{2}$, desde que os dados medidos se ajustem ao modelo e sejam consistentes com os erros.

Muitas das incertezas aparecem na forma de matrizes de covariância, ao invés de aparecerem como simples variâncias. Essas matrizes podem ser interpretadas em termos de "incertezas padrões", que são estatisticamente independentes e contribuem para a incerteza total.

Uma análise das incertezas da observação deste sistema de sensoriamento remoto, com a estimativa $\hat{\mathbf{x}}$ incluíram os seguintes cálculos:

a ) A matriz de covariância $\mathbf{S}_{\mathbf{x}}$ da estimativa, por meio de (3.4.29), [24].

$$
\mathbf{S}_{\mathbf{x}}=\left(\mathbf{S}_{\mathbf{a}}^{-1}+\mathbf{K}^{\mathbf{T}} \mathbf{S}_{\mathbf{y}}^{-1} \mathbf{K}+\mathbf{L L}^{\mathbf{T}} \sigma_{\tau}^{-2}\right)^{-1}
$$

O vetor $\mathbf{L}$ é descrito na seção 3.4.2.

b ) Obter a "matriz de contribuição" $\mathbf{D}_{\mathbf{y}}$, algebricamente ou pela perturbação do modelo inverso.

A matriz $\mathbf{D}_{\mathbf{y}}$ definida como $\frac{\partial \hat{\mathbf{x}}}{\partial \mathbf{y}}[18]$, na qual $\hat{\mathbf{x}}=I$ é o "modelo inverso" descrito anteriormente pela equação (3.4.2).

A construção da matriz $\mathbf{D}_{\mathbf{y}}$ se baseia na procura de um preditor [7] tal que:

$$
\hat{\mathbf{x}}=\mathbf{D}_{\mathbf{y}} \mathbf{y}
$$

A determinação de $\mathbf{D}_{\mathbf{y}}$ pode ser descrita por (3.4.31), [8], 


$$
\begin{aligned}
\mathbf{D}_{\mathbf{y}} & =\mathbf{S}_{\mathbf{a}} \mathbf{K}^{\mathbf{T}}\left(\mathbf{K S}_{\mathbf{a}} \mathbf{K}^{\mathbf{T}}+\mathbf{S}_{\mathbf{y}}\right)^{-\mathbf{1}} \\
& =\left(\mathbf{S}_{\mathbf{a}}^{-\mathbf{1}}+\mathbf{K}^{\mathbf{T}} \mathbf{S}_{\mathbf{y}}^{-\mathbf{1}} \mathbf{K}\right)^{-\mathbf{1}} \mathbf{K}^{\mathbf{T}} \mathbf{S}_{\mathbf{y}}^{-\mathbf{1}}
\end{aligned}
$$

ou ainda:

$$
\mathbf{D}_{\mathbf{y}}=\mathbf{S}_{\mathbf{x}} \mathbf{K}^{\mathrm{T}} \mathbf{S}_{\mathbf{y}}^{-1}
$$

A contribuição dos erros das medidas diretamente no valor recuperado é $\mathbf{D}_{\mathbf{y}} \varepsilon_{\mathbf{y}}$, na qual $\varepsilon_{\mathbf{y}}$ é o erro da medida $\mathbf{y}$.

c ) Construir a matriz de covariância:

$$
D_{y} S_{y} D_{y}^{T}
$$

determinando desta forma as incertezas associadas as medidas,[8],[18].

d ) Determinar a matriz de sensibilidade A, definida como $\frac{\partial \hat{x}}{x}$. A resolução espacial do sistema de observação é descrita pelas linhas ou pelas colunas de $\mathbf{A}$.

$$
\mathrm{A}=\mathrm{D}_{\mathbf{y}} \mathrm{K}
$$

Para um sistema de observação ideal, $\mathbf{A}$ é a matriz identidade, pois $\mathbf{D}_{\mathbf{y}}$ por 3.4.30 realiza o papel da inversa de $\mathbf{K}$. Para um sistema inteiramente dependente do "a priori" temos que A é a matriz nula, [18, 8]. 
e ) Obter a matriz $\mathbf{D}_{\mathbf{a}}$ que relaciona as mudanças do "a priori" na informação recuperada

$$
\mathbf{D}_{\mathbf{a}}=\frac{\partial \hat{\mathbf{x}}}{\mathbf{x}_{\mathbf{a}}}=\mathbf{I}-\mathbf{A}
$$

Se assumirmos que o valor verdadeiro de $\mathbf{x}_{\mathbf{a}}$ é $\mathbf{x}$, então a contribuição para o erro total provinda desta fonte é $\mathbf{D}_{\mathbf{a}}\left(\mathbf{x}_{\mathbf{a}}-\mathbf{x}\right)$. Já a matriz de covariância devido ao "a priori" é dada por (3.4.35), [8],[18].

$$
\mathrm{D}_{\mathrm{a}} \mathrm{S}_{\mathrm{a}} \mathrm{D}_{\mathrm{a}}^{\mathrm{T}}
$$

f ) Buscar relacionar o vínculo, construindo a matriz $\mathbf{D}_{\tau}$ pela expressão abaixo $[24]$,

$$
\mathbf{D}_{\tau}=\mathbf{S}_{\mathbf{x}} \mathbf{K}^{\mathbf{T}} \sigma_{\tau}^{-2}
$$

Com matriz de covariância devido ao vínculo dada por

$$
\mathbf{D}_{\tau} \mathbf{S}_{\tau} \mathbf{D}_{\tau}^{\mathbf{T}}
$$

A matrix $\mathbf{S}_{\mathbf{x}}$ descrita por (3.4.29), pode ser expressa ainda em função da contribuição das matrizes de covariância das medidas, do a priori e do vínculo utilizado:

$$
\mathbf{S}_{\mathbf{x}}=\mathbf{D}_{\mathbf{y}} \mathbf{S}_{\mathbf{y}} \mathbf{D}_{\mathbf{y}}^{\mathbf{T}}+\mathbf{D}_{\mathbf{a}} \mathbf{S}_{\mathbf{a}} \mathbf{D}_{\mathbf{a}}^{\mathbf{T}}+\mathbf{D}_{\tau} \mathbf{S}_{\tau} \mathbf{D}_{\tau}^{\mathbf{T}}
$$


g ) Com a hipótese de que os dados medidos se ajustam ao modelo (problema direto e seus erros associados) e são consistentes com os erros da medida, considerando ainda que os dados a priori são "medidas virtuais", o $\chi^{2}$ apropriado para testar a qualidade do ajuste é dado por

$$
\chi^{2}=[\mathbf{y}-\mathbf{f}(\hat{\mathbf{x}})]^{\mathbf{T}} \mathbf{S}_{\mathbf{y}}^{-\mathbf{1}}[\mathbf{y}-\mathbf{f}(\hat{\mathbf{x}})]+\left(\mathbf{x}_{\mathbf{a}}-\hat{\mathbf{x}}\right)^{\mathbf{T}} \mathbf{S}_{\mathbf{a}}^{-\mathbf{1}}\left(\mathbf{x}_{\mathbf{a}}-\hat{\mathbf{x}}\right)+\left[\mathbf{x}_{\tau}-\mathbf{G}(\hat{\mathbf{x}})\right]^{\mathbf{2}} \sigma_{\tau}^{-2} .
$$

Temos que (3.4.39) com as hipóteses apresentadas deveria seguir uma distribuição de $\chi^{2} \operatorname{com} n_{y}$ graus de liberdade, no qual $n_{y}$ é a dimensão do vetor de medidas y. O número de graus de liberdade foi determinado pelo número de medidas, $n_{y}$, mais o número de "medidas virtuais" (as medidas a priori, $\mathbf{x}_{\mathbf{a}}$ ), menos o número de informações recuperadas. Ou seja:

$$
\left\{\begin{array}{l}
n_{y}:=\text { número de medidas; } \\
n_{x}:=\left\{\begin{array}{l}
\text { número de "medidas virtuais"; } \\
\text { número de informações recuperadas; }
\end{array}\right. \\
\text { graus de liberdade }:=n_{y}+n_{x}-n_{x} .
\end{array}\right.
$$

Neste trabalho o vetor a priori, $\mathbf{x}_{\mathbf{a}}$, tem a mesma dimensão do vetor de elemento recuperados $\hat{\mathbf{x}}$.

Uma avaliação do processo de inversão utilizando o valor de $\chi^{2}$ é realizada por Marks e Rodgers [18]. Avaliam que se $\chi^{2}$ é muito grande (ou seja a estimativa junto ao modelo não se ajusta as medidas) as possibilidades são diversas: o modelo não é bom (por exemplo contem aproximações inadequadas), a medida 
foi calibrada incorretamente, os erros das medidas foram subestimado, os erros das medidas não são normalmente distribuídos, o estado a priori é inapropriado ou o vínculo utilizado ("constraint") é muito "justo".

Por outro lado se $\chi^{2}$ é muito pequeno (ou seja a estimativa junto ao modelo se ajusta muito bem as medidas) os erros das medidas foram superestimado ou o vínculo utilizado ("constraint") é muito "solto".

Ainda segundo Engelen e Stephens [21], utilizam a condição $\chi^{2} \ll n_{y}$ como teste de qualidade. 


\section{Capítulo 4}

\section{Resultados}

\subsection{Cálculo do Espalhamento Rayleigh}

Segue o cálculo para o espalhamento Rayleigh, começando pelo cálculo da seção de choque de espalhamento Rayleigh total,$\varphi\left(\mathrm{cm}^{2}\right)$, na qual $\lambda(\mathrm{cm})$ é o comprimento de onda , $m_{r}$ é o índice de refração do ar para o comprimento de onda $\lambda, F\left(\right.$ air,$\left.C_{2}\right)$ é o fator de King, $N_{s}\left(\mathrm{~cm}^{-3}\right)$ é a densidade molecular de referência para a pressão $P_{s} \mathrm{e}$ a temperatura $T_{s}$ na altitude $z_{s}$, descrita por (4.1.1).

$$
\varphi(\lambda)=\frac{24 \Pi^{3}\left(m_{r}^{2}-1\right)^{2}}{\lambda^{4} N_{s}^{2}\left(m_{r}^{2}+2\right)^{2}} F\left(\text { air }, C O_{2}\right)
$$

De acordo com [1] podemos calcular o índice de refração do ar para $\lambda>0.23 \mu m$ através da equação (4.1.2).

$$
\left(m_{r}-1\right) \times 10^{8}=\frac{5791817}{238,0185-(1 / \lambda)^{2}}+\frac{167909}{57,362-(1 / \lambda)^{2}}
$$

na qual o comprimento de onda, $\lambda$, é dado em microns.

Considerando ainda uma quantia dos principais constituintes secos do ar, para calcular o Fator de King, para uma concentração de $\mathrm{CO}_{2}$ variável (expresso aqui 
como concentração por volume em porcentagem), pode ser calculado pela equação (4.1.3), utilizado $C_{\mathrm{CO}_{2}}=0,03$.

$$
F\left(\text { air }, C_{2}\right)=\frac{78,084 F\left(N_{2}\right)+20,946 F\left(O_{2}\right)+0,934 \times F(A r)+C_{C O_{2}} \times F\left(C O_{2}\right)}{78,084+20,946+0,934+C_{C O_{2}}}
$$

O Fator King para $\mathrm{N}_{2}, \mathrm{O}_{2}, \mathrm{Ar}$ e $\mathrm{CO}_{2}$ são:

$$
\begin{gathered}
F\left(N_{2}\right)=1,034+3,17 \times 10^{-4} \frac{1}{\lambda^{2}} \\
F\left(O_{2}\right)=1,096+1,385 \times 10^{-3} \frac{1}{\lambda^{2}}+1,448 \times 10^{-4} \frac{1}{\lambda^{4}} \\
F(A r)=1,00 \\
F\left(C O_{2}\right)=1,15
\end{gathered}
$$

O coeficiente de espalhamento Rayleigh total num volume, $\beta_{s}$ em $\left(\mathrm{km}^{-1}\right)$, como uma função do comprimento de onda para uma atmosfera de referência pode ser obtido pela equação (4.1.8).

$$
\beta_{s}(\lambda)=N_{s} \varphi(\lambda)\left(10^{5} \mathrm{~cm} / \mathrm{km}\right)
$$

Temos ainda o coeficiente de espalhamento total Rayleigh $\beta_{\text {ray }}$, o qual é dado pelo produto da seção de choque de espalhamento Rayleigh total, $\varphi$, definida na equação (4.1.1), pela densidade molecular $N$ para uma dada pressão, temperatura e altitude, $z$. 


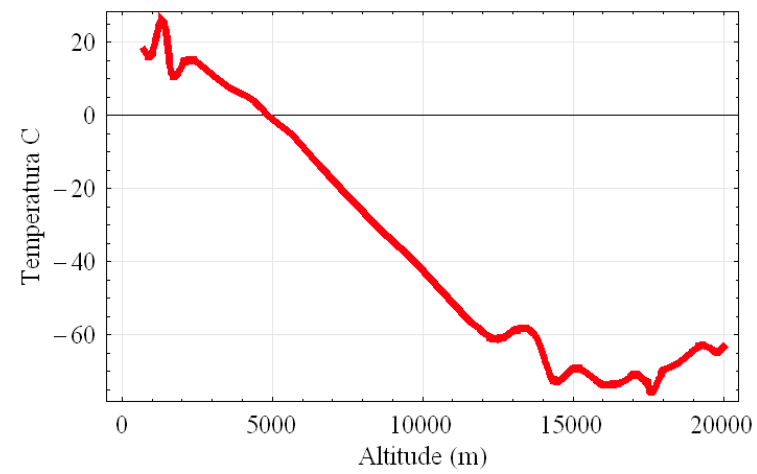

Figura 4.1: Perfil de temperatura.

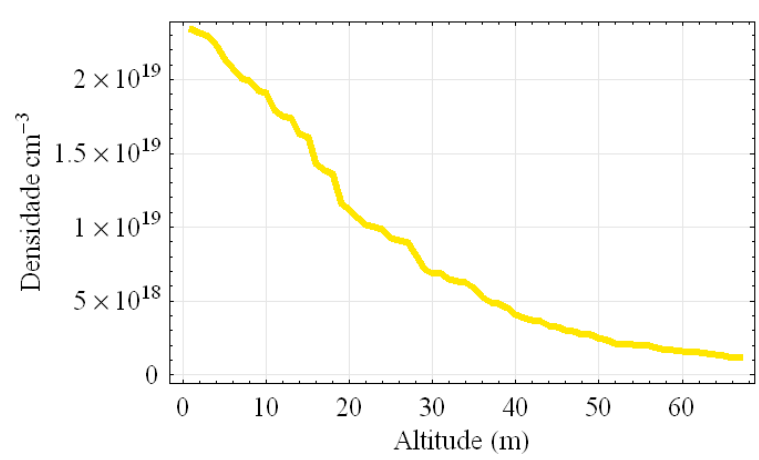

Figura 4.3: Densidade do ar calculado com Figura 4.4: Espalhamento Rayleigh calcu-

dados de sondagem para o cálculo do espa- lado com dados de sondagem e para uma lhamento Rayleigh.

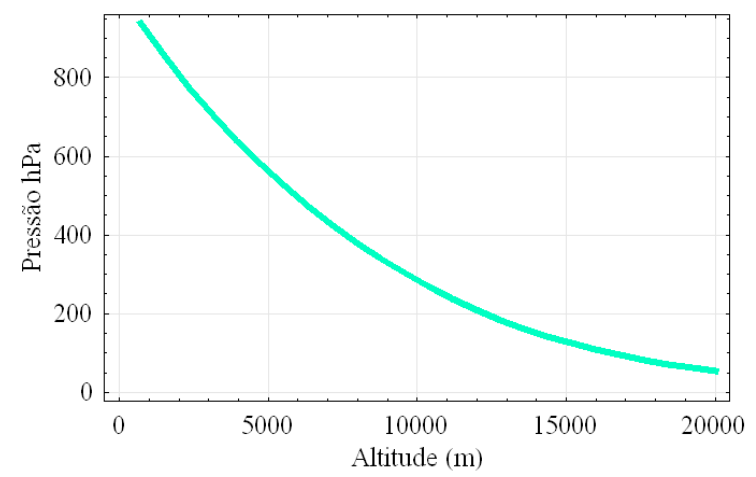

Figura 4.2: Perfil de pressão atmosférica

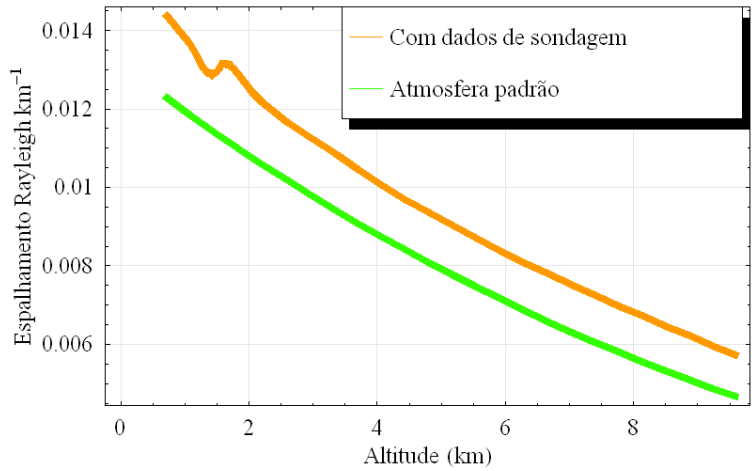
atmosfera padrão

$$
\beta_{\text {ray }}(\lambda, z)=N(z) \varphi(\lambda)
$$

Ou alternativamente, $\beta_{\text {ray }}$ pode ser calculado em termos de $\beta_{s}$ (descrito na equação (4.1.8))para valores de pressão, $(P)$, e temperatura, $(T)$

$$
\beta_{\text {ray }}=\beta_{s} \frac{N}{N_{s}} \frac{T_{s}}{T}=\beta_{s} \frac{P}{P_{s}} \frac{T_{s}}{T} .
$$

Para calcular o coeficiente de espalhamento Rayleigh para um ângulo específico, consideramos a função de fase Rayleigh, $P_{\text {ray }}$, em função do ângulo $(\theta)$ 


$$
P_{\text {ray }}(\theta)=\frac{3}{4(1+2 \gamma)}\left[(1+3 \gamma)+(1-\gamma) \cos ^{2} \theta\right]
$$

na qual

$$
\gamma=\frac{\rho_{n}}{2-\rho_{n}}
$$

com termo de despolarização $\rho_{n}$ obtido por

$$
F(a r)=\frac{6+3 \rho_{n}}{6-7 \rho_{n}}
$$

com $F($ ar $)$ sendo o Fator King para o ar atmosférico, temos assim $\beta_{\text {ray }}(\theta, \lambda, z)$ para um ângulo $\theta$

$$
\beta_{\text {ray }}(\theta, \lambda, z)=\frac{\beta_{\text {ray }}(\lambda, z)}{4 \pi} P_{\text {ray }}(\theta)
$$

E desta forma determinamos particularmente o coeficiente de retroespalhamento Rayleigh $\beta_{\pi}$, como descrito na equação (4.1.15).

$$
\beta_{\pi}=\frac{\beta(\lambda, z)}{4 \pi} P_{r a y}(\pi)
$$

\subsection{Aplicando o algoritmo de recuperação para o si- nal Lidar}

O processo de inversão é iniciado pela leitura do arquivo de dados de potência retornada, $P(r)$, representada pela equação (2.2.1). A sequência de figuras 4.6 até 4.16 ilustra o processo de inversão, para um dado medido no dia 19/05/2006, tal medida é a média de 2000 tiros realizados no intervalo de $10 \mathrm{~h} 51 \mathrm{~min} 37 \mathrm{~s}$ até $10 \mathrm{~h} 53 \mathrm{~min} 18 \mathrm{~s}$, a 
figura (4.5) mostra a atmosfera do dia citado, enquanto a espessura ótica foi medida no mesmo dia (19/05/2006) às 10h 49min 51s pelo "sunphotometer" situado aproximadamente a $300 \mathrm{~m}$ do sistema lidar responsável pelos dados. Os valores de espessura ótica por aerossóis são disponibilizados pela AEROSOL ROBOTIC NETWORK NASA (AERONET). As matrizes de covariância, $\mathbf{S}_{\mathbf{y}}$ e $\mathbf{S}_{\mathbf{a}}$, são assumidas diagonal com os elementos da diagonal especificados por

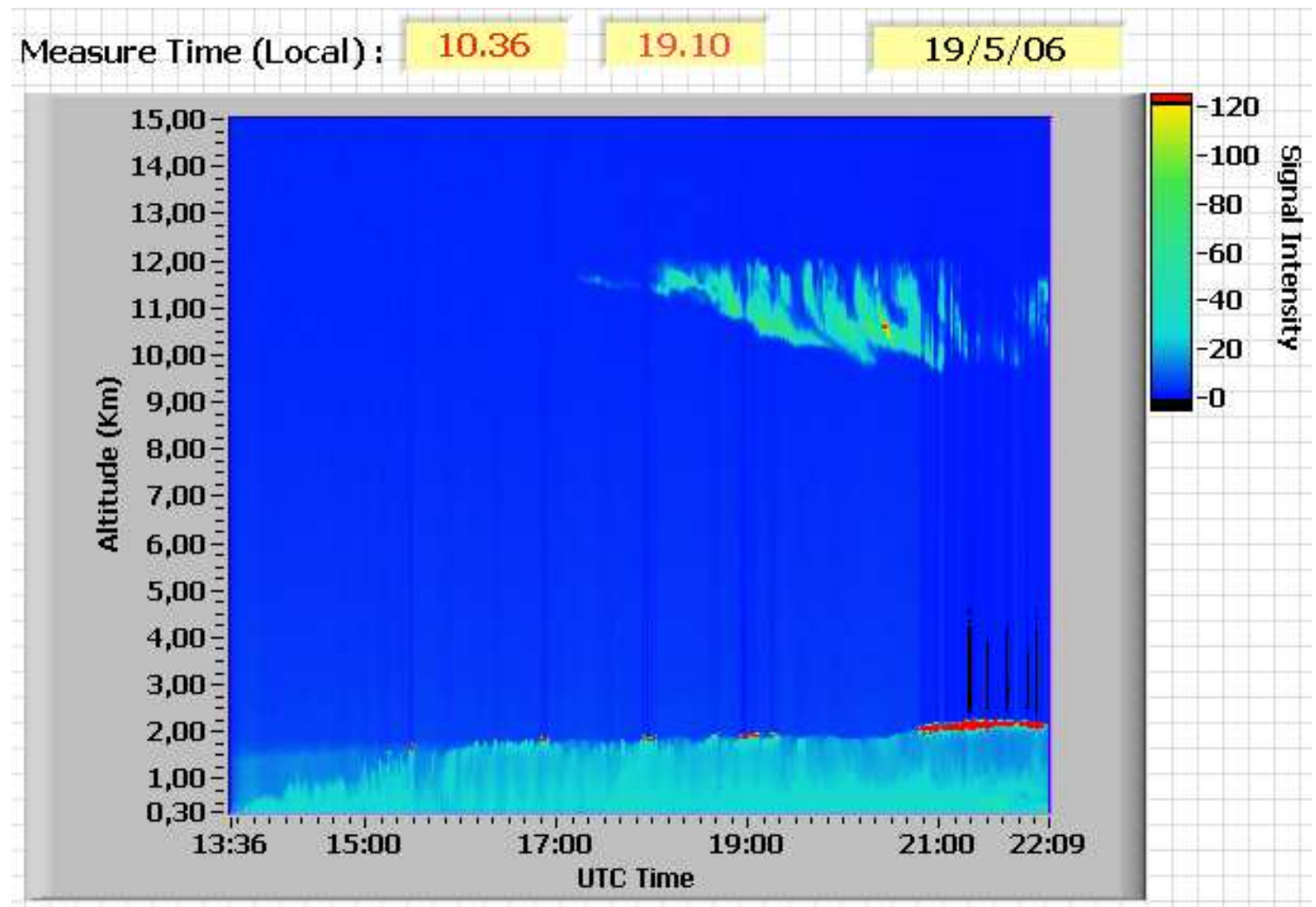

Figura 4.5: Evolução temporal da atmosfera detectada pelo sistema lidar no dia $19 / 05 / 2006$.

$$
\begin{aligned}
& \mathbf{S}_{\mathbf{a}}=\sigma_{a}^{2} \\
& \mathbf{S}_{\mathbf{y}}=\varepsilon_{y}^{2}+\sigma_{b 1}^{2}+\sigma_{b 2}^{2}
\end{aligned}
$$


na qual foi tomado $\sigma_{a}=5 \mathbf{S}_{\mathbf{y}, \mathbf{i i}}$

Na qual $\varepsilon_{y}$ é o erro das medidas, tomados como $5 \%$ do valor da potência retornada, como sugerido por [24], os erros remanescentes seguem das equações (2.2.15) até (2.2.19), apresentados na equação (4.2.2)

$$
\begin{aligned}
\sigma_{b 1} & =\frac{0.02 \beta_{\pi, i}}{\beta_{\pi}+\omega x_{i}} \\
\sigma_{b 2} & =\frac{\Delta \omega_{i} x_{i}}{\beta_{\pi}+\omega x_{i}}
\end{aligned}
$$

Tal dado (medido no dia 19/05/2006, no intervalo de 10h 51min 37s até 10h 53min 18s) foi lido pelo software comercial Mathematica no qual o método foi implementado. Os dados originalmente gravados no formato binário são convertidos para ascii seguindo os padrões de gravação do mesmo descrito pelo Manual da LICEL, [14]. O sinal sem nenhum tratamento é representado na figura 4.6.

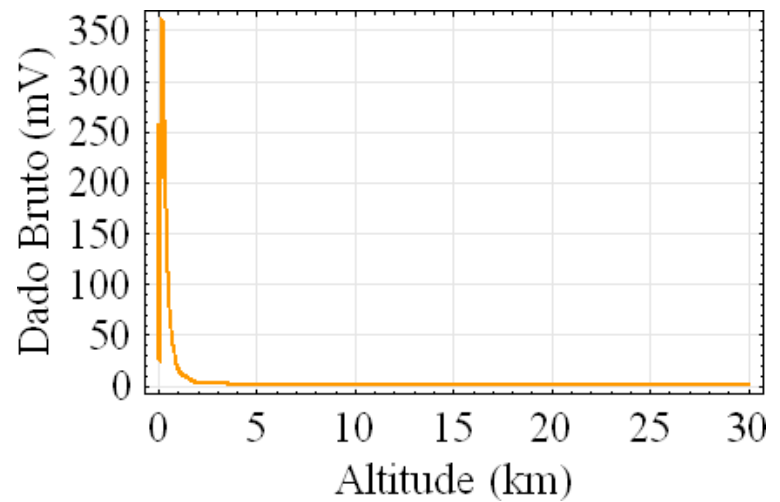

Figura 4.6: Sinal Bruto de lidar

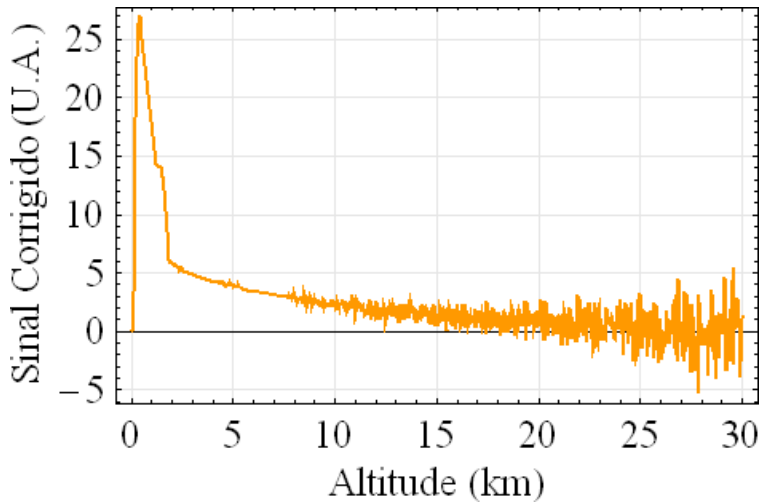

Figura 4.7: Sinal corrigido pela distância

Os primeiros tratamentos relatados na seção 4.6 são iniciados, com a subtração do ruído e pela correção do sinal pela distância ao quadrado, a figura 4.7 mostra um perfil deste sinal. 
Utilizando os resultados do capítulos 1 e da seção 2.2.2 temos:

Pela equação (2.2.4):

$$
S-S_{0}=\ln [\beta(r)]-\ln \left[\beta\left(r_{0}\right)\right]-2 \int_{r_{0}}^{r} \sigma\left(r^{\prime}\right) d r^{\prime}
$$

se utilizando das equações (2.2.6) e (2.2.9) temos:

$$
\bar{S}=S-S_{0}=\ln \left[\beta_{\pi}(r)+\beta_{p}(r)\right]-\ln \left[\beta\left(r_{0}\right)\right]-2 \int_{r_{0}}^{r}\left[\sigma_{m}\left(r^{\prime}\right)+\sigma_{p}\left(r^{\prime}\right)\right] d r^{\prime}
$$

Tomando a relação dada por (3.3.1) na equação (2.2.4) temos:

$$
\bar{S}=\ln \left[\beta_{\pi}(r)+\omega \sigma_{p}^{k}(r)\right]-\ln \left[\omega \sigma^{k}\left(r_{0}\right)\right]-2 \int_{r_{0}}^{r}\left[\sigma_{m}\left(r^{\prime}\right)+\sigma_{p}\left(r^{\prime}\right)\right] d r^{\prime}
$$

Tomando $r_{0}=0, \sigma\left(r_{0}\right)=0$ e $\kappa=1$ temos:

$$
\bar{S}=\ln \left[\beta_{\pi}+\omega \sigma_{p}\right]-2 \int_{0}^{r}\left[\sigma_{m}\left(r^{\prime}\right)+\sigma_{p}\left(r^{\prime}\right)\right] d r^{\prime}
$$

A matriz $\mathbf{K}$ para o dado anteriormente citada apresentou os seguintes números de condição (descrito na seção A):

$$
\begin{aligned}
\operatorname{Cond}(\mathbf{K})_{\text {norma } 1} & =3,261664552705789 \times 10^{7} \\
\operatorname{Cond}(\mathbf{K})_{\text {norma } 2} & =1,4771104074144594 \times 10^{6} \\
\operatorname{Cond}(\mathbf{K})_{\text {norma } \infty} & =259830
\end{aligned}
$$

Um vetor de informações a priori sugerido por Stephens et al, [24], $x_{a}$, pode ser obtido de forma recursiva, uma coordenada por índice, $i$, iterado pela expressão $(4.2 .6)$ : 


$$
x_{a}=\left[\exp \left(y_{i}-2 \sum_{l=1}^{i-1}\left[u \beta_{m, l}+x_{a, l}\right] \Delta r\right)-\beta_{m, i}\right] / \omega
$$

na qual $u$ represneta

A calibração ou normalização representada por $C$ na equação (2.2.13) foi derivada a partir da condição que para determinadas altitudes temos apenas espalhamento molecular, ou seja temos apenas efeitos de espalhamento Rayleigh. Na figura (4.8) temos um exemplo desta calibração, na qual temos um perfil de sinal corrigido pela distância, as altitudes mais elevadas deste perfil (correspondentes a menores valores de retroespalhamento) representam um perfil puramente de espalhamento Rayleigh, com uma simples interpolação linear a partir desta faixa, dominada pela contribuição Rayleigh, determina-se a normalização do sinal lidar. O espalhamento Rayleigh foi simulado, e seus termos estão descritos na seção 4.1. Após normalizado é aplicado o ln ao sinal, estando o sinal de acordo com a equação (2.2.10) e a figura 4.9.

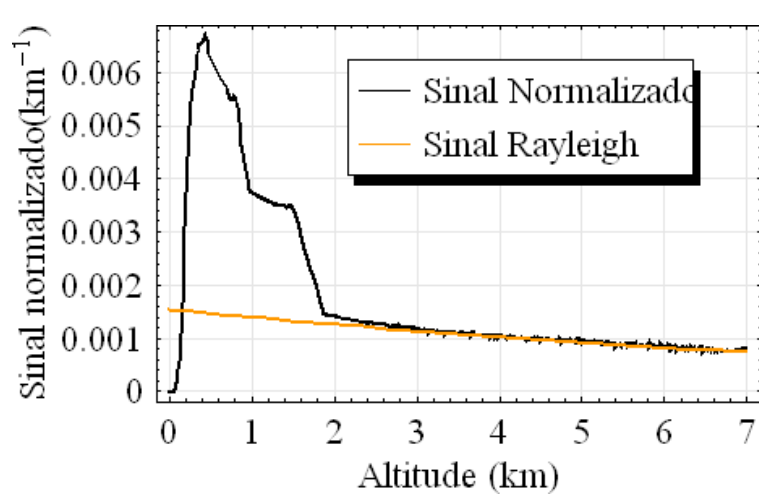

Figura 4.8: Exemplo de calibração do sinal Figura 4.9: Sinal identificado como o vetor lidar

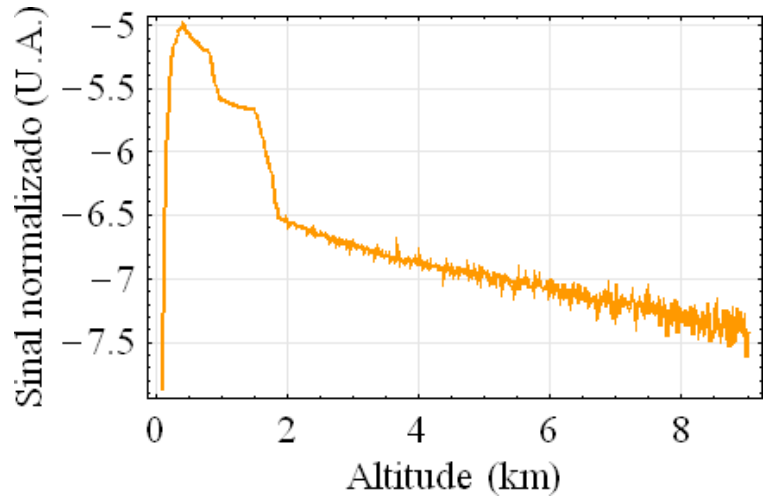

de medidas y no algoritmo

A seqüência de figuras 4.10 à 4.15 são alguns exemplos de estimativas pelo método de Klett (para o dado medido no dia 19/05/2006, no intervalo de 10h 51min 37s até 10h 53min 18s, anteriormente citado), para diferentes altitudes de referência (uma 

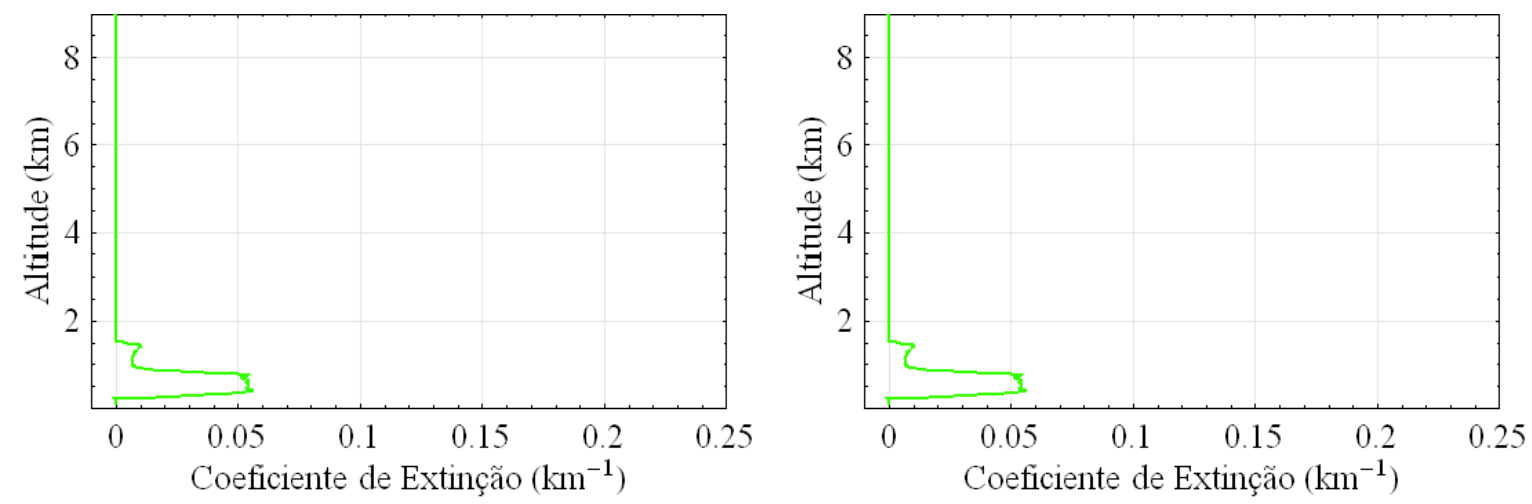

Figura 4.10: Estimativa pelo método de Figura 4.11: Estimativa pelo método de Klett para uma altitude de referência de Klett para uma altitude de referência de $1,5 \mathrm{~km}$ $1,6 \mathrm{~km}$
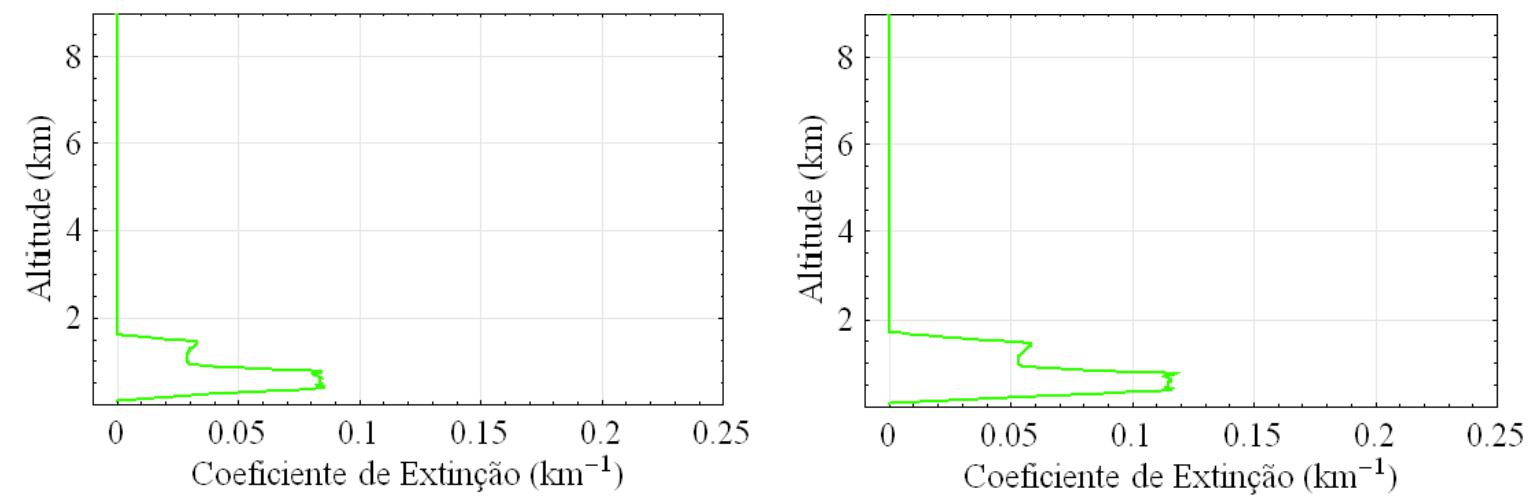

Figura 4.12: Estimativa pelo método de Figura 4.13: Estimativa pelo método de Klett para uma altitude de referência de Klett para uma altitude de referência de $1,7 \mathrm{~km}$ $1,8 \mathrm{~km}$

das condições de contorno requeridas para se obter uma estimativa por esse método). Já a figura 4.16 é um exemplo da estimativa obtida (para o mesmo dado) pelo método descrito neste trabalho gerada após 4 iterações, Inversão ótima, e pelo método utilizado atualmente pelo grupo lidar, Método de Klett utilizando agora a altitude de referência recuperada de forma independente pela Inversão ótima, o Método de Klett não é capaz de recuperar a altitude de referência.

Algumas linhas da matriz A foram graficadas na figura 4.17, relativa a estimativa 

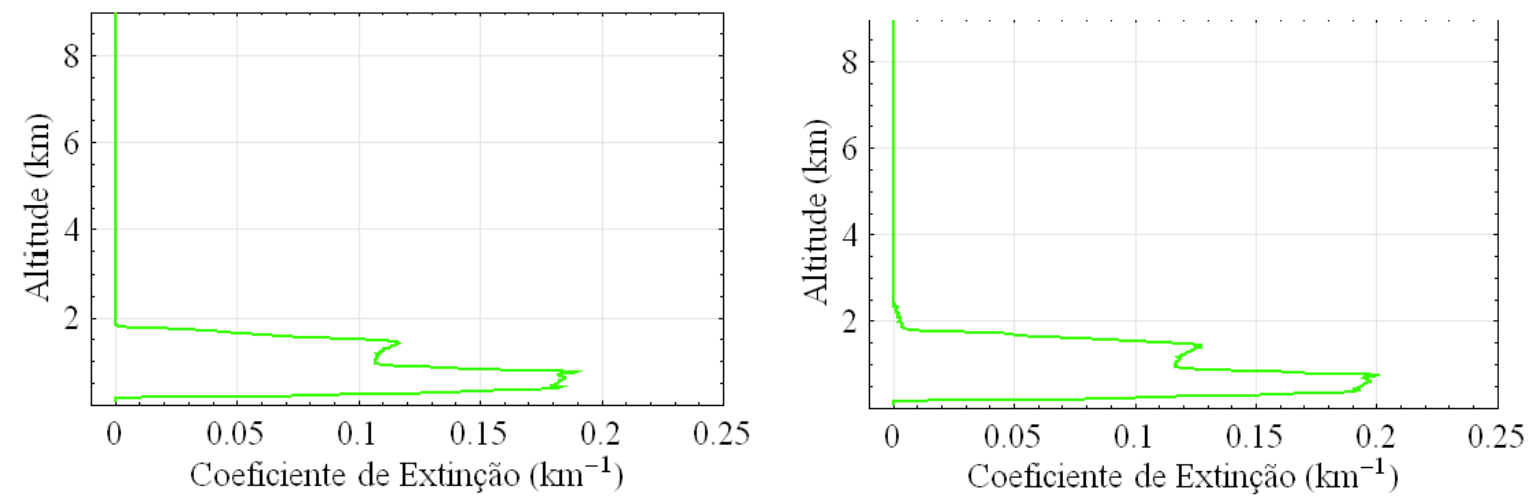

Figura 4.14: Estimativa pelo método de Figura 4.15: Estimativa pelo método de Klett para uma altitude de referência de Klett para uma altitude de referência de 7 $2,5 \mathrm{~km}$ $\mathrm{km}$

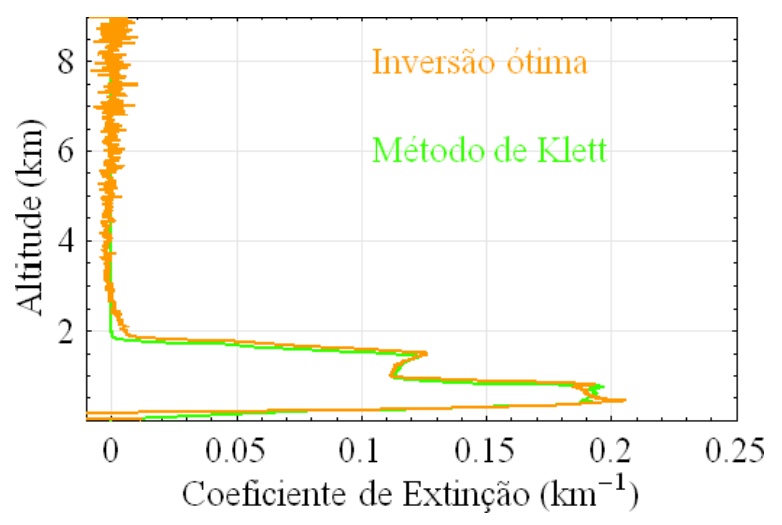

Figura 4.16: Estimativa do coeficiente de extinção (a estimativa por Klett apresentada dependeu de informações recuperadas pela Inversão ótima).

da figura 4.16, cuja fonte foi o dado medido dia 19/05/2006, utilizado como exemplo nesta seção. As altitudes maiores que $1 \mathrm{~km}$ revelaram picos próximos a 1 , revelando segundo Rodgers [8] um bom resultado para a inversão.

A figura 4.18 apresenta o desvio padrão para a estimativa representada na figura 4.16 e obtida do dado, medido dia 19/05/2006, utilizado como exemplo na seção 4.2. Tal desvio foi calculado por: $\sigma_{x i}=\sqrt{\mathbf{S}_{\mathbf{x i i}}}$, com $\mathbf{S}_{\mathbf{x}}$ descrita pela expressão 3.4.38, além da utilização dos termos da equação 3.4 .38 para o cálculo dos desvios relativos a medida, ao a priori e o vínculo. O valor da profundidade ótica recuperada pela inversão ótima foi de $(0,2084 \pm 0.0004)$ (o valor fornecido pela AERONET foi de 0,209119) 

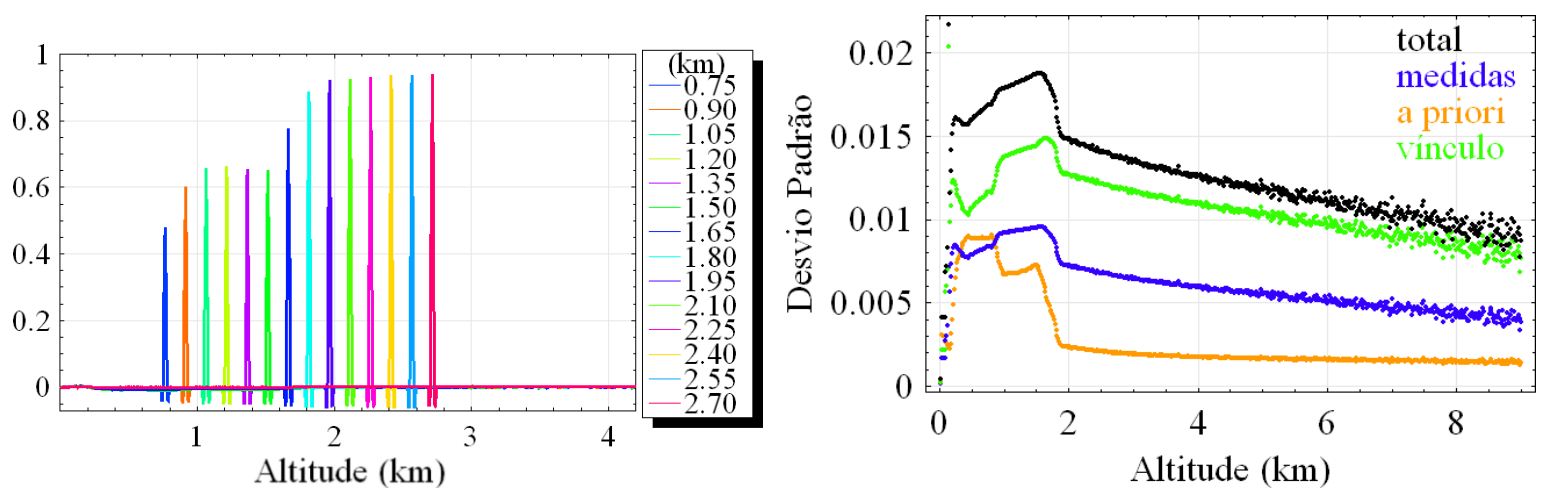

Figura 4.17: Algumas linhas da matriz de Figura 4.18: Desvio padrão da estimativa sensibilidade A. e seus componentes.

já $\omega$ recuperado foi $(0,0125 \pm 0,0004)$, o valor a priori utilizado foi $\omega_{a}=0,015$. Com o método de Klett aplicado sob as mesmas condições a priori, utilizadas para a inversão ótima (pressão, temperatura, espessura ótica e $\omega_{a}$ ), a altitude de referência tomada como limite para a existência de aerossóis é tomada como 1,965 km obtida pela inversão ótima. Tais informações foram compiladas na tabela 4.1 a seguir.

Tabela 4.1: Informações referentes ao dado medido 19/05/2006 de 10h 51min 37s a 10h 53min 18s.

\begin{tabular}{|c|c|c|}
\hline & Estimação Ótima & Estimativa por Klett \\
\hline \hline espessura ótica AERONET & 0,209119 & 0,209119 \\
\hline espessura ótica recuperada & $(0,2084 \pm 0,0004)$ & 0,20856 \\
\hline$\omega_{a}$ & 0,015 & 0,015 \\
\hline$\omega$ & $(0,0125 \pm 0,0004)$ & 0,015 \\
\hline altitude de referência & - & $(1,965 \pm 0,015) \mathrm{km}$ \\
\hline
\end{tabular}

\section{Outros resultados}

Tendo como objetivo avaliar a qualidade das estimativas, obtidas com o método, foi simulado um sinal lidar se utilizando da equação de retroespalhamento único 2.2.1, 
a qual relaciona a potência retornada, com os parâmetros ópticos atmosféricos $(\sigma$ e $\beta)$, além de fatores da geometria do sistema.

O coeficiente de retroespalhamento $\sigma(r)$ tomado é descrito como:

$$
\sigma(r)= \begin{cases}\frac{4}{45} r, & \text { se } 0 \leq r \leq 2,25 k m \\ \frac{-4}{45} r+\frac{4}{10}, & \text { se } 2,25<r \leq 4,5 k m \\ 0, & \text { se } r>4,5 k m\end{cases}
$$

Buscando atender a hipótese de que os erros são normalmente distribuídos, dois tipos diferentes de "ruído" gaussiano foram adicionados ao dado simulado, em situações separadas, gerando um "conjunto" de dados com os quais o método foi testado, para o método aqui descrito (Inversão ótima) e para o método em uso até o presente momento pelo grupo lidar no ipen (Método de Klett). A espessura ótica utilizada no processo de inversão com o dado simulado foi tomada por $\tau_{532}=\sum_{i} \sigma\left(r_{i}\right) \Delta r=0,45$, de acordo com [16], já $\omega$ adotado foi de $75^{-1} \simeq 0,0133333$.

Como primeira tentativa de simular o "ruído" optou-se por uma variável normalmente distribuída com média zero e desvio padrão igual a $10 \%$ da mediana do perfil de dado simulado (veja figura 4.19), a escolha do desvio padrão como a mediana dos dados foi assim definida devido ao comportamento exponencial dos dados. Para algumas faixas tal "ruído" gerou erros que superaram 100\%. Algumas etapas do processo de inversão, pela Inversão ótima, para o dado com esse "ruído" são apresentadas nas figuras 4.19 à 4.26. Temos ainda a seqüência de figuras 4.27 à 4.30 com estimativas pela inversão com o método de Klett (para o mesmo dado) para diferentes altitudes de referência, o conjunto de estimativas (apresentadas na ultima seqüência de figuras) evidencia uma das maiores lacunas do método de Klett que é a necessidade de uma altitude de referência como condição de contorno, enquanto a Inversão ótima se 
mostrou auto-suficiente na busca de tal parâmetro. Uma boa estimativa (pelo método de Klett) só foi possível quando se utilizou a altitude de referência recuperada pelo método proposto (Inversão ótima), veja figura 4.25 .
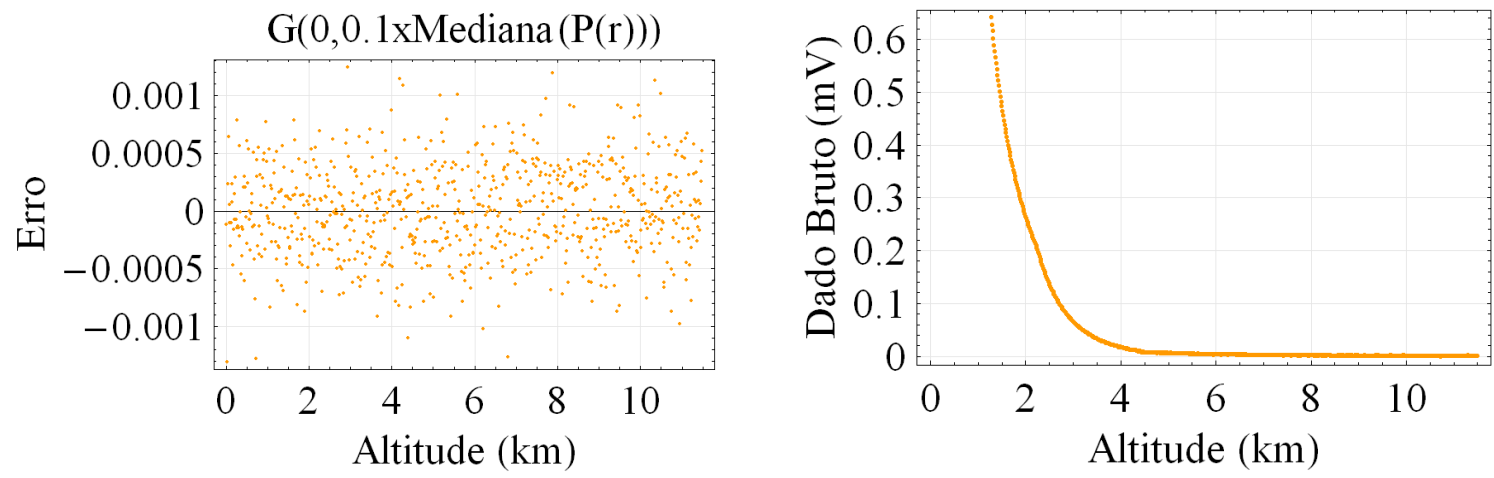

Figura 4.19: Erro aleatório Gaussiano de Figura 4.20: Dado bruto de lidar simulado média zero e desvio padrão $10 \%$ da medi- no módulo analógico, acrescido de um erro ana das potências retornadas gaussiano

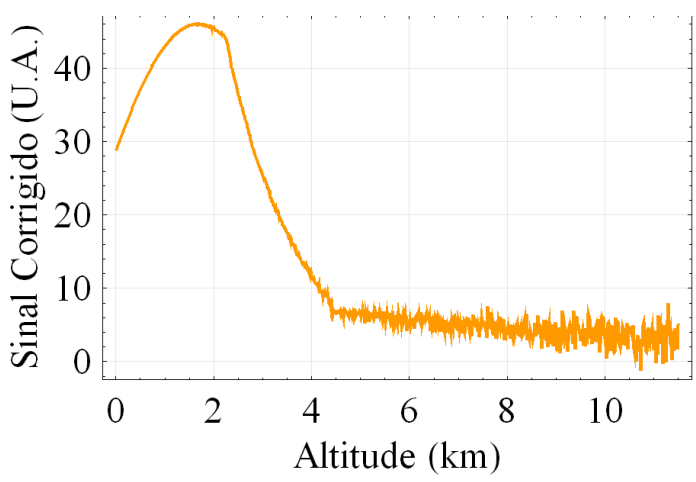

Figura 4.21: Sinal corrigido pela distância Figura 4.22: Sinal normalizado pela conao quadrado.

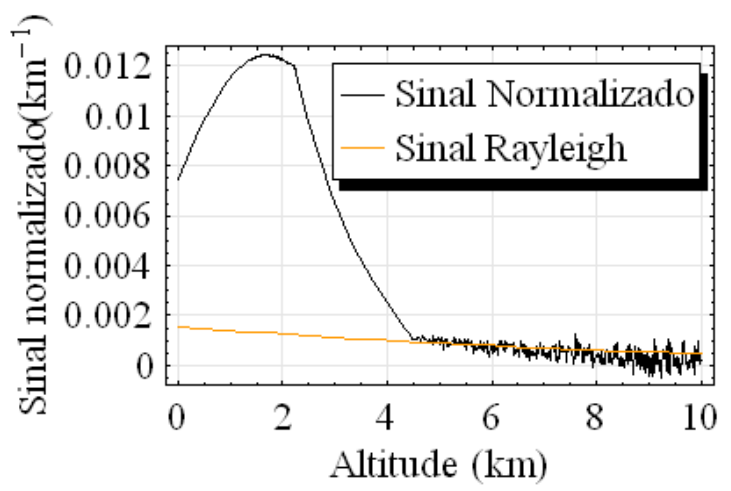

tribuição Rayleigh.

O método, para esse dado proposto, mostrou-se convergente para a solução até certo ponto, depois divergiu. Tal característica foi monitorada com a matriz de sensibilidade A, com o valor de $\chi^{2}$ e com o valor dos desvios padrão. Na figura 4.31 podemos ver o resultado de 01 iteração, um $\chi^{2}=1380,28$ cujo valor é alto para um 


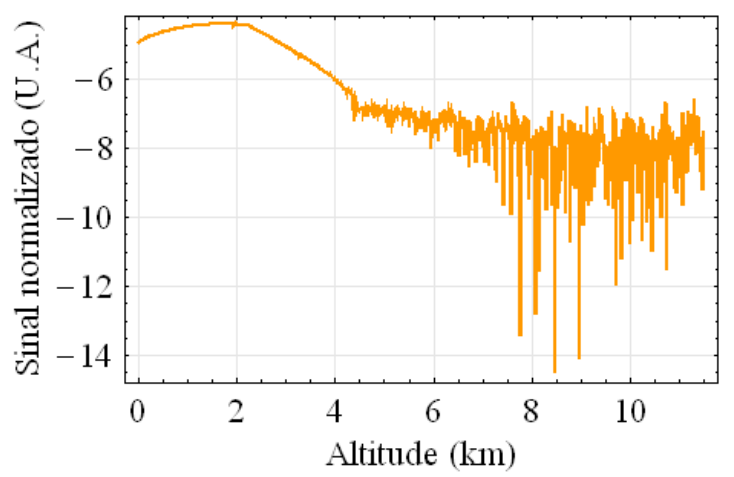

Figura 4.23: $\ln$ do sinal normalizado, considerado como o vetor $\mathbf{y}$ do algoritmo.

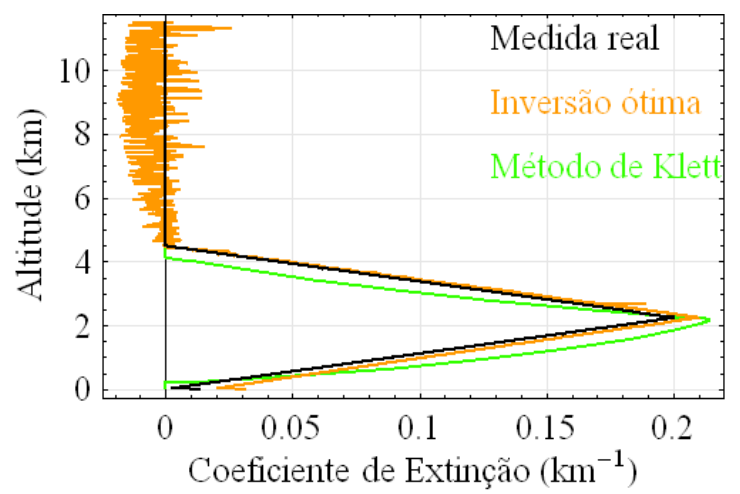

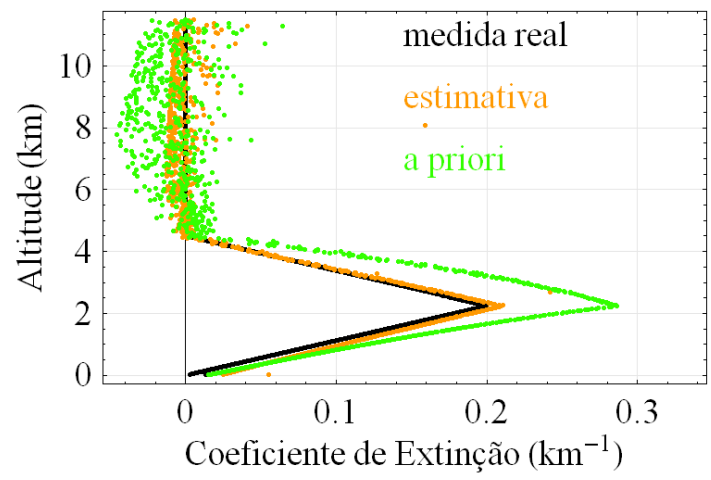

Figura 4.24: Estimativa obtida pelo algoritmo com 05 iterações.

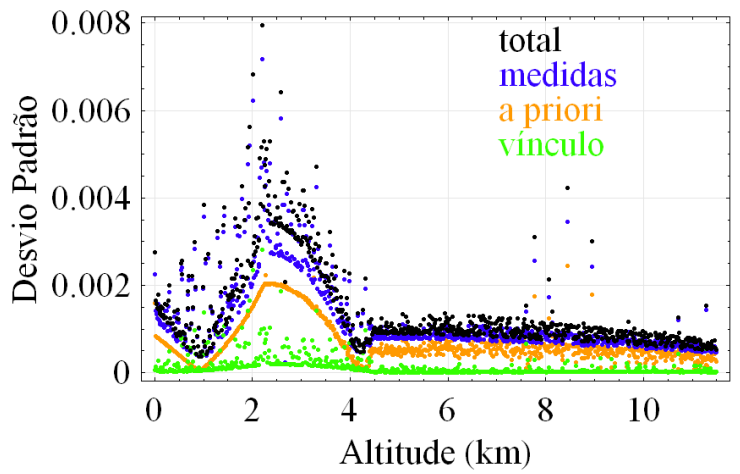

Figura 4.25: Duas estimativas (a esti- Figura 4.26: Desvio padrão da estimativa mativa por Klett apresentada dependeu e seus componentes, obtido pela Inversão de informações recuperadas pela Inversão ótima aplicado para um sinal simulado de ótima) para os mesmos parâmetros.

Lidar.

sistema com 766 graus de liberdade, as linhas da matriz A, para suas respectivas altitudes, apresentaram valores próximos a 1, com pequena discrepância (nos padrões do delta de Dirac) com valores de -0.05 próximo aos picos de valor 1 , em específico a linha correspondente a altitude $2,7 \mathrm{~km}$ apresenta uma discrepância um pouco maior. Em geral as relativas faixas nas altitudes não apresentam claramente evidencias de problemas no processo de inversão. Já na figura 4.33 visualmente notamos tratar-se de uma boa estimativa, obtida na iteração de número 05 apresentando $\chi^{2}=726,387$, 

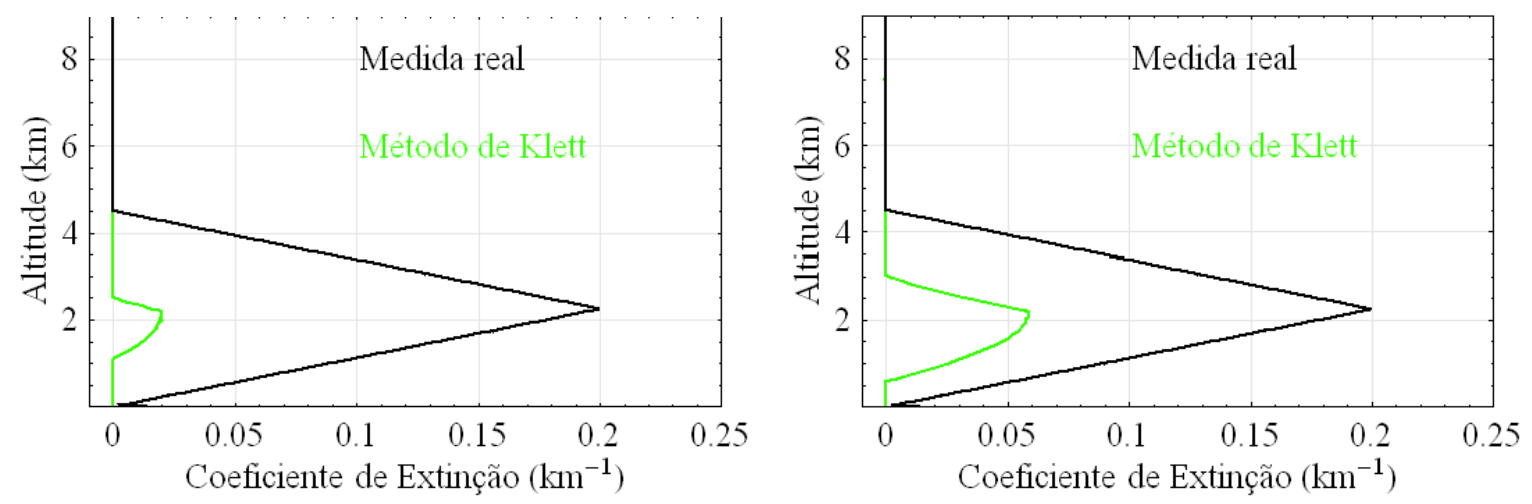

Figura 4.27: Estimativa pelo método de Figura 4.28: Estimativa pelo método de Klett para uma altitude de referência de Klett para uma altitude de referência de 3 $2,5 \mathrm{~km}$. $\mathrm{km}$.
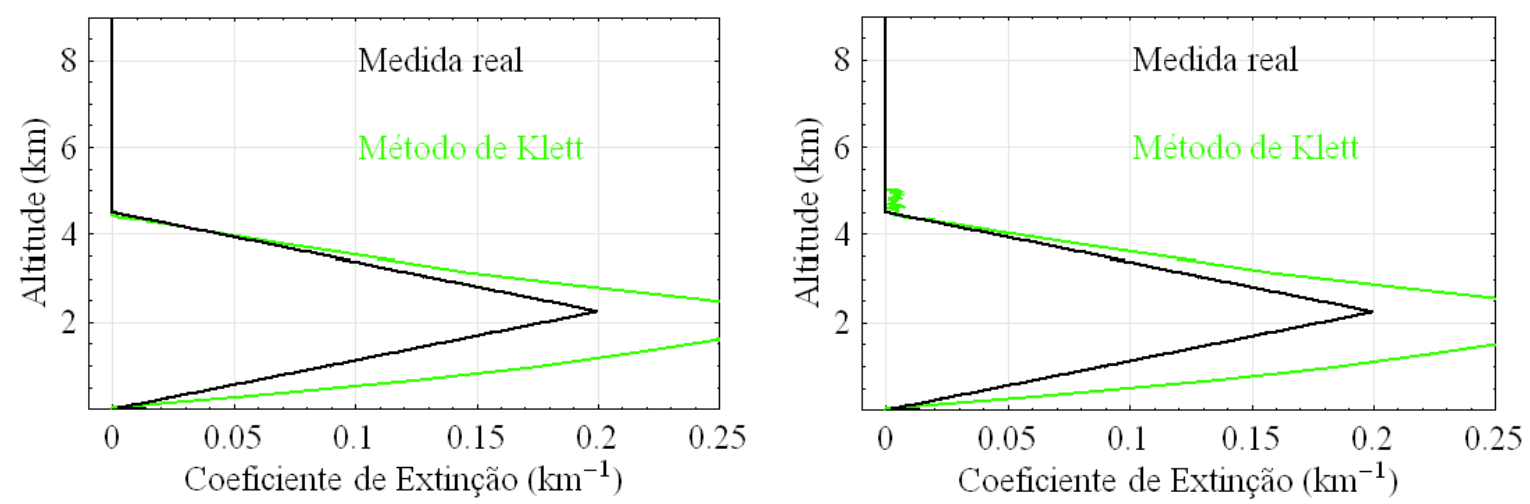

Figura 4.29: Estimativa pelo método de Figura 4.30: Estimativa pelo método de Klett para uma altitude de referência de Klett para uma altitude de referência de 5 $4,5 \mathrm{~km}$. $\mathrm{km}$.

um número abaixo do de graus de liberdade e as linhas da matriz A muito semelhantes a situação anterior mencionada não evidenciam problemas. Ainda no mesmo processo de inversão na iteração 12 , apresentado na figura 4.35, visualmente notamos que o método se afasta consideravelmente da solução, neste momento $\chi^{2}=614252$, um valor muito acima do número de graus de liberdade (766), as linhas da matriz $\mathbf{A}$ referentes as altitudes 0,$75 ; 0,90 ; 1,50 ; 1,65$ e 2,70 apresentam valores muito maiores que zero para diferentes altitudes (não configurando o padrão do Delta de Dirac), 
revelando problemas no processo de inversão. Notemos entretanto os desvios padrão da iteração 01 , da 05 e da 12 respectivamente nas figuras 4.37, 4.26 e 4.38, eles são de certa forma coerentes com a proximidade da estimativa com a solução, quanto mais proxima a estimativa da solução menores foram os valores dos desvios. Dado a ordem de grandeza dos desvios e considerando que o erro da estimativa seja gaussiano todas as estimativas são "válidas" estatisticamente. Para a melhor das estimativas (iteração $05)$ tivemos uma espessura ótica igual a $(0,4469 \pm 0,0007)$ e $(w=0,023 \pm 0,003)$. A estimativa pelo método de Klett foi tomada sob os mesmos parâmetros atmosféricos e valores a priori da estimação ótima, as informações seguem compiladas na tabela 4.2 a seguir.

Tabela 4.2: Informações referentes ao dado simulado com "ruído" gaussiano de média zero e desvio padrão igual a $10 \%$ da mediana do perfil de dado simulado.

\begin{tabular}{|c|c|c|}
\hline & Estimação Ótima & Estimativa por Klett \\
\hline \hline espessura ótica real & 0,450000 & 0,450000 \\
\hline espessura ótica recuperada & $(0,4469 \pm 0,0007)$ & 0,45731 \\
\hline$\omega_{a}$ & 0,015 & 0,015 \\
\hline$\omega$ & $(w=0,023 \pm 0,003)$ & 0,015 \\
\hline altitude de referência & - & $(4,140 \pm 0,015) \mathrm{km}$ \\
\hline
\end{tabular}

$$
\begin{aligned}
\operatorname{Cond}(\mathbf{K})_{\text {norma } 1} & =1,75119 \times 10^{6} \\
\operatorname{Cond}(\mathbf{K})_{\text {norma } 2} & =11274,8 \\
\operatorname{Cond}(\mathbf{K})_{\text {norma } \infty} & =9665,65
\end{aligned}
$$

Acima o condicionamento da matriz K, (seção A), nesse processo de inversão. Numa segunda tentativa de reproduzir o "ruído" presente num sinal de lidar foi 
utilizada uma distribuição gaussiana com média zero e desvio padrão definido localmente como $9 \%$ da potência retornada para cada altitude $r_{i}$ (veja figura 4.40 ) tal "ruído gerou erros variando de zero a valores próximos de $30 \%$ para todo o conjunto de dados, tal variação é representada na figura 4.39. Algumas das etapas com tal "ruído" são representadas nas figuras 4.39 à 4.47, alguns dos resultados são listados na tabela 4.3. Lembrando que cada linha da matriz A está associada a uma altitude, numa condição ideal cada linha seguiria o padrão de Delta de Dirac (1 para a altitude correspondente e 0 para as demais altitudes). A maior parte das linhas observadas na figura 4.46 apresentam um valor próximo a 1 para as altitudes que estão associadas. Entretanto para as demais altitudes nem sempre o valor associado é zero ou próximo de zero. Por exemplo a linha associada a altitude $1,95 \mathrm{~km}$ teve contribuição significante na altitude $1,65 \mathrm{~km}$ e entre o intervalo [1,8 km; 1,95 km]. Ou ainda a linha associada a altitude $3,45 \mathrm{~km}$ que teve diversas contribuições no intervalo $[3,0 \mathrm{~km} ; 4,2$ $\mathrm{km}]$.

Tabela 4.3: Informações referentes ao dado simulado com "ruído" gaussiano de média zero e desvio padrão definido localmente como $9 \%$ da potência retornada (simulada).

\begin{tabular}{|c|c|c|}
\hline & Estimação Ótima & Estimativa por Klett \\
\hline \hline espessura ótica real & 0,450000 & 0,450000 \\
\hline espessura ótica recuperada & $(0,518 \pm 0,004)$ & 0,45188 \\
\hline$\omega_{a}$ & 0,015 & 0,015 \\
\hline$\omega$ & $(w=0,01459 \pm 0,0.00001)$ & 0,015 \\
\hline altitude de referência & - & $(4,110 \pm 0,015) \mathrm{km}$ \\
\hline
\end{tabular}




$$
\begin{aligned}
\operatorname{Cond}(\mathbf{K})_{\text {norma } 1} & =1,1654421668144078 \times 10^{6} \\
\operatorname{Cond}(\mathbf{K})_{\text {norma } 2} & =3382,81 \\
\operatorname{Cond}(\mathbf{K})_{\text {norma } \infty} & =106,227
\end{aligned}
$$

Acima o condicionamento da matriz K, (seção A), nesse processo de inversão.

O presente dado foi submetido a um "alisamento" no qual a cada 7 pontos foi realizado uma média, tendo como produto final uma alteração no número de pontos de 766 para 760, as figuras 4.48 à 4.54 apresentam algumas das etapas e a tabela 4.4 alguns resultados. Tal prática buscou avaliar se o procedimento contribui na busca de melhores estimativas em dados muito "ruidosos". Levando em consideração apenas o mesmo conjunto de linhas observados na matriz A, nas figuras 4.46 e 4.53, para o dado "alisado" o tratamento possibilitou um melhor "processo de inversão", dado que, comparativamente, um número maior de linhas da matriz $\mathbf{A}$ se aproximou do padrão do Delta de Dirac (1 para a altitude associada e zero para as demais altitudes). Entretanto os desvios padrões foram ampliados de maneira considerável, compare as figuras 4.47 e 4.54, demonstrando que as incertezas para essa ultima estimativa são maiores. Portanto, se o que buscamos são estimativas com maior acurácia o "alisamento" dos dados não seria indicado para esse caso. 
Tabela 4.4: Informações do dado simulado "alisado" com "ruído" gaussiano de média zero e desvio padrão definido localmente como $9 \%$ da potência retornada (simulada).

\begin{tabular}{|c|c|c|}
\hline & Estimação Ótima & Estimativa por Klett \\
\hline \hline espessura ótica real & 0,450000 & 0,450000 \\
\hline espessura ótica recuperada & $(0,396 \pm 0,001)$ & 0,440552 \\
\hline$\omega_{a}$ & 0,015 & 0,015 \\
\hline$\omega$ & $(w=0,01474 \pm 0,00006)$ & 0,015 \\
\hline altitude de referência & - & $(4,110 \pm 0,015) \mathrm{km}$ \\
\hline
\end{tabular}

$$
\begin{aligned}
\operatorname{Cond}(\mathbf{K})_{\text {norma } 1} & =1,18565 \times 10^{6} \\
\operatorname{Cond}(\mathbf{K})_{\text {norma } 2} & =3844,5 \\
\operatorname{Cond}(\mathbf{K})_{\text {norma } \infty} & =246,815
\end{aligned}
$$

Acima o condicionamento da matrizf $\mathbf{K}$, (seção A), nesse processo de inversão.

Ainda sob as mesmas condições do dado apresentado na seção 4.2 outros dois dados do dia 19/05/2006 foram submetidos à Inversão ótima e ao Método de Klett. Um deles medido no intervalo de $11 \mathrm{~h} 35 \mathrm{~min} 15 \mathrm{~s}$ a $11 \mathrm{~h} 36 \mathrm{~min} 0 \mathrm{~s}$, com espessura ótica do período igual a 0,209119 (de acordo com a AERONET ), com algumas das etapas representadas nas figuras 4.61 à 4.55 , um resumo dos dados se encontra na tabela 4.5.

Tabela 4.5: Informações referentes ao dado medido no dia 19/05/2006 no intervalo de $11 \mathrm{~h} 35 \mathrm{~min} 15 \mathrm{~s}$ a $11 \mathrm{~h} 36 \mathrm{~min} 0 \mathrm{~s}$.

\begin{tabular}{|c|c|c|}
\hline & Estimação Ótima & Estimativa por Klett \\
\hline \hline espessura ótica real & 0,209119 & 0,209119 \\
\hline espessura ótica recuperada & $(0,281 \pm 0,008)$ & 0,271125 \\
\hline$\omega_{a}$ & 0,015 & 0,015 \\
\hline$\omega$ & $(w=0,0137 \pm 0,0016)$ & 0,015 \\
\hline altitude de referência & - & $(3,405 \pm 0,015) \mathrm{km}$ \\
\hline
\end{tabular}




$$
\begin{aligned}
\operatorname{Cond}(\mathbf{K})_{\text {norma } 1} & =7,56615 \times 10^{6} \\
\operatorname{Cond}(\mathbf{K})_{\text {norma } 2} & =516166 \\
\operatorname{Cond}(\mathbf{K})_{\text {norma } \infty} & =159716
\end{aligned}
$$

Acima o condicionamento da matriz K, (seção A), nesse processo de inversão.

E outro dado medido entre $13 \mathrm{~h} 17 \mathrm{~min} 37 \mathrm{~s}$ e $13 \mathrm{~h} 19 \mathrm{~min} 18 \mathrm{~s}$ com espessura neste horário de 0,21462 (segundo a AERONET), tendo seus dados agrupados na tabela 4.6 e alguns passos do processo registrados nas figuras 4.62 à 4.68. As matrizes diagnostica A para os dados medidos (reais) apresentaram comportamento semelhante, com picos em torno do valor 0,7 para as altitudes compreendidas entre $0 \mathrm{~km}$ e próximas a $1,8 \mathrm{~km}$, após esse intervalo mostraram picos mais próximos a 1 .

Tabela 4.6: Informações referentes ao dado medido no dia 19/05/2006 no intervalo de $13 \mathrm{~h} 17 \mathrm{~min} 37 \mathrm{~s}$ a $13 \mathrm{~h} 19 \mathrm{~min} 18 \mathrm{~s}$.

\begin{tabular}{|c|c|c|}
\hline & Estimação Ótima & Estimativa por Klett \\
\hline \hline espessura ótica real & 0,21462 & 0,21462 \\
\hline espessura ótica recuperada & $(0,230 \pm 0,007)$ & 0,257091 \\
\hline$\omega_{a}$ & 0,015 & 0,015 \\
\hline$\omega$ & $(w=(0,0125 \pm 0,0006)$ & 0,015 \\
\hline altitude de referência & - & $(1,890 \pm 0,015) \mathrm{km}$ \\
\hline
\end{tabular}

$$
\begin{aligned}
\operatorname{Cond}(\mathbf{K})_{\text {norma } 1} & =1,2752 \times 10^{6} \\
\operatorname{Cond}(\mathbf{K})_{\text {norma } 2} & =38023 \\
\operatorname{Cond}(\mathbf{K})_{\text {norma } \infty} & =9957,54
\end{aligned}
$$

Acima o condicionamento da matriz K, (seção A), nesse processo de inversão. 


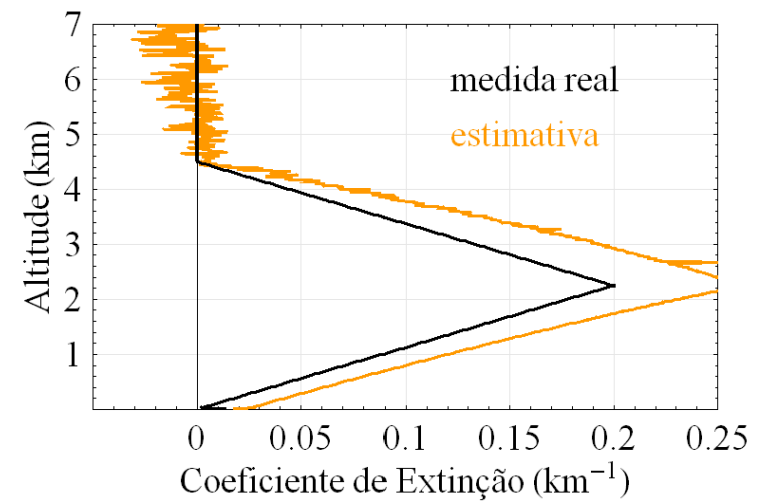

Figura 4.31: Iteração 01 e $\chi^{2}=1380,28$

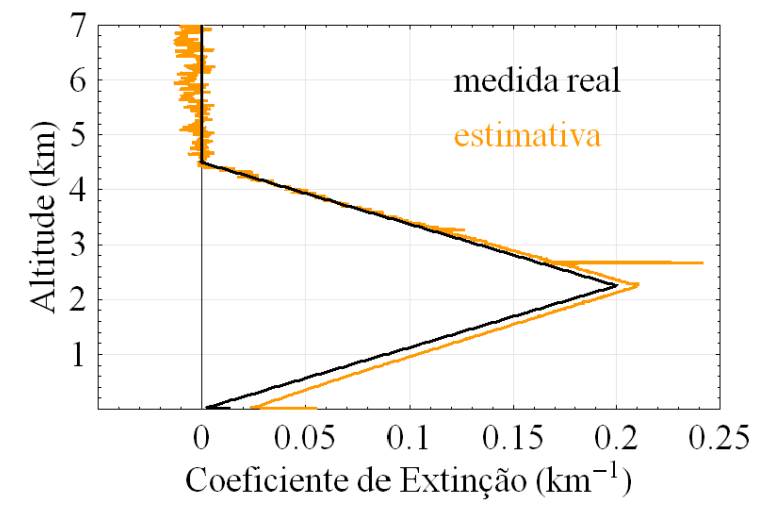

Figura 4.33: Iteração 05 apresentando $\chi^{2}=726,387$

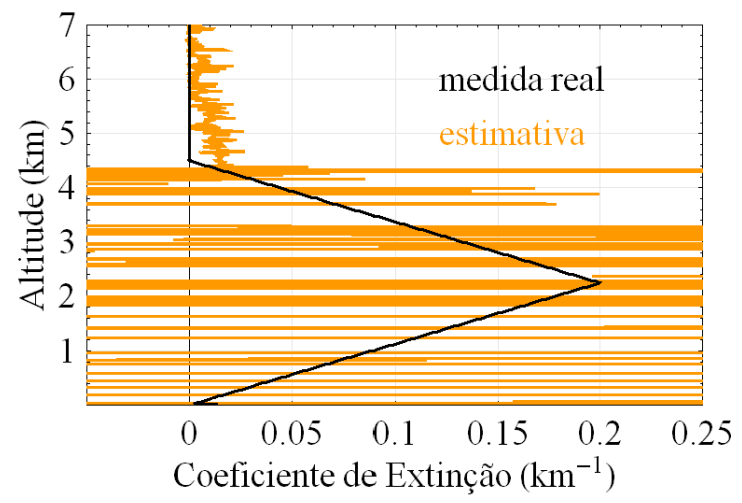

Figura 4.35: Iteração 12 apresentando Figura 4.36: Linhas da matriz A na itera$\chi^{2}=614252$

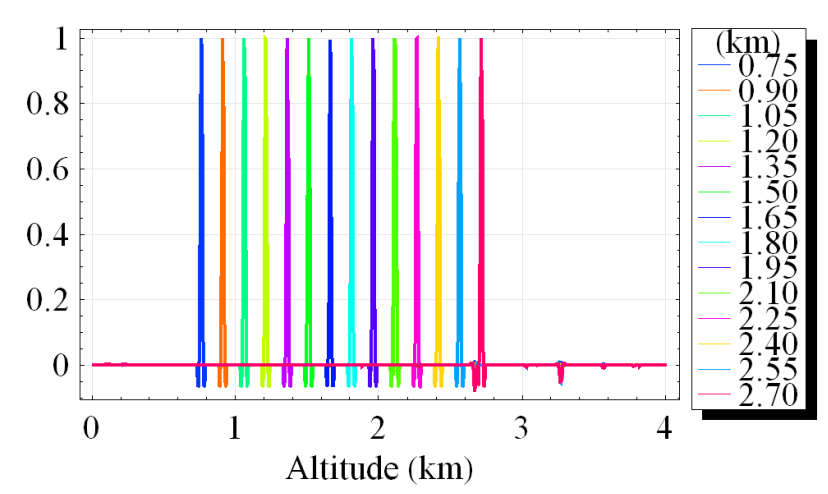

Figura 4.32: Linhas da matriz A na iteração 01.

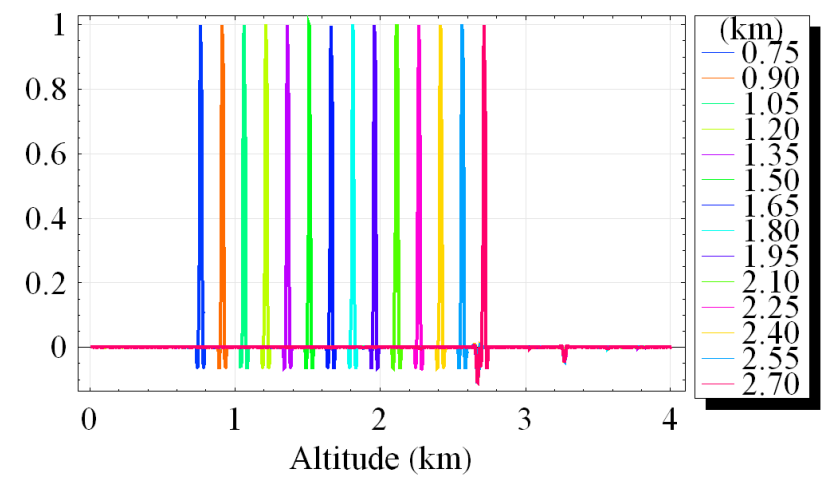

Figura 4.34: Linhas da matriz A na iteração 05.

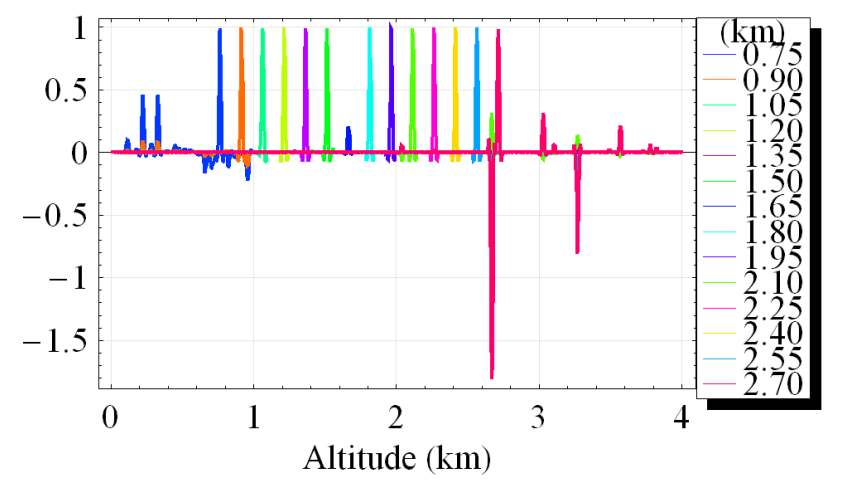

ção 12. 

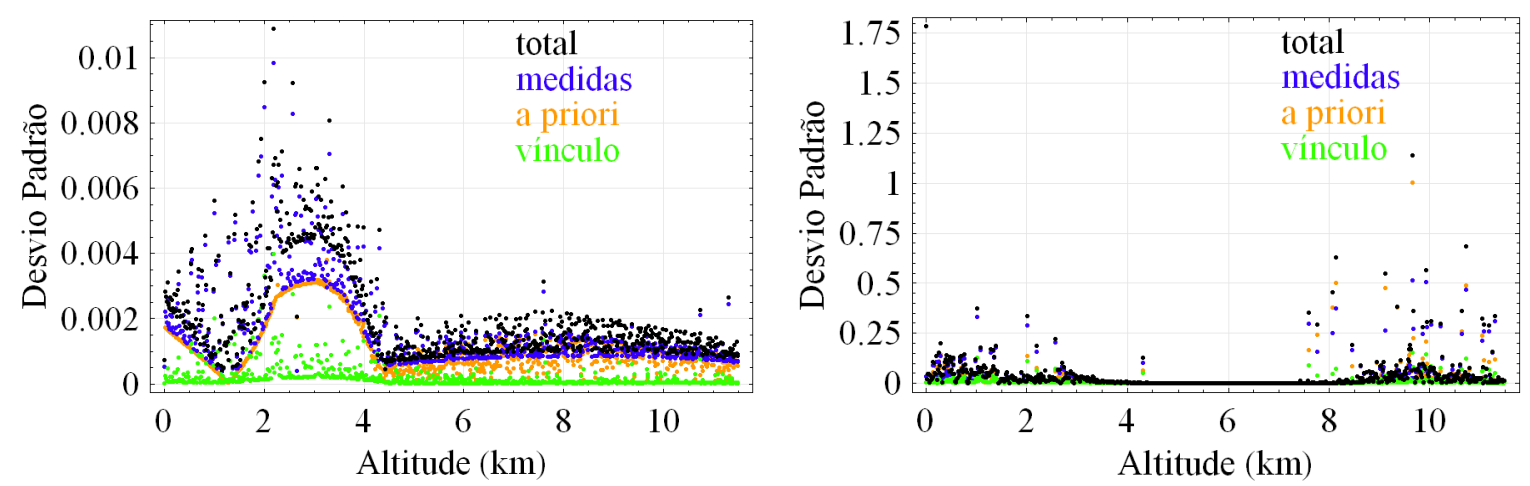

Figura 4.37: Desvio padrão da estimativa Figura 4.38: Desvio padrão da estimativa na iteração 01. na iteração 12 .
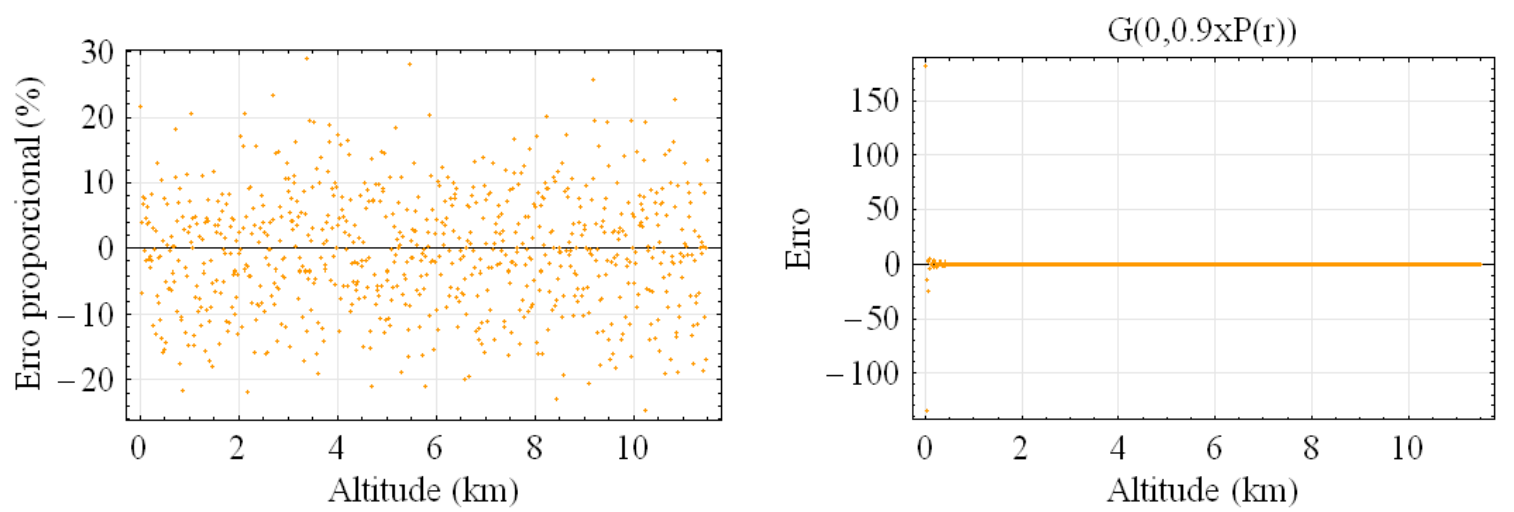

Figura 4.39: Erro percentual na medida Figura 4.40: Erro gaussiano de média zero devido a adição de "ruído".

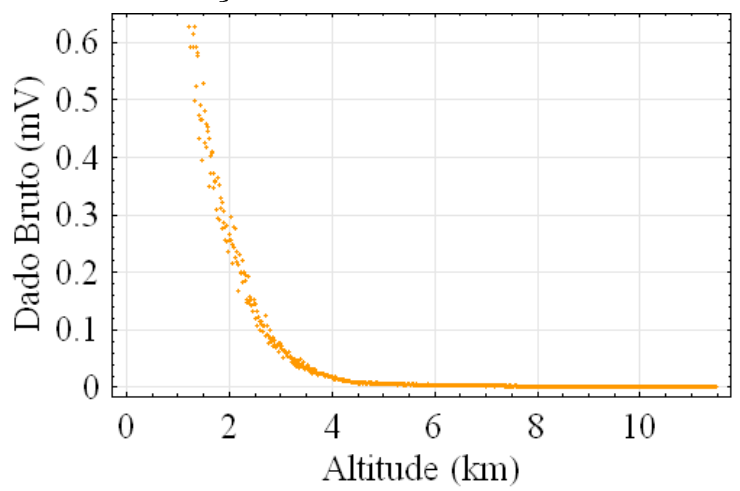
e desvio padrão de $9 \%$ de $P\left(r_{i}\right)$.

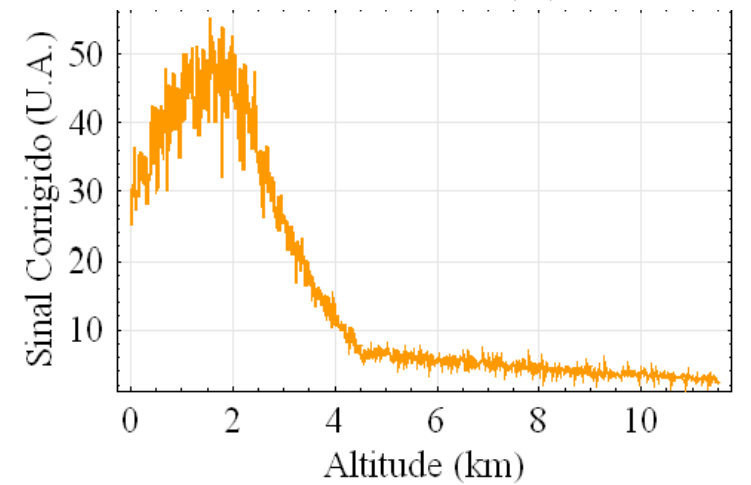

Figura 4.41: Dado bruto de lidar simulado, Figura 4.42: Sinal corrigido pela distância acrescido de um erro gaussiano ao quadrado. 


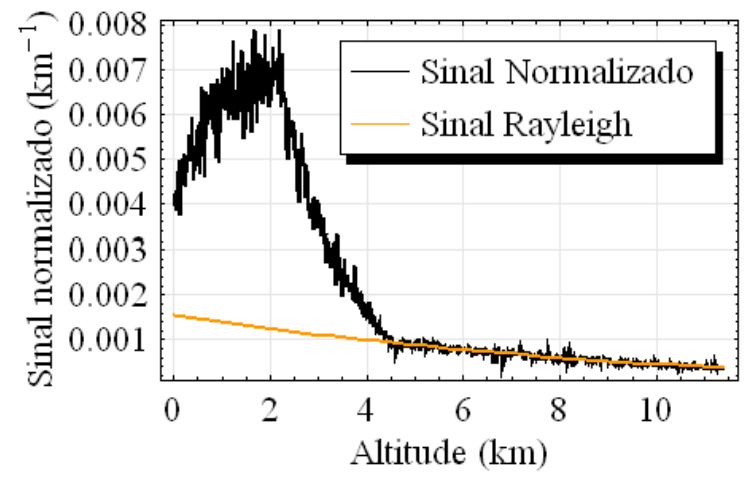

Figura 4.43: Sinal normalizado pela con- Figura 4.44: $\ln$ do sinal normalizado, contribuição Rayleigh.

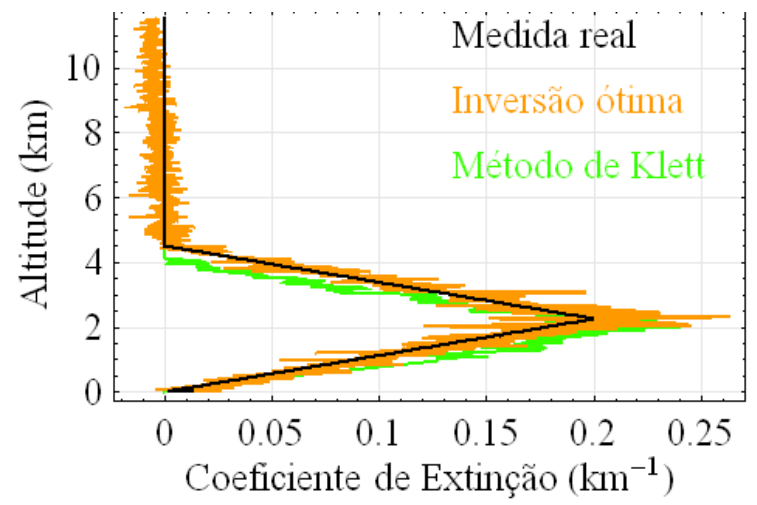

Figura 4.45: Duas estimativas (a estima- Figura 4.46: Algumas linhas da matriz de tiva por Klett dependeu de informações re- sensibilidade A, obtida durante o processo cuperadas pela Inversão ótima).

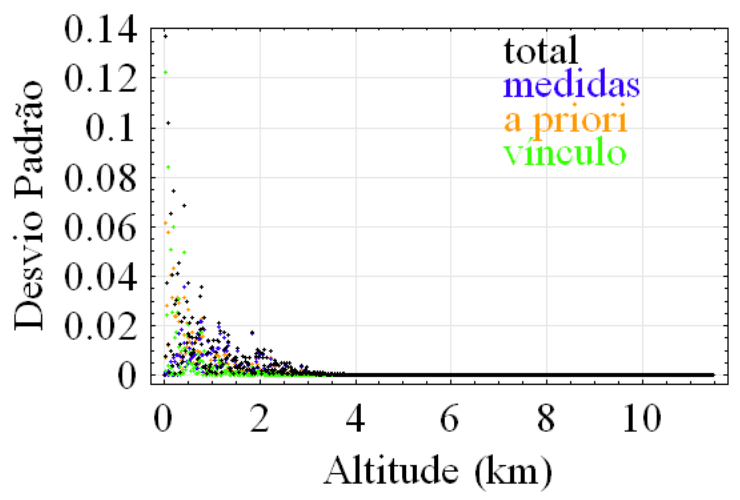

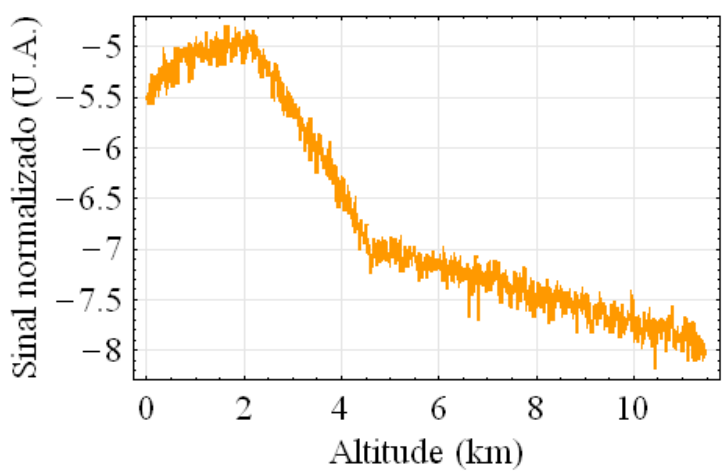

siderado como o vetor $\mathbf{y}$ do algoritmo.

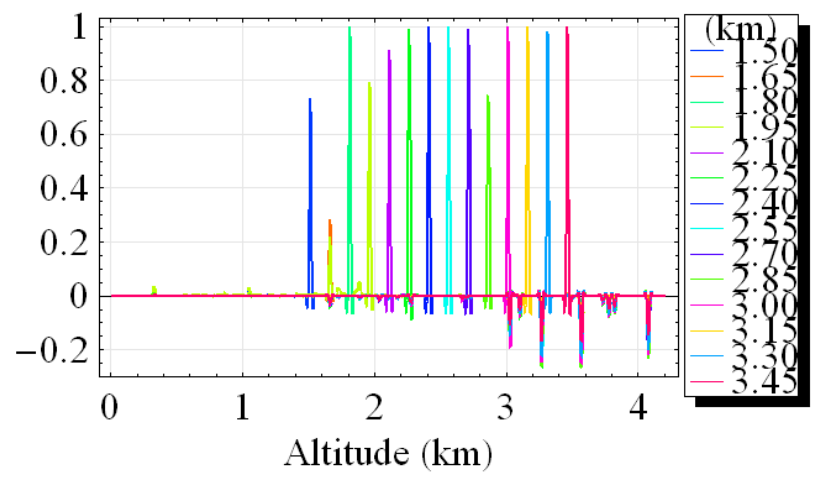

de inversão pela Inversão ótima.

Figura 4.47: Desvio padrão da estimativa e seus componentes. 

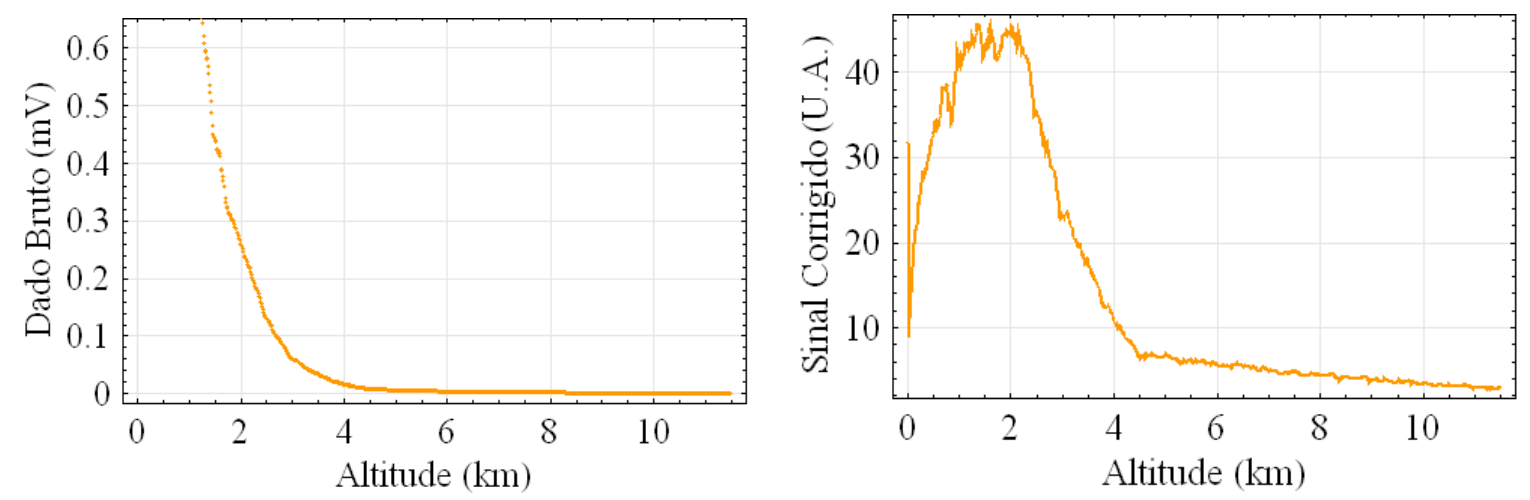

Figura 4.48: Dado bruto de lidar simulado, Figura 4.49: Sinal corrigido pela distância acrescido de um erro gaussiano

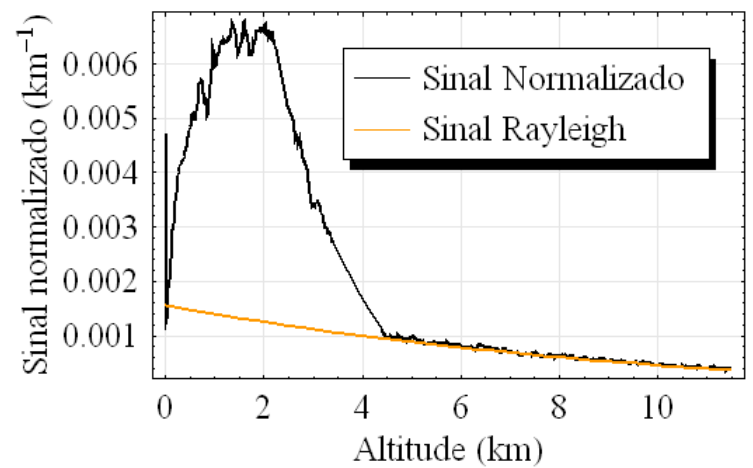
ao quadrado.

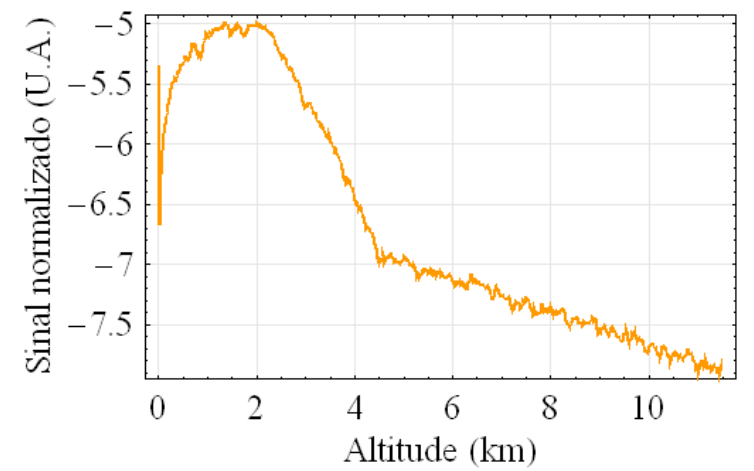

Figura 4.50: Sinal normalizado pela contribuição Rayleigh.

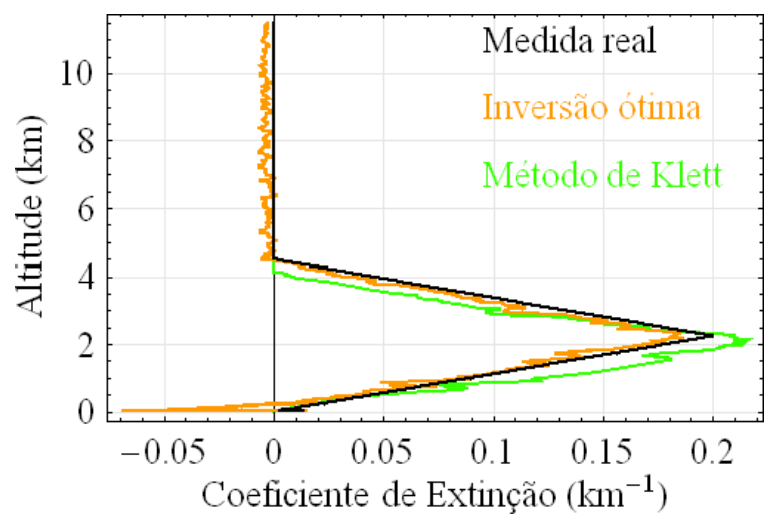

Figura 4.51: ln do sinal normalizado, considerado como o vetor $\mathbf{y}$ do algoritmo.

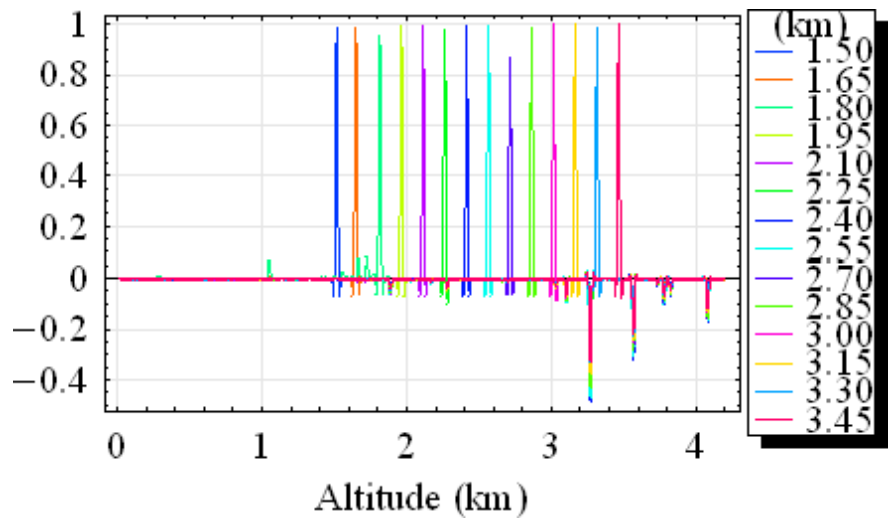

Figura 4.52: Duas estimativas (a estima- Figura 4.53: Algumas linhas da matriz de tiva por Klett dependeu de informações recuperadas pela Inversão ótima).

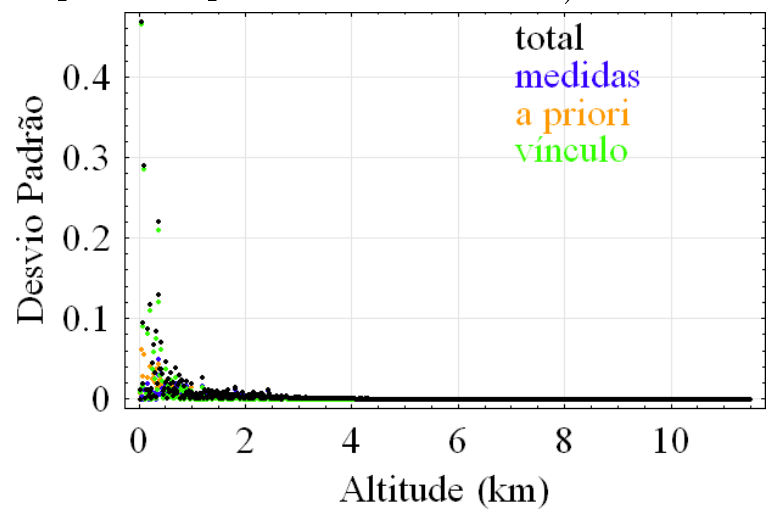
de inversão pela Inversão ótima.

Figura 4.54: Desvio padrão da estimativa e seus componentes. 

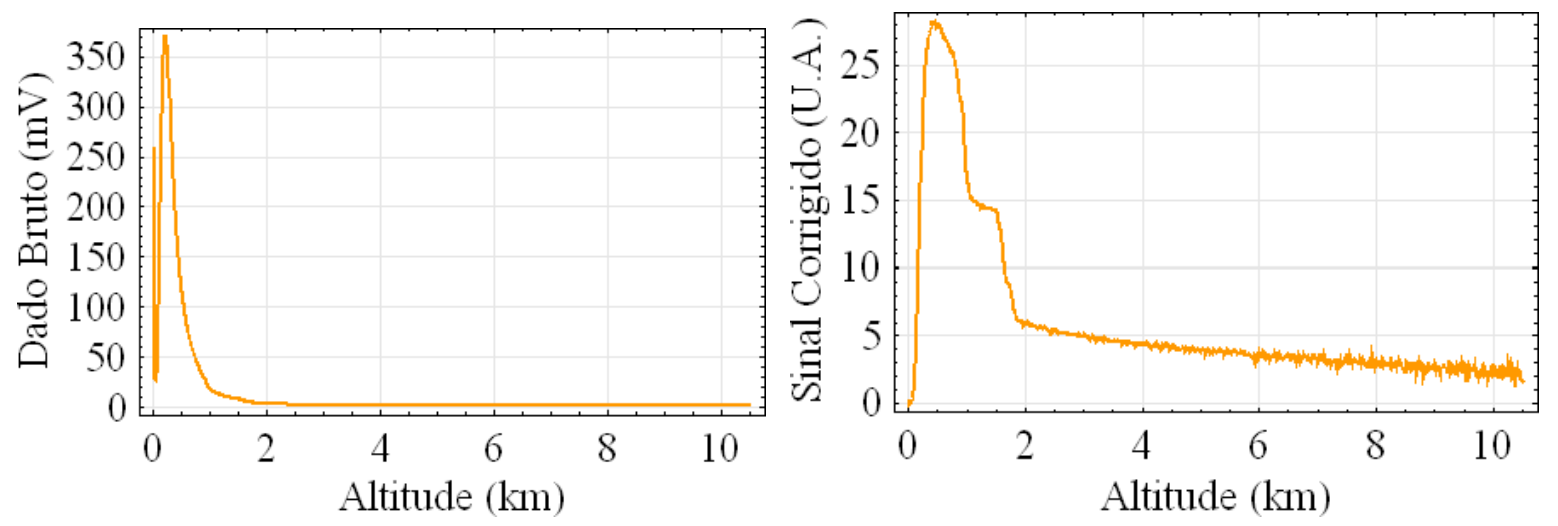

Figura 4.55: Dado bruto de lidar.

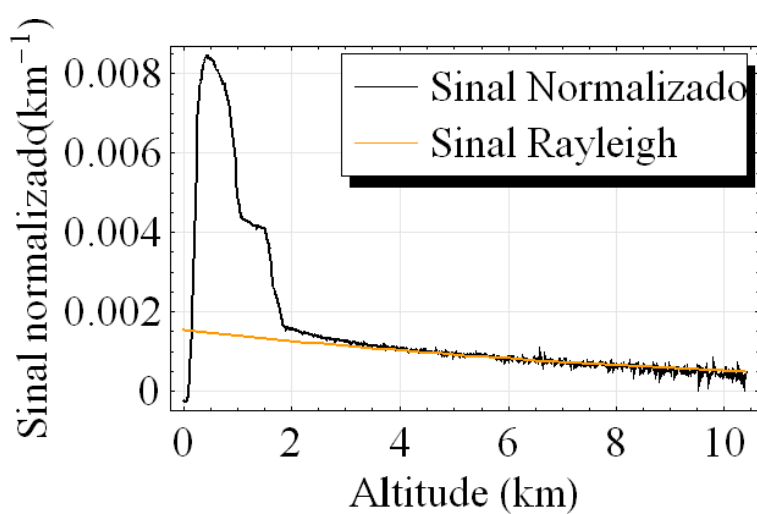

Figura 4.56: Sinal corrigido pela distância.

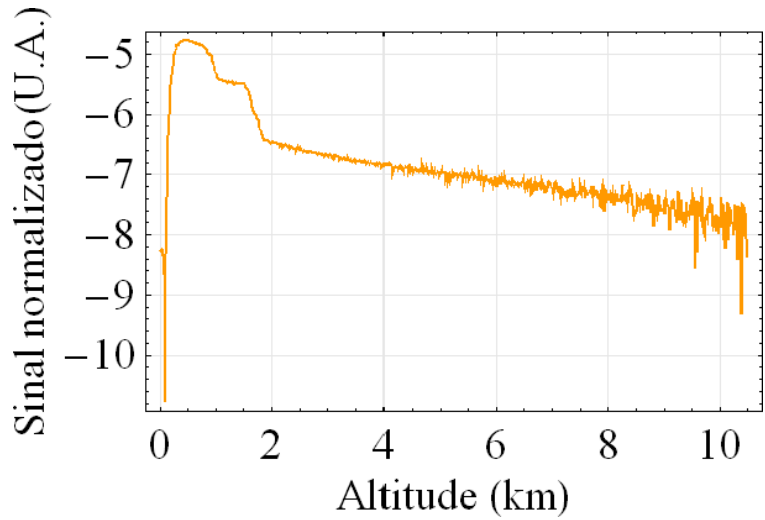

Figura 4.57: Sinal normalizado pela contribuição Rayleigh.

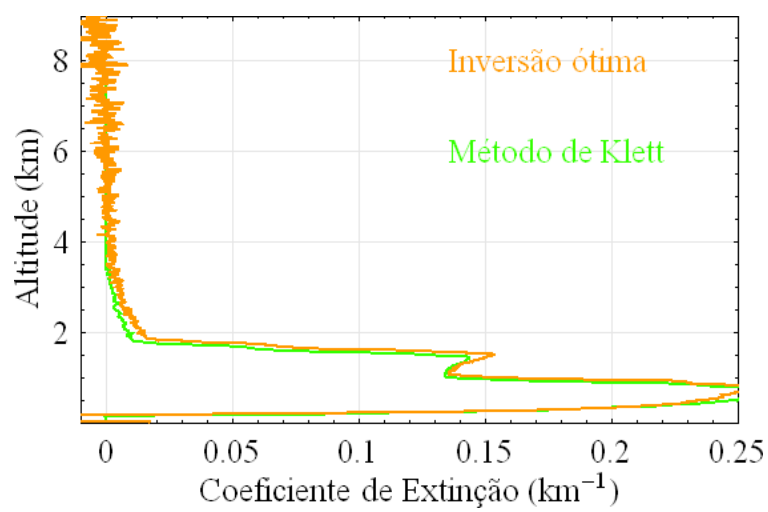

Figura 4.58: $\ln$ do sinal normalizado, considerado como o vetor $\mathbf{y}$ do algoritmo.

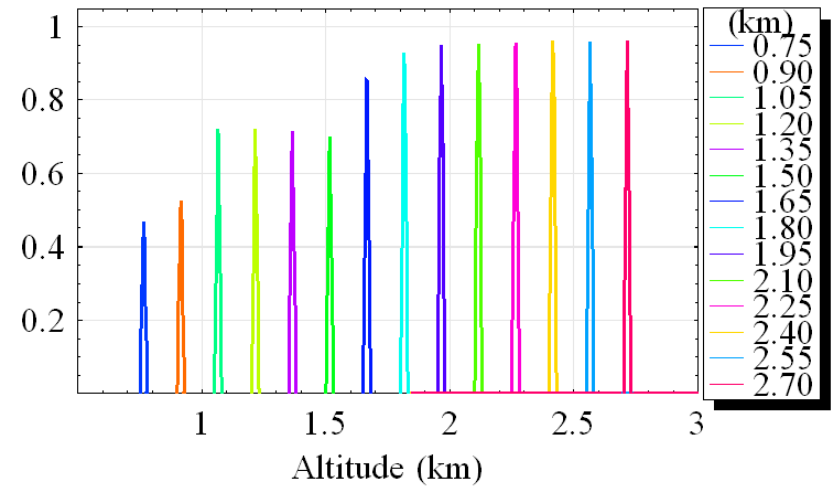

Figura 4.59: Duas estimativas (a estima- Figura 4.60: Algumas linhas da matriz de tiva por Klett dependeu de informações re- sensibilidade A, obtida durante o processo cuperadas pela Inversão ótima).

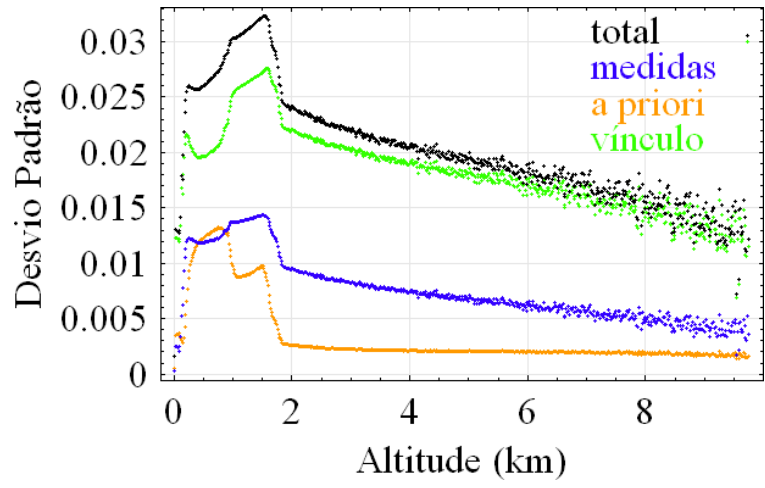
de inversão pela Inversão ótima.

Figura 4.61: Desvio padrão da estimativa e seus componentes. 

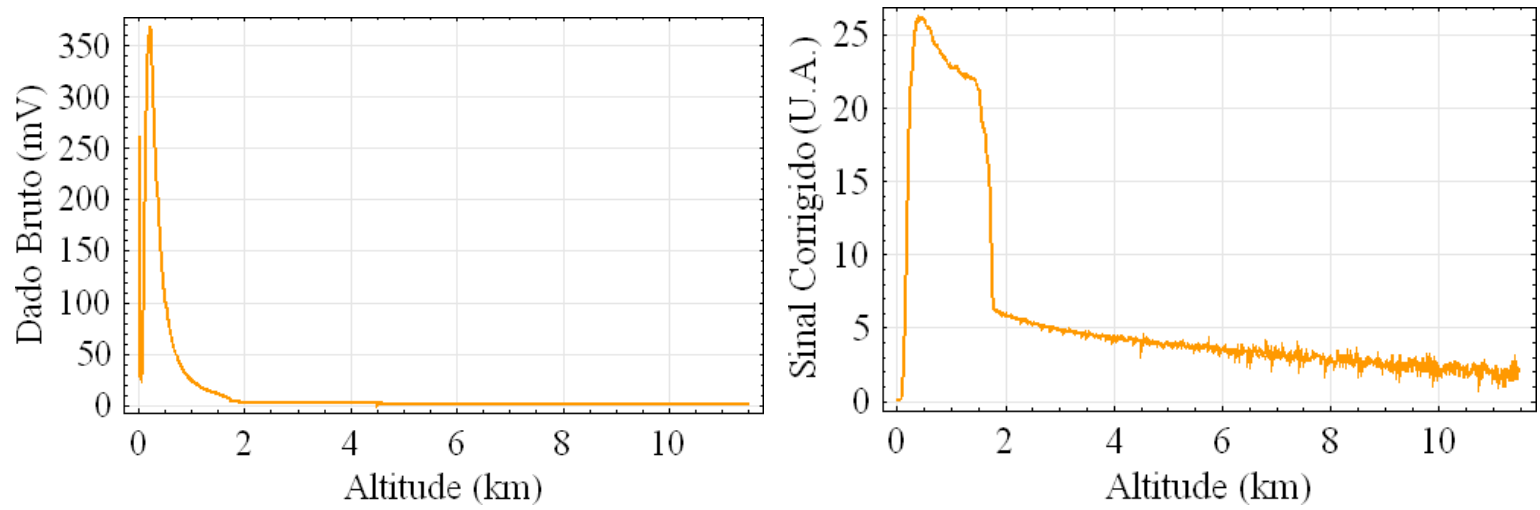

Figura 4.62: Dado Bruto de lidar.

Figura 4.63: Sinal corrigido pela distância.
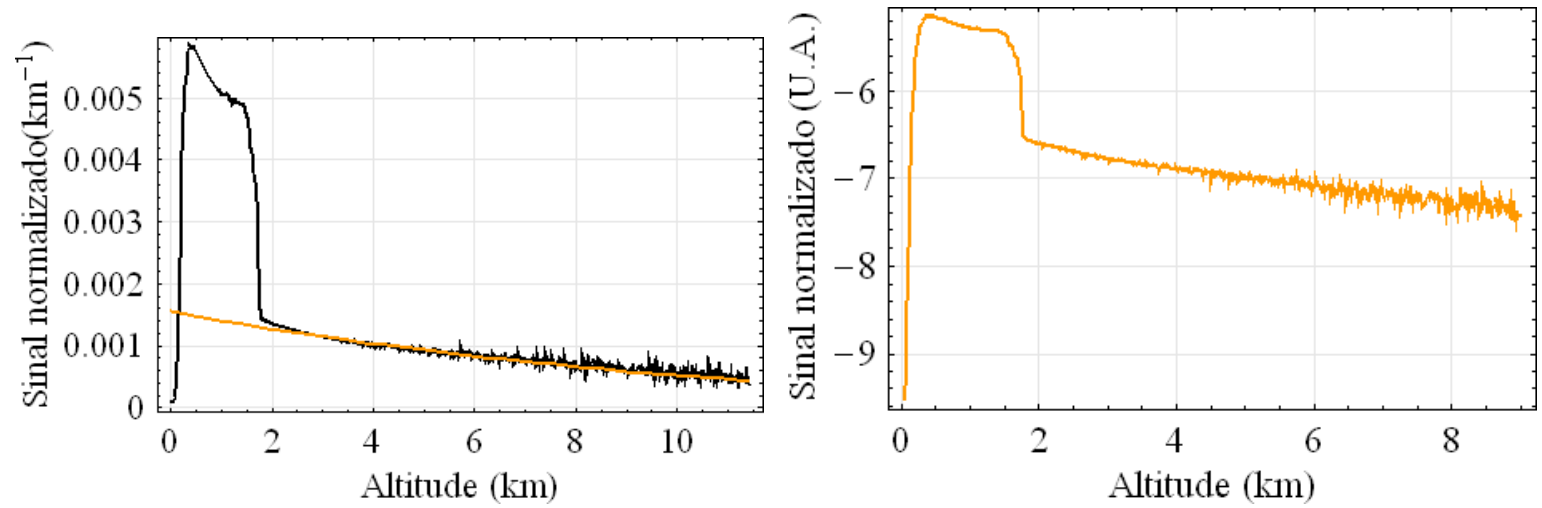

Figura 4.64: Sinal normalizado pela contribuição Rayleigh.

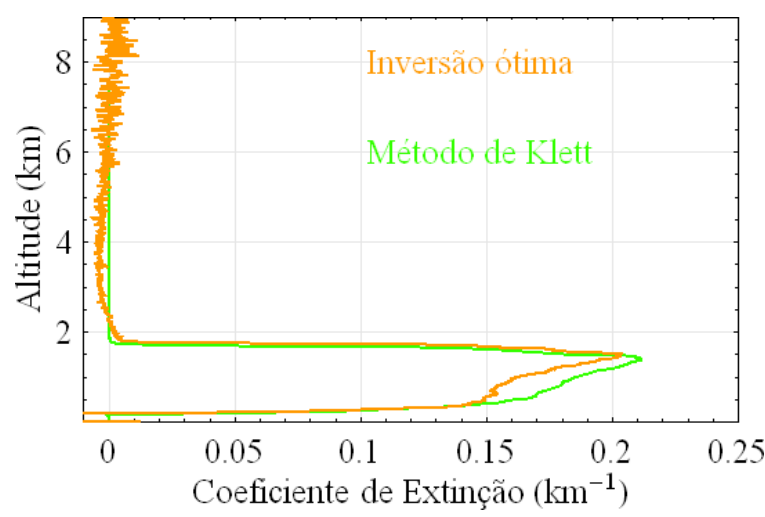

Figura 4.65: ln do sinal normalizado, considerado como o vetor $\mathbf{y}$ do algoritmo.

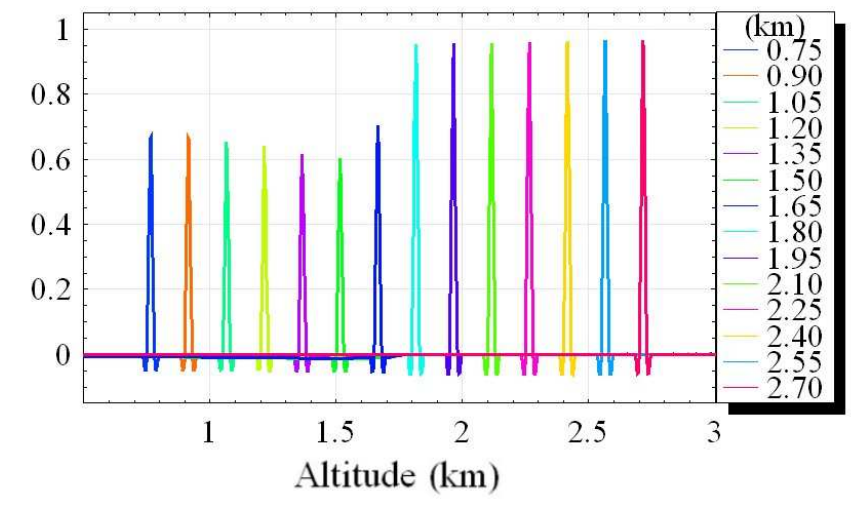

Figura 4.66: Duas estimativas (a estima- Figura 4.67: Algumas linhas da matriz de tiva por Klett dependeu de informações re- sensibilidade A, obtida durante o processo cuperadas pela Inversão ótima).

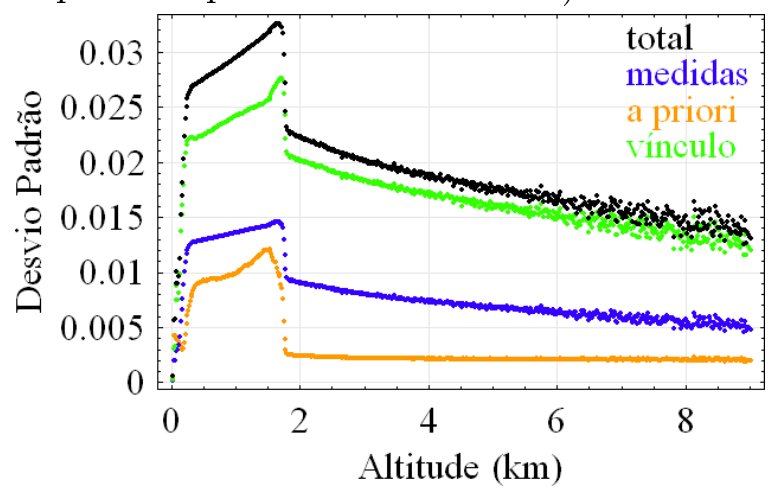
de inversão pela Inversão ótima.

Figura 4.68: Desvio padrão da estimativa e seus componentes. 


\section{Capítulo 5}

\section{Conclusões}

A conversão de medidas lidar para informações relevantes sobre os aerossóis atmosféricos é uma tarefa complicada, pois temos a necessidade de separar efeitos de retroespalhamento e extinção ao mesmo tempo que o processo de inversão sofre grande influência das relações assumidas entre retroespalhamento e extinção, necessárias ao processo. Uma das principais relações é a razão de retroespalhamento e extinção, representada neste trabalho pelo caracter $\omega$. Tal consideração indica que resultados de inversão de medidas lidar estão fortemente conectados a relação entre retroespalhamento e extinção. Portanto a grande variedade de possibilidades de comportamentos para a relação de retroespalhamento e extinção na atmosfera legitimam, segundo Stephens [24], o desenvolvimento de métodos capazes de integrar informações adicionais no processo de inversão.

Este trabalho apresentou um método que permite incorporar diferentes fontes de informação no processo de recuperação de parâmetros lidar. Os capítulos anteriores descreveram a inversão da equação de lidar por meio de estimação ótima (Inversão ótima) metodologia popularizada pelo trabalho de Rodgers [7, 8] e aplicada por Stephens [24] (para dados de um lidar a bordo de um satélite). No processo de 
inversão do problema de lidar utilizou-se a forma analítica do modelo direto em especial a sua matriz Jacobiana $\mathbf{K}$, o vetor $\mathbf{y}$ contendo o valor do logaritmo do sinal recebido corrigido pela distância e um valor de espessura ótica, $\mathbf{x}$ representando o coeficiente de extinção por aerossóis e (em uma de suas posições) a razão de retroespalhamento e extinção, (vetores descritos na seção 2.2.3). O método de recuperação é ilustrado usando dados simulados de lidar (descritos na seção 4.2) além de medidas de um sistema lidar situado no Instituto de Pesquisa Energéticas e Nucleares (IPEN). Os dados de espessura ótica por aerossóis são disponibilizados pela AEROSOL ROBOTIC NETWORK (AERONET)- NASA, foram medidos por um fotômetro solar localizado no Instituto de Física da Universidade de São Paulo (IFUSP).

O algoritmo proposto (Inversão ótima) oferece inúmeras vantagens comparada com o método atual em uso pelo grupo, Método de Klett, pois diferente do mesmo:

a ) na possibilidade de incorporação de diferentes tipos de informações de fontes heterogêneas durante a inversão. Permitindo por exemplo limitar parâmetros como a espessura ótica no modelo, ou ainda a razão $\omega$, que reconhecidamente possui intervalo de variabilidade grande, validar erros no processo de medição, entre outras associações físicas pertinentes ao problema. Neste estudo a espessura ótica, provinda de uma fonte externa, foi utilizada na criação de um vínculo no processo de inversão;

b ) o método fornece diversas maneiras para avaliar a qualidade do processo de inversão e do parâmetro recuperado, tais como a matriz diagnostica (de sensibilidade) A, o valor de $\chi^{2}$ e o estudo parcial das contribuições para os desvios padrão da estimativa; no método em uso (Método de Klett) pelo grupo lidar ipen tal avaliação é praticamente inexistente. 
No método proposto (Inversão ótima) a análise das incertezas indica fontes de erros provindos das medidas (devido a instrumentos e calibração), a influência do $a$ priori e do vínculo. Contudo a análise dos erros não leva em consideração muitas das fontes de erro, por exemplo, a razão de retroespalhamento e extinção, $\omega$, que apresenta grande variedade de possibilidades de comportamento na atmosfera, entretanto neste trabalho foi assumida constante para a região estudada, em especial contribuiu durante o processo de inversão para as incertezas associadas ao vínculo e ao a priori. Outra fonte importante de incertezas não mensurada explicitamente são as incertezas na aproximação do modelo direto.

$\mathrm{Na}$ comparação entre os métodos a Inversão ótima apresenta vantagens, pois consegue recuperar informações que não são acessíveis quando se utiliza o método de Klett tais como:

a ) a altitude de referência;

b ) uma estimativa para a razão de retroespalhamento e extinção;

c ) desvios padrão para as estimativas;

d ) a parcela de contribuição comparativa das medidas, do apriori e do vínculo.

Os métodos de inversão foram aplicados à sinais simulados, nos quais as informações desejadas eram conhecidas. Segue a seguir algumas informações sobre o processo de inversão para cada método.

Comparativamente a Inversão ótima dependeu de menos informações para obter um bom resultado. Já o método de Klett aplicado isoladamente não teve bom desempenho na recuperação das informações, pois depende de condições de contorno 
para um bom desempenho, tais como a altitude de referência (altitude que delimita superiormente a presença de aerossóis). Outro fator relevante, na comparação dos métodos, é a possibilidade de avaliar e quantificar contribuições para as incertezas finais na estimativa.

A estimação ótima se mostrou eficiente na recuperação independente da altitude de referência, do coeficiente de extinção e da razão de retroespalhamento e extinção. Entretanto é importante ressaltar que o modelo para o dado simulado considerou uma aproximação do comportamento da razão de retroespalhamento e extinção (a razão foi considerada constante).

Em concordância com os objetivos deste trabalho, a possibilidade de estimativas com maior acurácia foi atendida.

Existe também inúmeras maneiras para o procedimento discutido neste trabalho ser extendido, por meio da inclusão de outras informações, tais como o retroespalhamento provindo de um segundo comprimento de onda, um refinamento mais apurado do $a$ priori levando em consideração outras medidas do tipo de aerossol. Ou ainda buscar meios para que a razão de retroespalhamento e extinção, $\omega$, não seja tomado como constante ao longo de todo o perfil estudado. 


\section{Apêndice A}

\section{Número de condicionamento de uma matriz}

Em aplicações descritas por um sistema de equações lineares os elementos da matriz de coeficientes e o vetor independente são muitas vezes inexatos. Esta falta de exatidão pode ser originada porque os dados são resultados de experimentos, como é o caso neste trabalho, ou computados através de operações que carregam erros de arredondamento, ou mesmo do próprio armazenamento dos elementos em uma aritmética finita. A questão é quando a perturbação introduzida em elementos do sistema podem alterar a resposta.

Alterações na resposta do sistema estão associadas ao comportamento do sistema. Este comportamento é medido pelo número de condição (condicionamento) da matriz [23].

Para entender o número de condicionamento de uma matriz é preciso relembrar o conceito de norma de vetores e matrizes.

\section{Norma de vetores [19]}

A norma de vetores em $R^{n}$ é uma função $\|\|:.=R^{n} \rightarrow R$ que satisfaz

a ) $\mathbf{x} \neq 0 \rightarrow\|\mathbf{x}\|>0$ 
b ) $\|\alpha \mathbf{x}\|=|\alpha|\|\mathbf{x}\|$

c ) $\|\mathbf{x}+\mathbf{y}\| \leq\|\mathbf{x}\|+\|\mathbf{y}\|$

Embora existam uma infinidade de normas, as mais utilizadas na prática são [23]:

$$
\begin{aligned}
\|\mathbf{x}\|_{1} & =\sum_{i}\left|x_{i}\right| \\
\|\mathbf{x}\|_{2} & =\left(\sum_{i} x_{i}^{2}\right)^{1 / 2} \\
\|\mathbf{x}\|_{\infty} & =\max _{i}\left|x_{i}\right|
\end{aligned}
$$

\section{Normas de matrizes [19]}

A norma de uma matriz é definida de forma análogo a norma de vetores. A norma de uma matriz em $R^{m \times n}$ é uma função $\|\|:.=R^{m \times n} \rightarrow R$ que satisfaz:
a ) $\mathbf{A} \neq 0 \rightarrow\|\mathbf{A}\|>0$
b ) $\|\alpha \mathbf{A}\|=|\alpha|\|\mathbf{A}\|$
c ) $\|\mathbf{A}+\mathbf{B}\| \leq\|\mathbf{A}\|+\|\mathbf{B}\|$

\section{Propriedade Adicional}

$\|\mathrm{AB}\| \leq\|\mathbf{A}\|\|\mathbf{B}\|$

Obs: Uma norma de vetor $\|$. $\|_{v}$ é consistente com uma norma de matriz $\|\cdot\|_{M}$ se:

\| A $\mathbf{x}\|\leq\| \mathbf{A}\|\| \mathbf{x} \|$

Sempre que o produto A.B é definido. A norma de matriz pode ser definida como: $\|\mathbf{A}\|=\max \frac{\|\mathbf{A} \mathbf{x}\|}{\|\mathbf{A}\|}=\max \|\mathbf{A} \mathbf{u}\|$ 
$\mathbf{x} \neq 0 \quad\|\mathbf{u}\|=1$

As principais normas utilizadas são:

$\|\mathbf{A}\|_{1}=\max _{j} \sum_{i=1}^{n}\left\|a_{i j}\right\|(\max$ soma absoluta de colunas de $\mathbf{A})$

$\|\mathbf{A}\|_{2}=\left(\text { max autovalor de } \mathbf{A}^{\mathbf{T}} \mathbf{A}\right)^{1 / 2}(\max$ valor singular de $\mathbf{A})$

$\|\mathbf{A}\|_{\infty}=\max _{i} \sum_{j=1}^{n}\left\|a_{i j}\right\|(\max$ soma absoluta de linhas de $\mathbf{A})$

\section{Condição de uma matriz não-singular}

Seja o sistema linear $\mathbf{A x}=\mathbf{b}$.

Suponha que o vetor independente $\mathbf{b}$ é alterado por $\mathbf{b}+\delta \mathbf{b}$ e $\mathbf{A}$ permanece inalterado. A solução exata do problema alterado é dado por: $\mathbf{A}\left(\mathbf{x}+\delta x_{b}\right)=\mathbf{b}+\delta b$ e como $\mathbf{A x}=\mathbf{b}$ pode-se obter um limite para $\delta x_{b}$

$$
\left\|\delta x_{b}\right\| \leq\left\|\mathbf{A}^{-1}\right\||\delta b|
$$

A relação $\mathbf{A x}=\mathbf{b}$ implica em

$$
\|\mathbf{b}\| \leq\|\mathbf{A}\|\|\mathbf{x}\|
$$

Multiplicando as duas relações anteriores chega-se a relação:

$$
\frac{\|\delta \mathbf{b}\|}{\|\mathbf{x}\|} \leq\left\|\mathbf{A}^{-1}\right\|\|\mathbf{A}\| \frac{\|\delta b\|}{\|\mathbf{b}\|}
$$

Se perturbarmos a matriz $\mathbf{A}$ enquanto b é mantido fixo tem-se a solução:

$$
(\mathbf{A}+\delta A)\left(\mathbf{x}+\delta x_{A}\right)=\mathbf{b}
$$

por um processo similar chega-se a expressão para o erro relativo.

$$
\frac{\left\|\delta x_{A}\right\|}{\|\mathbf{x}\|} \leq\left\|\mathbf{A}^{-1}\right\|\|\mathbf{A}\| \frac{\|\delta A\|}{\|\mathbf{A}\|}
$$


A quantidade $\left\|\mathbf{A}^{-1}\right\|\|\mathbf{A}\|$ reflete a máxima mudança relativa possível na solução exata para um sistema linear com dados perturbados, portanto

$$
\operatorname{cond}(\mathbf{A})=\left\|\mathbf{A}^{-1}\right\|\|\mathbf{A}\|
$$

Das relações anteriores pode-se chegar a:

$$
\operatorname{cond}(\mathbf{A}) \geq \frac{\frac{\left\|\delta x_{b}\right\|}{\|\mathbf{x}\|}}{\frac{\|\delta b\|}{\|\mathbf{b}\|}} \text { e } \operatorname{cond}(\mathbf{A}) \geq \frac{\frac{\left\|\delta x_{A}\right\|}{\left\|\mathbf{x}+\delta x_{A}\right\|}}{\frac{\|\delta A\|}{\|\mathbf{A}\|}}
$$

Estas relações mostram que, se a mudança relativa é muito grande para uma pequena perturbação em $\mathbf{A}$ ou b, nós sabemos que $\mathbf{A}$ é mal condicionada.

\section{Propriedades:}

a ) A norma da matriz identidade, para qualquer norma, vale 1.

b ) Como $\mathbf{I}=\mathbf{A}^{-1} \mathbf{A}$ e $\left\|\mathbf{I}=\mathbf{A}^{-1} \mathbf{A}\right\| \leq\left\|\mathbf{A}^{-1}\right\|\|\mathbf{A}\|$ conclui-se que $\operatorname{cond}(\mathbf{A}) \geq 1$.

c ) Se a matriz $\mathbf{A}$ for multiplicada por um escalar $\alpha$, então $\operatorname{cond}(\alpha A)=\operatorname{cond}(\mathbf{A})$.

d ) Se D for uma matriz diagonal, então $\operatorname{cond}(\mathbf{D})=\frac{\max \left|d_{i i}\right|}{\min \left|d_{i i}\right|}$.

e ) Se $\mathbf{A}$ for não-singular e simétrica $\operatorname{cond}(\mathbf{A})=\frac{\sigma_{n}}{\sigma_{1}}$, onde $\sigma_{1}$ é o mínimo valor singular e $\sigma_{n}$ é o máximo valor singular. Se $\mathbf{A}$ for não-simétrica $\operatorname{cond}(\mathbf{A}) \geq \frac{\sigma_{1}}{\sigma_{n}}$.

O mal condicionamento de uma matriz está associado à proximidade da singularidade da matriz. 
Dado o sistema linear $\mathbf{A x}=\mathbf{b}$, no qual $\mathbf{A}$ é uma matriz mal condicionada o uso da pseudo-inversa ou inversa generalizada (descrita na seção B) de A pode aumentar a estabilidade dos cálculos na resolução deste sistema [13] e [25].

Regularizações tais com Truncamento de Valores Singulares, [3], ou Regularização de Tikhonov descrita por [13], são alguns dos recursos utilizados na resolução de problemas mal-postos. Outros métodos de resolução estão presentes neste trabalho, um deles descrito na seção 3.3, neste ocorre a resolução analítica do problema e a solução é encontrada por condições de contorno; outro, figurando como o objetivo principal deste trabalho é um método de estimação ótima. 


\section{Apêndice B}

\section{Decomposição de Valores Singulares (SVD)}

A Decomposição de Valores Singulares permite avaliar o condicionamento de uma matriz, além da possibilidade de reduzir causas de propagação de erros, [13]. Pode ainda servir como método de regularização por truncamento de valores singulares, sob alguns critérios, para a resolução de um sistema linear mal condicionado por mínimos quadrados [3].

A seguir são listados tópicos sobre a decomposição de uma matriz em valores singulares [20]:

- a decomposição em valores singulares vale tanto para matrizes quadradas quanto retangulares.

- além disso, a matriz pode ter elementos reais ou complexos. Neste estudo, iremos considerar apenas matrizes com elementos reais.

- se $X$ é uma matriz com posto $r \leq \min (N, p)$, então $X$ pode ser expressa na forma:

$$
X=U D V^{T}
$$


$\operatorname{com} U \in R^{N x r}, V \in R^{p x r}, U^{T} U=V^{T} V=I_{r}$, e $D \in R^{r x r}$ uma matriz diagonal cujos elementos na diagonal são os valores singulares e obedecem $d_{1} \geq d_{2} \geq$ $\ldots \geq d_{r}>0$.

- $X \in R^{N x p}$ também pode ser expressa na forma:

$$
X=U D V^{T}
$$

com $U \in R^{N x p}, V \in R^{p x p}, U^{T} U=V^{T} V=I_{p}$, e $D \in R^{p x p}$ uma matriz diagonal cujos elementos na diagonal são os valores singulares e obedecem $d_{1} \geq d_{2} \geq$ $\ldots \geq d_{p}>0$.

- ainda como uma outra opção, $X \in R^{N x p}$ também pode ser expressa na forma:

$$
X=U\left(\begin{array}{cc}
D & 0 \\
0 & 0
\end{array}\right) V^{T}
$$

$\operatorname{com} U \in R^{N x N}, V \in R^{p x p}, U^{T} U=U^{T} U=I_{N}, V^{T} V=V^{T} V=I_{p}$ e $D \in R^{r x r}$ uma matriz diagonal cujos elementos na diagonal são os valores singulares e obedecem $d_{1} \geq d_{2} \geq \ldots \geq d_{r}>0$.

- repare que as decomposições acima são sempre possíveis, independente de se ter $N=p, \quad N<p$ ou $N>p$.

- as colunas de $U$ são os autovetores de $X X^{T}$ e as colunas de $V$ são os autovetores de $X^{T} X$. Os autovalores de $X X^{T}$ e $X^{T} X$ são os mesmos.

- note também que o número de valores singulares positivos coincide com o posto da matriz $X$, o que implica que a decomposição em valores singulares representa um método prático para se obter o posto de uma matriz. 
- se a matriz $X$ for simétrica, então seus valores singulares correspondem aos valores absolutos de seus autovalores não-nulos.

- os valores singulares de $X \in R^{N x p}$ correspondem ao comprimento dos semi-eixos do hiperelipsóide denotado por:

$$
\left\{X y: y \in R^{p} \text { e }\|y\|=1\right\}
$$

- se $u_{i} \in R^{N}$ e $v_{i} \in R^{p}$ representam as i-ésimas colunas de $U$ e $V$, respecticvamente, então é possível decompor $X$ na forma:

$$
X=\sum_{i=1}^{r} d_{i} u_{i} v_{i}^{T}
$$

Uma aplicação importante da Decomposição de Valores Singulares é o cálculo da pseudo-inversa:

- seja uma matriz $X$ de dimensão $N x p\left(X \in R^{N x p}\right)$ e de posto $r$, com $r \leq$ $\min (N, p)$, que tenha uma decomposição em valores singulares tal que $U^{T} X V=\left(\begin{array}{cc}D & 0 \\ 0 & 0\end{array}\right)$

Então, a pseudo-inversa da matriz X pode ser obtida na forma:

$$
X^{+}=V\left(\begin{array}{cc}
D^{-1} & 0 \\
0 & 0
\end{array}\right) U^{T}
$$

onde $D^{-1}=\operatorname{diag}\left(d_{1}^{-1}, d_{2}^{-1}, \ldots, d_{r}^{-1}\right)$

- quando a matriz $X$ tem posto completo, ou seja, quando $r=\min (N, p)$, então é possível mostrar que: 


$$
\begin{aligned}
& X^{+}=V\left(\begin{array}{cc}
D^{-1} & 0 \\
0 & 0
\end{array}\right) U^{T}=\left(X^{T} X\right)^{-1} X^{T}, \text { quando } N>p \\
& X^{+}=V\left(\begin{array}{cc}
D^{-1} & 0 \\
0 & 0
\end{array}\right) U^{T}=X^{T}\left(X^{T} X\right)^{-1}, \text { quando } N<p
\end{aligned}
$$

Na resolução de um sistema linear mal condicionado por mínimos quadrados, no qual a matriz de coeficientes $X$ de dimensão $N x p\left(X \in R^{N x p}\right)$ é não singular, um dos critérios para regularização do tal problema é após um certo índice $r$ (caracterizados pelos menores valores singulares ), substituir os elementos da inversa da matriz de valores singulares por zero, $\left(d_{r+1}^{-1}=d_{r+2}^{-1}=\ldots=d_{p}^{-1}=0\right)$ [3] e [13].

$\mathbf{X}^{-\mathbf{1}}=\mathbf{V}\left[\operatorname{diag}\left(\mathbf{d}_{\mathbf{j}}^{-\mathbf{1}}\right)\right] \mathbf{U}^{\mathbf{T}}, \operatorname{com} 1 \leq j \leq p$ ou seja:

$$
X^{+}=V\left(\begin{array}{cc}
D^{-1} & 0 \\
0 & 0
\end{array}\right) U^{T}
$$

onde $D^{-1}=\operatorname{diag}\left(d_{1}^{-1}, d_{2}^{-1}, \ldots, d_{r}^{-1}\right)$ 


\section{Referências Bibliográficas}

[1] Bucholtz, A., Rayleigh-scattering calculations for the terrestrial atmosphere, Appl. Opt. 34 (1995), 2765-2773.

[2] Kovalev, V. A. and Eichinger, W. E., Elastic lidar : Theory, practice, and analysis methods, Wiley Interscience, 2004.

[3] Hansen, P. C., The truncated SVD as a method for regularization, Numerical Analysis Project - Stanford University 27 (1987), no. 94305, 534 - 553.

[4] Landulfo, E.; Papayannis, A.; Torres, A. S.; Uehara, S. T.; Pozzetti, L. M. V.; Matos, C. A.; Sawamura, P.; Nakaema, W. M.; Jesus, W. C., A Four-Year Lidar Sun Photometer Aerosol Study at São Paulo, Brazil, Journal of Atmospheric and Oceanic Technology 25 (2008).

[5] Klett, J. D., Stable analytical inversion solution for processing lidar returns, vol. 20 ,no.2, J. Applied Optics, 1981.

[6] _ , "Lidar Calibration and Extinction Coefficients", Appl. Opt. 22 (1983), 514.

[7] Rodgers, C. D., Retrieval of Atmospheric Temperature and Composition from Remote Measurements of Thermal Radiation, Rev. Geo phys. Space Phys. 14 (1976), $609-624$.

[8] _ Characterization and Error Analysis of Profiles Retrieved From Remote Sounding Measurements, J. Geophys. Res. 95 (1990), no. D5, 5587 - 5595. 
[9] Landulfo, E.; Papayannis, A.; de Freitas, A. Z.; Vieira Jr, N. D.; Souza, R. F.; Gonçalves, A.; Castanho, A. D. A.; Artaxo, P.; Sánchez-Ccoyllo, O. R.; Moreira, D. S.; Artaxo, M. P. M., Tropospheric aerosol observations in são paulo, brazil using a compact lidar systems, International Journal of Remote Sensing 26 (2005), no. 13, $2797-2816$.

[10] Viezee, W.; Uthe, E. E.; and Collis, R. T. H., J. Appl. Meteorol. 817 (1969), 274.

[11] Bussab, W. O. e Morettin, P. A., Estatística básica. $5^{a}$ - edição, Ed. Saraiva, S. P., 2003.

[12] Mizeraczyk, J.; Ohkubo, T.; Kanazawa, S.; Nomoto, Y.; Kawasaki, T.; Kocik, M.;(W.L., Jankiewicz, Z. Eds.), Laser Technology VI: Applications, In Proc. of SPIE 4238 (2000), 242-245.

[13] Campos Velho, H. F., Problemas Inversos: Conceitos Básicos e Aplicações, Disponível em: http://www.lac.inpe.br/ haroldo/CursoPI/CursoPI.pdf, Acesso em: 9 ago, 2007.

[14] Licel GmbH, Licel Transient Recorder and Ethernet-Controller - Programming Manual, Chausseestr 34-35, Berlin, Germany, September 2006.

[15] Collis, R. T. H. and (Hinkley, E. D. ) Russell, P. B., Laser monitoring of the atmosphere, vol. 20 ,no.2, Springer, New York, 1976.

[16] Seinfeld, J. H. and Pandis, S. N., Atmospheric and physics from air pollution to climate change, J. Wiley and Sons, New York, 1998, 1326 pp.

[17] Dubovik, O.; Sinyuk, A.; Lapyonok, T.; Holben, B.N.; Mishchenko, M.; Yang, P.; Eck, T.F.; Volten, H.; Munoz, O.; Veihelmann, B.; Zande, V.J.; Leon, J.P.; Sorokin, M.; Slutsker, I., The application of spheroid models to account for aerosol 
particle non-sphericity in remote sensing of desert dust, 111 (2006), no. D11208, doiL10.1029/2005GL06619.

[18] Marks, C. J. and Rodgers, C. D., A Retrieval Method for Atmospheric Composition From Limb Emission Measurements, J. Geophys. Res. 98 (1993), no. (D8), $14,939-14,953$.

[19] Stoer, J. and Bulirsch, R., Introduction to Numerical Analysis, vol. 2nd ed., Springer Verlag, New York, NY., 1993.

[20] VON ZUBEN, F. J., Decomposição em Valores Singulares e Análise de Componentes Principais, Notas de Aula, Disponível em: ftp://ftp.dca.fee.unicamp.br/pub/docs/vonzuben/ia36802/topico802.pdf, Acesso em: 11 nov, 2007, Tópico 8.

[21] Engelen, R. J.; Stephens, G. L., Characterization of water-vapor retrievals from TOVS/HIRS and SSM/T-2 measurements, Q. J. R. Meteorol. Soc. 125 (1999), $331-351$.

[22] Stephens, G. L., Remote Sensing of the Lower Atmosphere - An Introduction, Oxford University Press, 1994.

[23] Campagnolo, J. M., Sistemas Lineares - Condicionamento, Disponível em: http://www.labspot.ufsc.br/campagno/numericoAula-12-SLCondicionamento.doc, Acesso em: 9 ago, 2007.

[24] Stephens, G. L.; Engelen, R. J.; Vaughan, M. and Anderson, T. L., Toward retrieving properties of the tenuous atmosphere using space based lidar measurements, J. Geophys. Res 106(D22) (2001), 28,143 - 28,157.

[25] Wise, B. M. and Gallagher, N. B., An Introduction to Linear Algebra, Eigenvector Research, Inc, 830 Wapato Lake Road, Manson, 1998. WA 98831,USA,bmw@eigenvector.com. 
[26] Whiteman, D. N., Class 6, Aerosol Backscatter and Extinction Measurements by Lidar, Howard University,NASA-GSFC (Spring 2006).

[27] Vanin, V. R.; Gouffon, P.; Helene, O., Análise estatística de medidas em ciências exatas, Notas de Aula, 2005.

[28] Measures, R., Laser Remote Sensing: Fundamentals and Applications, Krieger Publ. Company, Florida., 1992.

[29] Barrett, E. W. and Ben-Dov, O., Application of the Lidar to Air Pollution Measurements, Appl. Meteorol 6 (1967), 500 - 515. 